\title{
Physical Modeling and Simulation Analysis of an Advanced Automotive Racing Shock Absorber using the 1D Simulation Tool AMESim
}

\author{
Master's thesis \\ Performed in Fluid and Mechatronic Systems \\ By \\ Maryam Sadeghi Reineh
}

Fluid and Mechatronic Systems

Department of Management and Engineering

Linköping University

LIU-IEI-TEK-A--12/01408-SE

June 2012 



\section{Physical Modeling and Simulation Analysis of an Advanced Automotive Racing Shock Absorber using the 1D Simulation Tool AMESim \\ Master's thesis \\ Performed in Fluid and Mechatronic Systems \\ Department of Management and Engineering \\ Linköping University \\ By Maryam Sadeghi Reineh \\ LIU-IEI-TEK-A--12/01408-SE}

Supervisor: Professor Karl-Erik Rydberg

Linköpings Universitet

Atsushi Ishii

Öhlins Racing AB

Examiner: Professor Karl-Erik Rydberg

Linköpings Universitet

Linköping, June 2012 


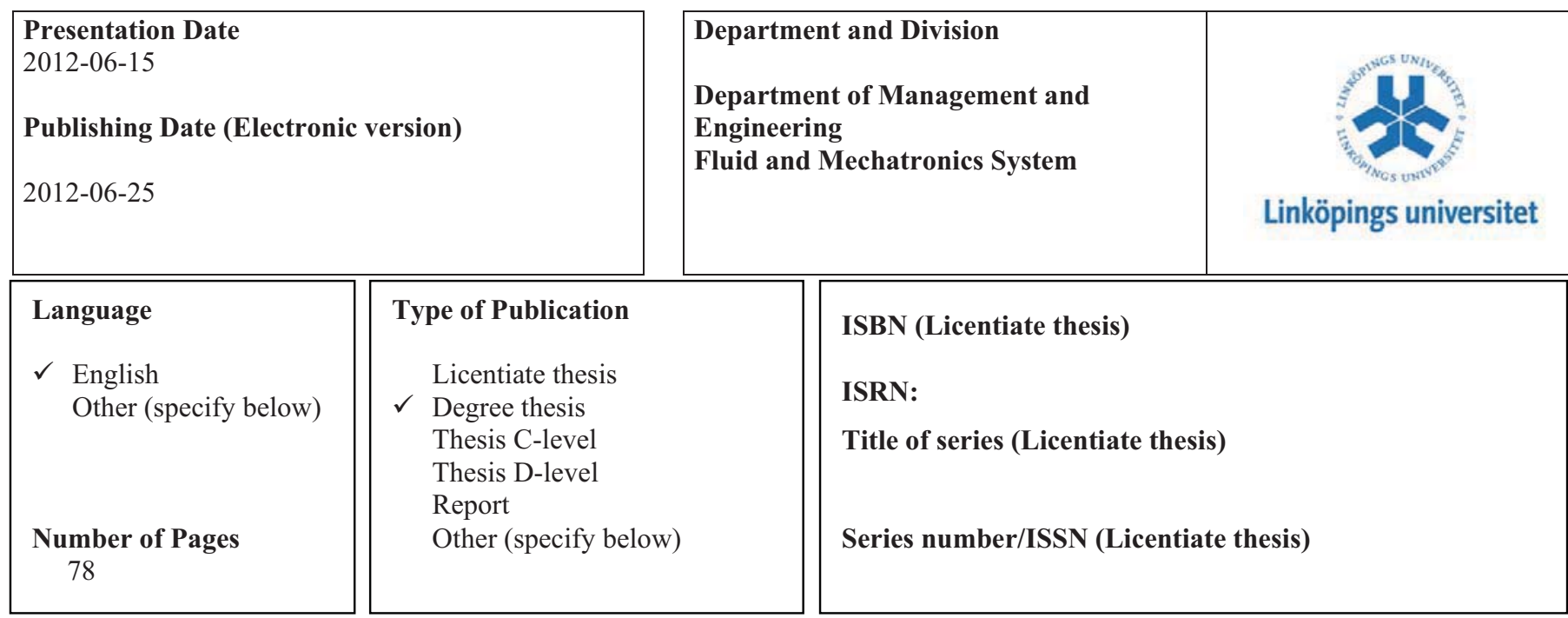

\section{URL, Electronic Version}

http://www.ep.liu.se

\section{Publication Title}

Physical Modeling and Simulation Analysis of an Advanced Automotive Racing Shock Absorber using the 1D Simulation Tool AMESim

Author(s)

Maryam Sadeghi Reineh

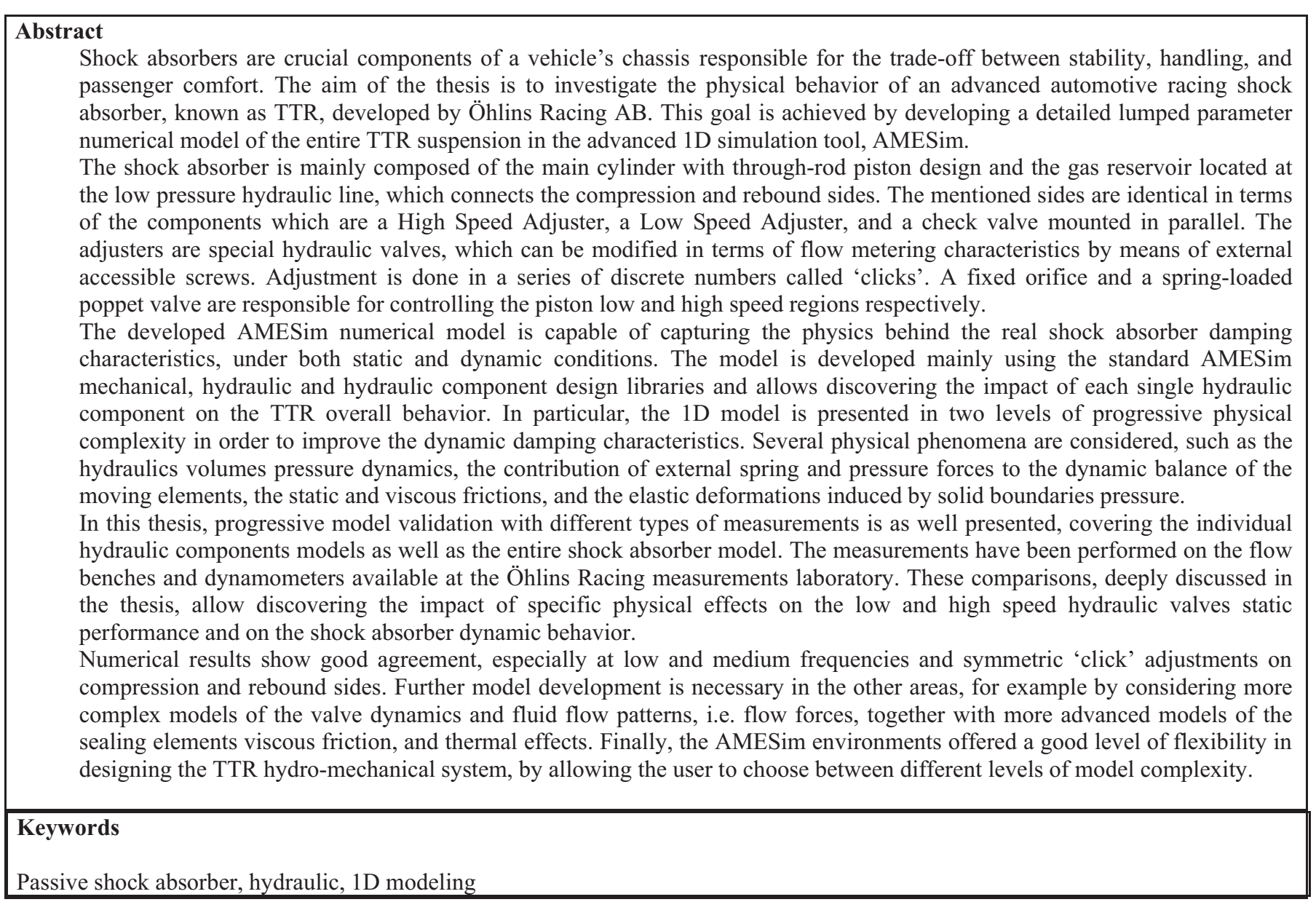




\section{Upphovsrätt}

Detta dokument hålls tillgängligt på Internet - eller dess framtida ersättare -från publiceringsdatum under förutsättning att inga extraordinära omständigheter uppstår.

Tillgång till dokumentet innebär tillstånd för var och en att läsa, ladda ner, skriva ut enstaka kopior för enskilt bruk och att använda det oförändrat för ickekommersiell forskning och för undervisning. Överföring av upphovsrätten vid en senare tidpunkt kan inte upphäva detta tillstånd. All annan användning av dokumentet kräver upphovsmannens medgivande. För att garantera äktheten, säkerheten och tillgängligheten finns lösningar av teknisk och administrativ art.

Upphovsmannens ideella rätt innefattar rätt att bli nämnd som upphovsman i den omfattning som god sed kräver vid användning av dokumentet på ovan beskrivna sätt samt skydd mot att dokumentet ändras eller presenteras i sådan form eller i sådant sammanhang som är kränkande för upphovsmannens litterära eller konstnärliga anseende eller egenart.

För ytterligare information om Linköping University Electronic Press se förlagets hemsida http://www.ep.liu.se/ 


\section{Copyright}

The publishers will keep this document online on the Internet - or its possible replacement -from the date of publication barring exceptional circumstances.

The online availability of the document implies permanent permission for anyone to read, to download, or to print out single copies for his/hers own use and to use it unchanged for non-commercial research and educational purpose. Subsequent transfers of copyright cannot revoke this permission. All other uses of the document are conditional upon the consent of the copyright owner. The publisher has taken technical and administrative measures to assure authenticity, security and accessibility.

According to intellectual property law the author has the right to be mentioned when his/her work is accessed as described above and to be protected against infringement.

For additional information about the Linköping University Electronic Press and its procedures for publication and for assurance of document integrity, please refer to its www home page: http://www.ep.liu.se/.

(C) Author names here. 


\begin{abstract}
Shock absorbers are crucial components of a vehicle's chassis responsible for the trade-off between stability, handling, and passenger comfort. The aim of the thesis is to investigate the physical behavior of an advanced automotive racing shock absorber, known as TTR, developed by Öhlins Racing AB. This goal is achieved by developing a detailed lumped parameter numerical model of the entire TTR suspension in the advanced 1D simulation tool, AMESim.

The shock absorber is mainly composed of the main cylinder with through-rod piston design and the gas reservoir located at the low pressure hydraulic line, which connects the compression and rebound sides. The mentioned sides are identical in terms of the components which are a High Speed Adjuster, a Low Speed Adjuster, and a check valve mounted in parallel. The adjusters are special hydraulic valves, which can be modified in terms of flow metering characteristics by means of external accessible screws. Adjustment is done in a series of discrete numbers called 'clicks'. A fixed orifice and a spring-loaded poppet valve are responsible for controlling the piston low and high speed regions respectively.

The developed AMESim numerical model is capable of capturing the physics behind the real shock absorber damping characteristics, under both static and dynamic conditions. The model is developed mainly using the standard AMESim mechanical, hydraulic and hydraulic component design libraries and allows discovering the impact of each single hydraulic component on the TTR overall behavior. In particular, the 1D model is presented in two levels of progressive physical complexity in order to improve the dynamic damping characteristics. Several physical phenomena are considered, such as the hydraulics volumes pressure dynamics, the contribution of external spring and pressure forces to the dynamic balance of the moving elements, the static and viscous frictions, and the elastic deformations induced by solid boundaries pressure.

In this thesis, progressive model validation with different types of measurements is as well presented, covering the individual hydraulic components models as well as the entire shock absorber model. The measurements have been performed on the flow benches and dynamometers available at the Öhlins Racing measurements laboratory. These comparisons, deeply discussed in the thesis, allow discovering the impact of specific physical effects on the low and high speed hydraulic valves static performance and on the shock absorber dynamic behavior.

Numerical results show good agreement, especially at low and medium frequencies and symmetric 'click' adjustments on compression and rebound sides. Further model development is necessary in the other areas, for example by considering more complex models of the valve dynamics and fluid flow patterns, i.e. flow forces, together with more advanced models of the sealing elements viscous friction, and thermal effects. Finally, the AMESim environments offered a good level of flexibility in designing the TTR hydromechanical system, by allowing the user to choose between different levels of model complexity.
\end{abstract}

Keywords: Passive shock absorber, hydraulic, 1D modeling 


\section{Acknowledgement}

I would like to express my gratitude to all those who gave me the possibility to complete this thesis. I want to thank the department of Fluid and Mechatronics Systems at Linköping University, Öhlins Racing AB, and LMS Imagine Lab who made the thesis possible with their kind supports.

I would like to express my deep appreciation to my university supervisor and examiner Prof. Karl-Erik Rydberg, who has been always willing for open discussions. I am grateful for all of his valuable guidance and advice which encouraged and challenged me throughout my academic program.

I would like to sincerely thank Öhlins Racing AB for giving me the opportunity to work on the current interesting project and providing a pleasant time during my visits to the company. Special thank to Dr. Urban Forssell, Mr. Atsushi Ishii, and Mr. Magnus Danek for their continuous support and professional supervision during the thesis.

Warm thanks are also extended to Dr. Matteo Pelosi for spending time on reviewing the thesis progress and sharing his valuable experiences.

I gratefully acknowledge Mr. Jan Smolders and Mr. Joon De Cock from LMS for clarifying my doubts in AMESim and sharing their knowledge to progress at a faster pace.

Finally I take the opportunity to thank my lovely parents for inspiring me to the work and my dear husband, Ali, for all of his love and kind supports.

Maryam Sadeghi Reineh 


\section{Table of Contents}

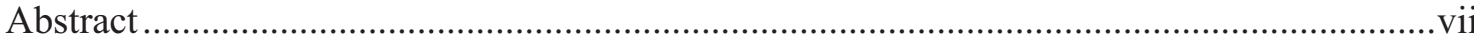

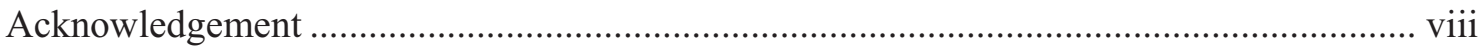

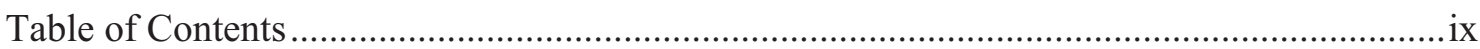

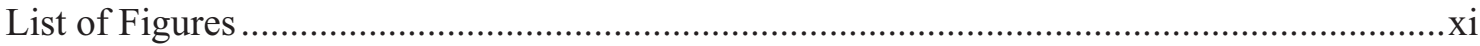

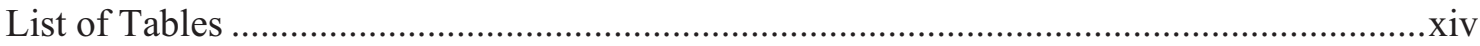

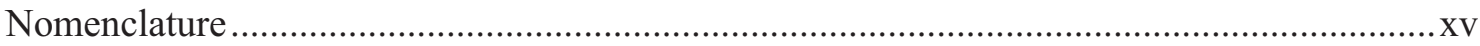

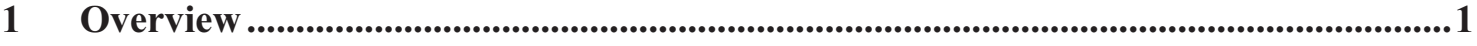

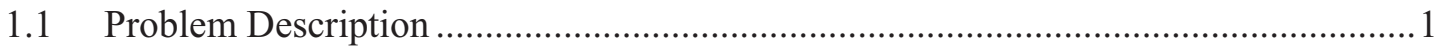

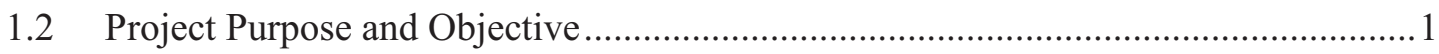

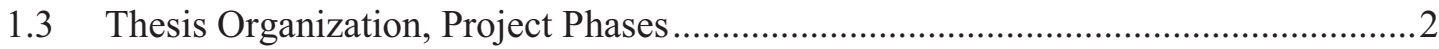

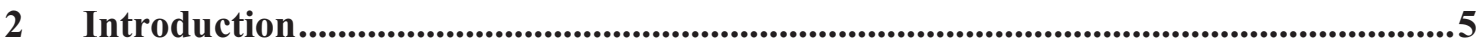

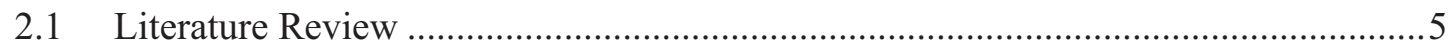

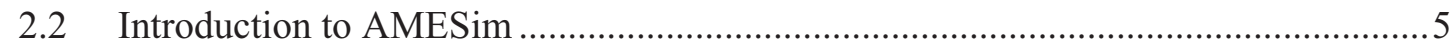

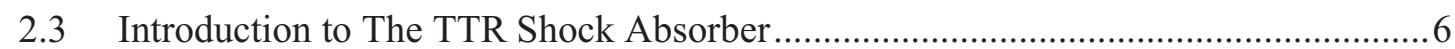

3 Preliminary Model Implementation........................................................................

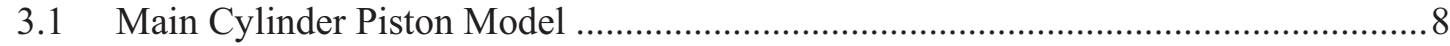

3.1.1 Velocity Input and the Simple Control Loop ............................................. 10

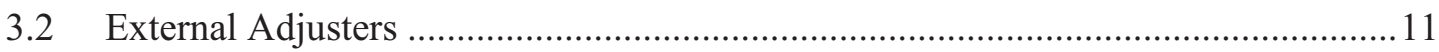

3.2.1 High Speed Adjuster Model ................................................................. 12

3.2.2 Low Speed Adjuster Model ................................................................. 15

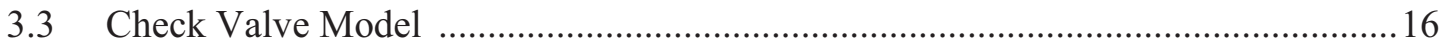

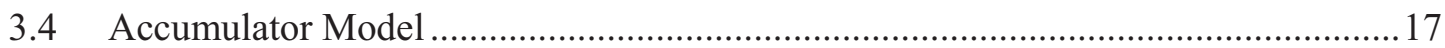

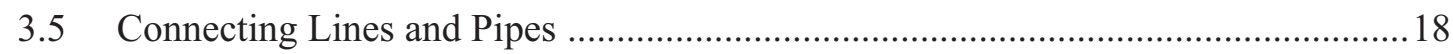

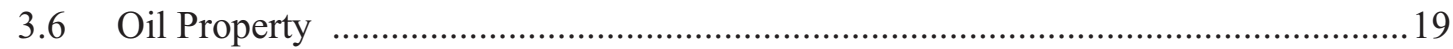

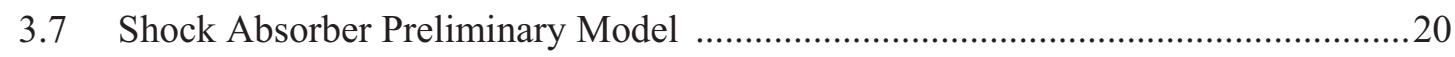

4 Preliminary Model Validation with Static Measurements........................................22

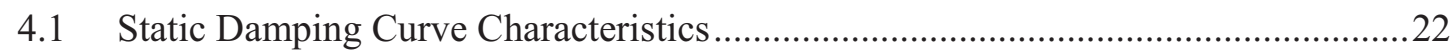

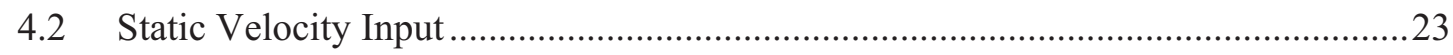

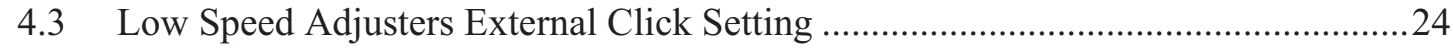

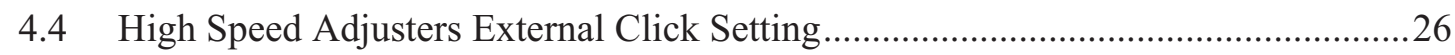

4.5 Model Validation with Static Measurements..........................................................29

5 Simple Model Dynamic Behavior .....................................................................................33

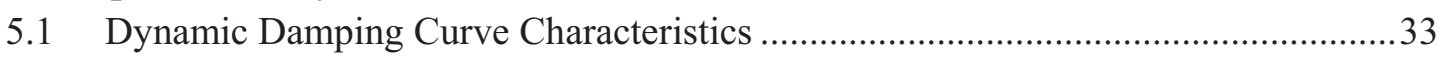

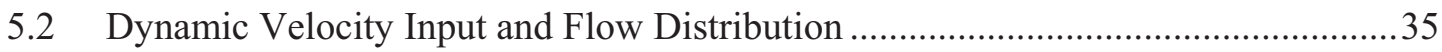

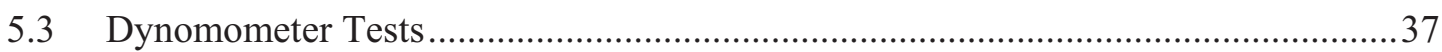

5.4 Dynamic Response of the Simple Model .............................................................. 37 
6 Advanced Model Implementation .............................................................................40

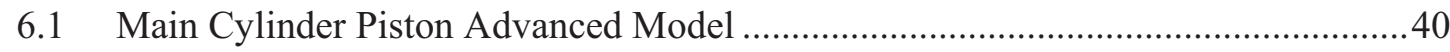

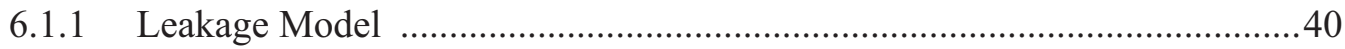

6.1.2 Inertia and Friction Model .......................................................................4 41

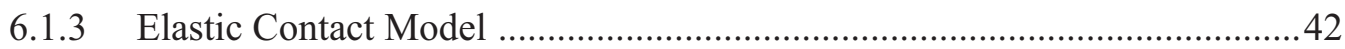

6.1.4 Channel Model between the Inner and Outer Tube ....................................43

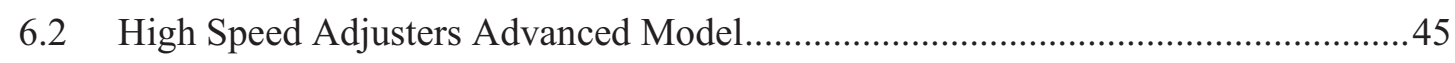

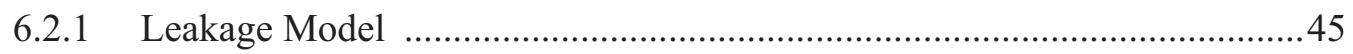

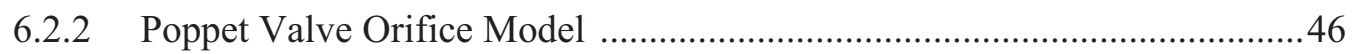

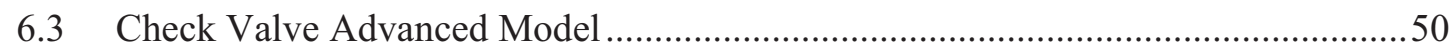

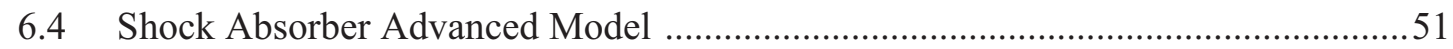

7 Flow Rate Versus Pressure Drop Validation...........................................................52

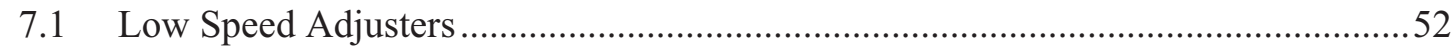

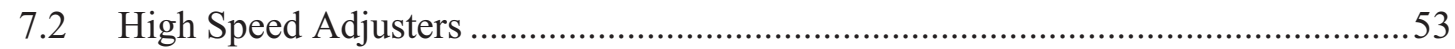

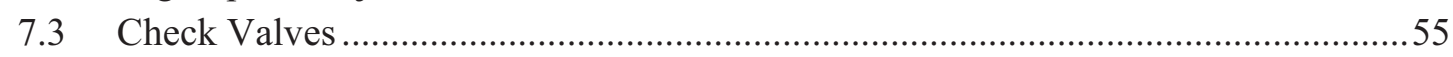

8 Advanced Model Validation with Dynamic Measurements.........................................58

8.1 Similar Click Setting on Compression and Rebound Sides.......................................58

8.2 Different Click Setting on Compression and Rebound Sides....................................62

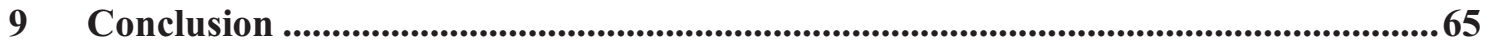

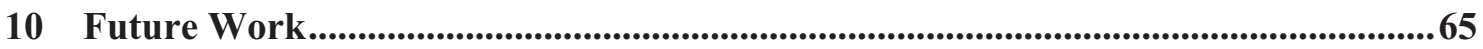

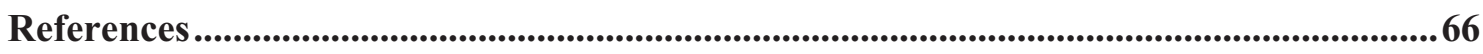

Appendix A - Complementary Figures .............................................................................................6 67

Appendix B - Derivation of Equations ..........................................................................75

Appendix C - MATLAB Codes.......................................................................................................78 


\section{List of Figures}

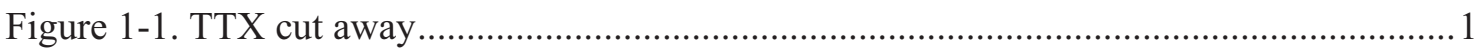

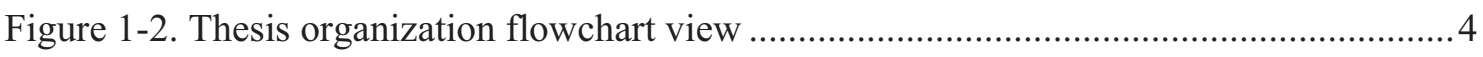

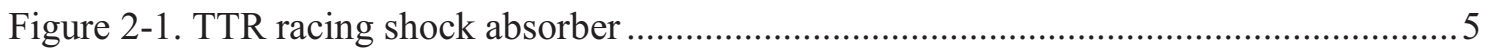

Figure 2-2. AMESim, a multi-domain simulation tool.................................................. 6

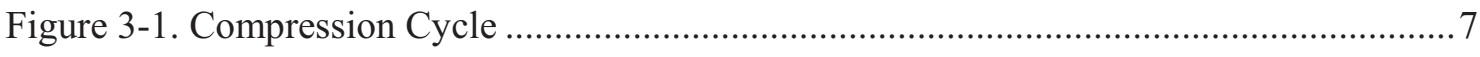

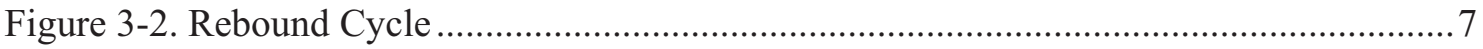

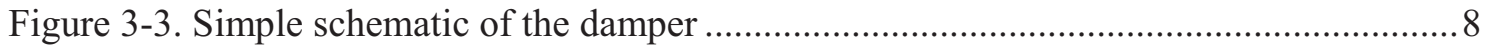

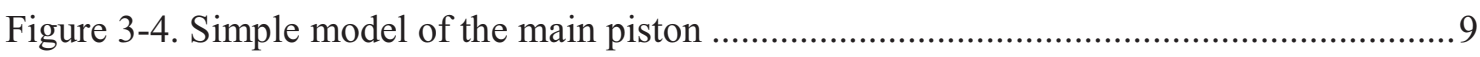

Figure 3-5. Main cylinder chambers volume versus time ................................................ 10

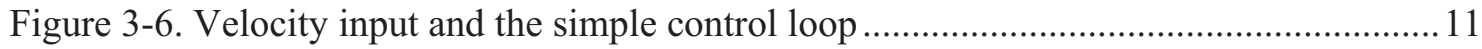

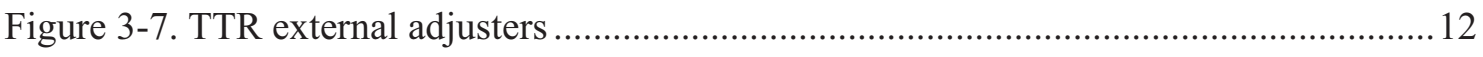

Figure 3-8. An illustration of the poppet valve pening characteristics ................................ 12

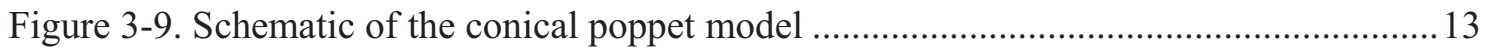

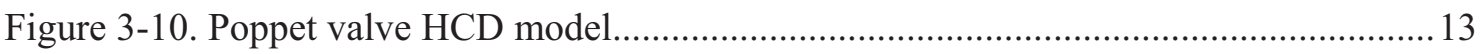

Figure 3-11. Poppet and spring with the same chamber volume........................................ 14

Figure 3-12. Drawing of the poppet valve sample........................................................... 14

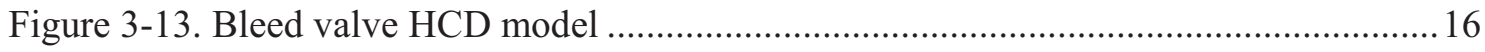

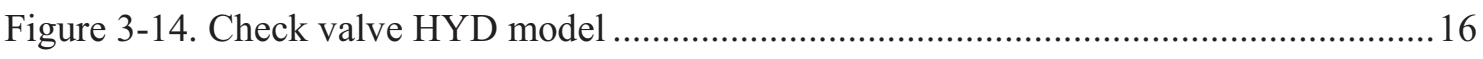

Figure 3-15. Check valve model, flow characteristics.................................................... 17

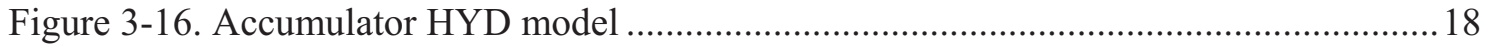

Figure 3-17. Viscosity of the oil as a function of temperature ........................................... 19

Figure 3-18. Henry's law compared to the software suggested expression for Bulk modulus 20

Figure 3-19. General sketch of the preliminary damper model ..........................................21

Figure 4-1. Static damping curve zones and the corresponding effective factors ..................22

Figure 4-2. LS valve click setting, measurement and simulation comparison ......................24

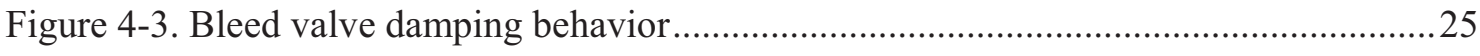

Figure 4-4. Linear interpolation for bleed valve click setting …........................................26

Figure 4-5. Damping curve at low speeds to find the exact equivalent orifice diameter at click

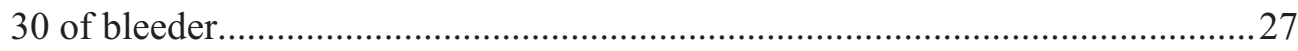

Figure 4-6. Damping curve for click 30 of LS and 40 of HS valves ..................................28 
Figure 4-7. Linear interpolation for poppet valve click setting .........................................29

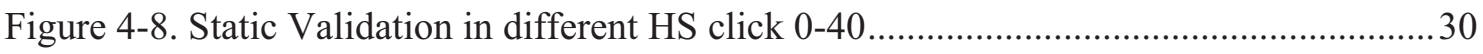

Figure 4-9. Static model validation, combined plot............................................................. 31

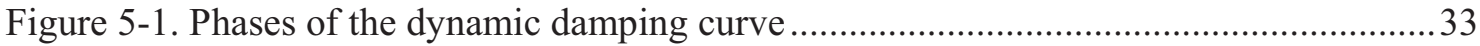

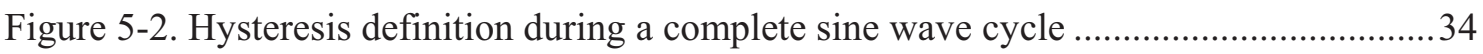

Figure 5-3. Dynamic damping curve zones and the corresponding effective factors..............35

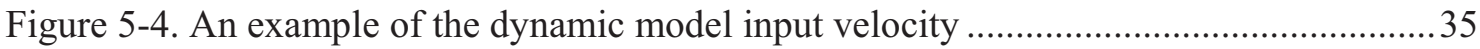

Figure 5-5. Flow distribution on (a) compression side, (b) rebound side................................36

Figure 5-6. Schematic diagram of the dynamometer rig and how it communicates with the

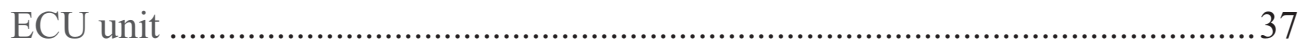

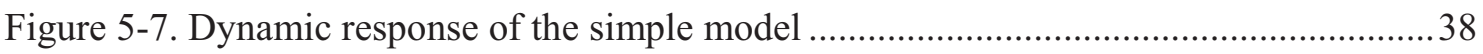

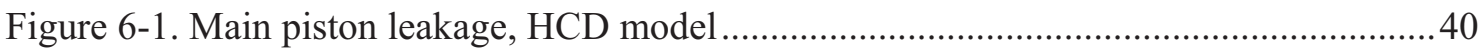

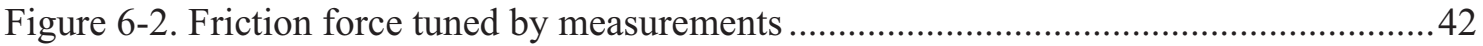

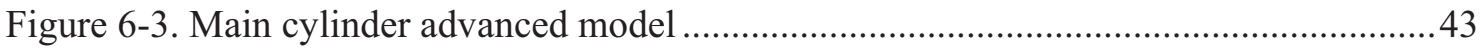

Figure 6-4. Model of the channel between the inner and outer tube of the main cylinder ......43

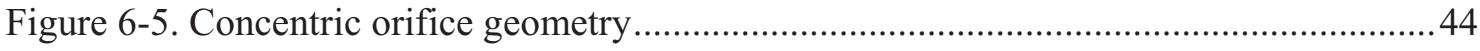

Figure 6-6. Effect of the advanced cylinder model on improving the hysteresis ................... 45

Figure 6-7. Poppet valve leakage, HCD model ............................................................. 45

Figure 6-8. Schematic of the poppet valve hole location...................................................46

Figure 6-9. Poppet valve hole considered as a fixed orifice in model ...................................47

Figure 6-10. Effect of the poppet valve hole on the static behavior .......................................48

Figure 6-11. Static damping force (a) without poppet valve hole, (b) with poppet valve hole48

Figure 6-12. Dynamic damping force(a) without poppet valve hole, (b) with poppet valve

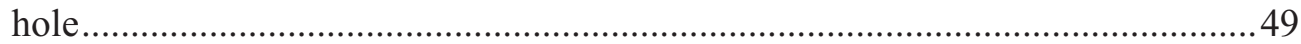

Figure 6-13. Effect of the advanced cylinder and poppet valve models on damping curve .... 49

Figure 6-14. Check valve HYD model replaced by HCD ..................................................50

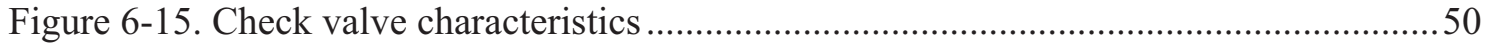

Figure 6-16. General sketch of the advanced damper model.............................................51

Figure 7-1. Measuring flow rate and pressure drop over the bleed valve.............................52

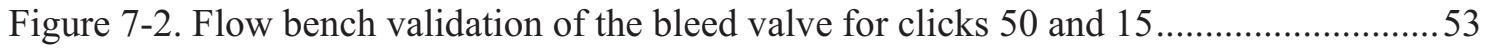

Figure 7-3. Measuring flow rate and pressure drop over the poppet valve ...........................54

Figure 7-4. Flow bench validation of the poppet valve for clicks 0 and 40 .........................54 
Figure 7-5. Flow bench measured data over the check valve ...............................................55

Figure 7-6. Design optimization for the check valve model...............................................56

Figure 7-7. Flow bench validation of the check valve.....................................................5

Figure 8-1. Influence of the poppet valve hole diameter on the damping curve ....................59

Figure 8-2. Dynamic validation for the nominal click setting at different frequencies ...........60

Figure 8-3. Dynamic validation for the low LSA and high HSA click settings at different frequencies

Figure 8-4. Dynamic validation for different LS click settings on compression and rebound sides, at different frequencies.

Figure 8-5. Dynamic validation for different HS click settings on compression and rebound

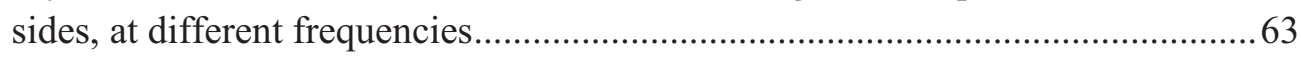

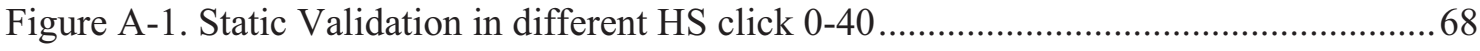

Figure A-2. Dynamic response of the simple model at medium click setting .......................69

Figure A-3. Flow bench validation of the bleed valve for different clicks ........................... 70

Figure A-4. Flow bench validation of the poppet valve for different clicks.......................... 71

Figure A-5. Dynamic validation for the nominal click setting at different frequencies ..........72

Figure A-6. Dynamic validation for the low LSA and high HSA click settings at different

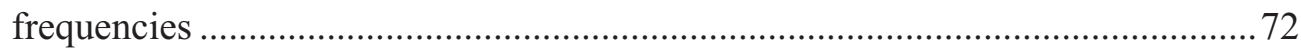

Figure A-7. Dynamic validation for different LS click settings on compression and rebound sides, at different frequencies....................................................................... 73

Figure A-8. Dynamic validation for different HS click settings on compression and rebound

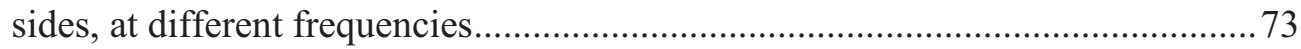

Figure A-9. Dynamic validation for the low LSA and low HSA click settings at different

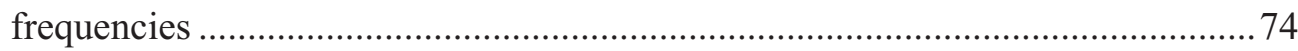

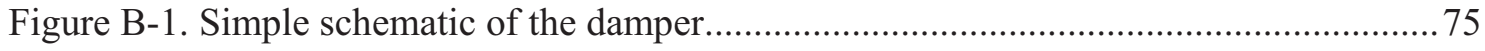

Figure B-2. Flow distribution during the compression cycle ............................................ 76 


\section{List of Tables}

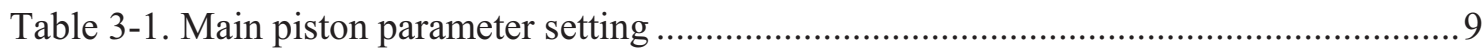

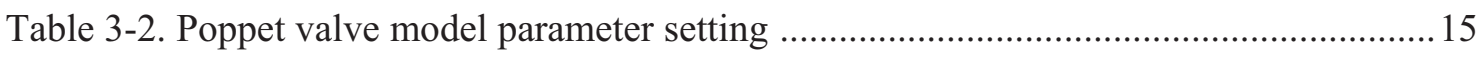

Table 3-3. Bleed valve model parameter setting ............................................................ 16

Table 3-4. Accumulator model parameter setting............................................................ 18

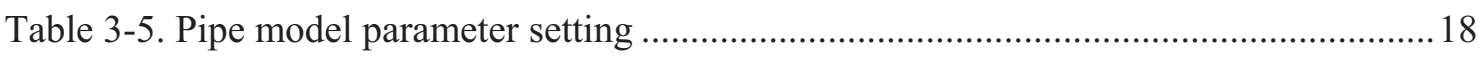

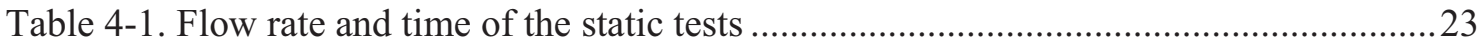

Table 4-2. Predicted orifice diameter for different clicks of LS valves based on the valve

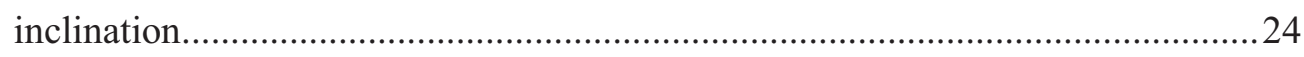

Table 4-3. Bleed valve clicks and the approximate orifice opening diameter.......................25

Table 4-4. Predicted spring pre-load for different clicks of HS valves based on the valve

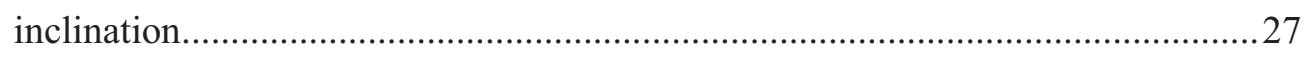

Table 4-5. Poppet valve clicks and the approximate spring pre-load ..................................28

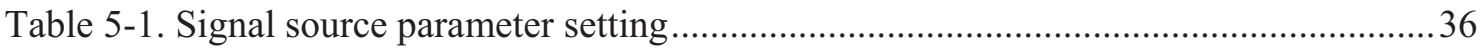

Table 6-1. Main piston leakage model parameter setting ................................................ 41

Table 6-2. Main piston inertia and friction model parameter setting ..................................41

Table 6-3. Elastic contact HCD model parameter setting ….................................................. 43

Table 6-4. Channel model parameter setting ................................................................... 44

Table 6-5. Poppet valve leakage model parameter setting .................................................46

Table 7-1. Check valve HCD model, optimization results ................................................56 


\section{Nomenclature}

Abbreviations

AMESim Advanced Modeling Environment for performing Simulations of

$\begin{array}{ll} & \text { engineering systems } \\ \text { LSA } & \text { Low Speed Adjuster } \\ \text { HSA } & \text { High Speed Adjuster } \\ \text { HYD } & \text { Hydraulic } \\ \text { HCD } & \text { Hydraulic Component Design }\end{array}$

\section{Denotations}

\begin{tabular}{|c|c|c|}
\hline $\mathrm{P}_{\text {in }}$ & Check valve input pressure & [bar] \\
\hline $\mathrm{P}_{\text {out }}$ & Check valve output pressure & [bar] \\
\hline$P_{\text {crack }}$ & Check valve crack pressure & [bar] \\
\hline $\mathrm{F}_{\max }$ & Maximum damping force & {$[\mathrm{N}]$} \\
\hline $\mathrm{V}_{\max }$ & Maximum piston velocity & {$[\mathrm{m} / \mathrm{s}]$} \\
\hline$A_{\text {piston }}$ & Piston cross sectional area & {$\left[\mathrm{m}^{2}\right]$} \\
\hline q & Flow rate & {$[\mathrm{lit} / \mathrm{min}]$} \\
\hline $\mathrm{V}$ & Piston velocity & {$[\mathrm{m} / \mathrm{s}]$} \\
\hline $\mathrm{F}$ & Damping force & {$[\mathrm{N}]$} \\
\hline $\mathrm{C}_{\mathrm{q}}$ & Flow coefficient & {[]} \\
\hline$\Delta \mathrm{P}$ & Pressure difference & [bar] \\
\hline$\rho$ & Oil density & {$\left[\mathrm{kg} / \mathrm{m}^{3}\right]$} \\
\hline $\mathrm{P}_{0}$ & Gas pre-charged pressure & [bar] \\
\hline $\mathrm{V}_{0}$ & Accumulator volume & {$\left[\mathrm{m}^{3}\right]$} \\
\hline $\mathrm{P}_{\mathrm{i}}$ & Initial pressure & [bar] \\
\hline $\mathrm{V}_{\mathrm{i}}$ & Initial volume & {$\left[\mathrm{m}^{3}\right]$} \\
\hline$\gamma$ & Gas polytropic index & [] \\
\hline $\mathrm{m}$ & Mass & {$[\mathrm{kg}]$} \\
\hline $\mathrm{g}$ & Gravity constant & {$\left[\mathrm{N} / \mathrm{s}^{2}\right]$} \\
\hline $\mathrm{d}_{\text {piston }}$ & Piston diameter & {$[\mathrm{m}]$} \\
\hline $\mathrm{d}_{\text {rod }}$ & Piston rod diameter & {$[\mathrm{m}]$} \\
\hline $\mathrm{d}_{0}$ & Low speed valve orifice diameter at click 0 & [m] \\
\hline $\mathrm{F}_{0}$ & High speed valve spring pre-load at click 0 & {$[\mathrm{~N}]$} \\
\hline $\mathrm{t}$ & Simulation time & {$[\mathrm{s}]$} \\
\hline K & Spring stiffness & {$[\mathrm{N} / \mathrm{m}]$} \\
\hline $\mathrm{x}$ & Spring displacement & [m] \\
\hline$\dot{\mathrm{x}}$ & Velocity & {$[\mathrm{m} / \mathrm{s}]$} \\
\hline$\ddot{\mathrm{x}}$ & Acceleration & {$\left[\mathrm{m} / \mathrm{s}^{2}\right]$} \\
\hline $\mathrm{F}_{\mathrm{s}}$ & Spring force & {$[\mathrm{N}]$} \\
\hline$A_{i}$ & Cross sectional area at port $\mathrm{i}$ & {$\left[\mathrm{m}^{2}\right]$} \\
\hline $\mathrm{P}_{\mathrm{i}}$ & Pressure at port $i$ & [bar] \\
\hline $\mathrm{K}_{\text {lam }}$ & Laminar flow pressure coefficient & {$\left[\mathrm{m}^{4} . \mathrm{s} / \mathrm{kg}\right]$} \\
\hline $\mathrm{x}_{\text {lap }}$ & Effective spool displacement & [m] \\
\hline $1_{\mathrm{c}}$ & Cone length & {$[\mathrm{m}]$} \\
\hline$\propto$ & Cone semi angle & {$[\mathrm{deg}]$} \\
\hline$d_{a}$ & Active diameter & {$[\mathrm{m}]$} \\
\hline
\end{tabular}




\section{Overview}

\subsection{Problem Description}

Shock absorbers play a key role in improving any vehicle's handling, driving pleasure, comfort of passengers, and reducing the road noises and vibration [7]. For racing shock absorbers, performance, traction, and grip are at higher levels of importance. The objectives are achieved by controlling the relative position and motion between vehicle body and wheels, and balancing the trade-off between ride comfort and road handling [8]. It filters the vibration and noise imposed by road to the vehicle by means of energy dissipation through the hydraulic oil in the shock absorber. Therefore, a well-designed shock absorber provides a satisfactory level of stability, performance, and damping characteristics.

In the current project a modern Öhlins TTR shock absorber is physically investigated in detail. The product is a 4-way fully independent adjustable damper, originally developed for automotive racing. Development of the product was mainly done by trial and error and using Öhlins' vast experience from racing and OEM applications. To increase the understanding for the involved physical phenomena and provide support for further product development, the current project aims to implement a mathematical model of the shock absorber which as closely as possible describes the static and dynamic behavior of the Öhlins TTR damper. The modeling is performed in the advanced 1D simulation environment, AMESim. The simulation model allows studying the dynamics of the whole damper as well as its individual component. Therefore, it makes it possible to investigate the physical phenomena responsible for different observed damping characteristics.

\subsection{Project Purpose and Objective}

The goal of the project is to investigate the physical behavior of the Öhlins TTR shock absorber by mathematical modeling in the modern simulation tool AMESim. Analyzing the achieved simulation results helps to clarify the theory behind the whole damper as well as its individual components' behaviors and functionalities. The ability of the software in simulating the real behavior of the damper is investigated as well in the project. Implementing a simple version of the damper which accurately simulates the static damping behavior is the first goal of the thesis. Afterwards, details are added to the model in order to enhance its ability in describing the physical dynamic behavior of the real damper.

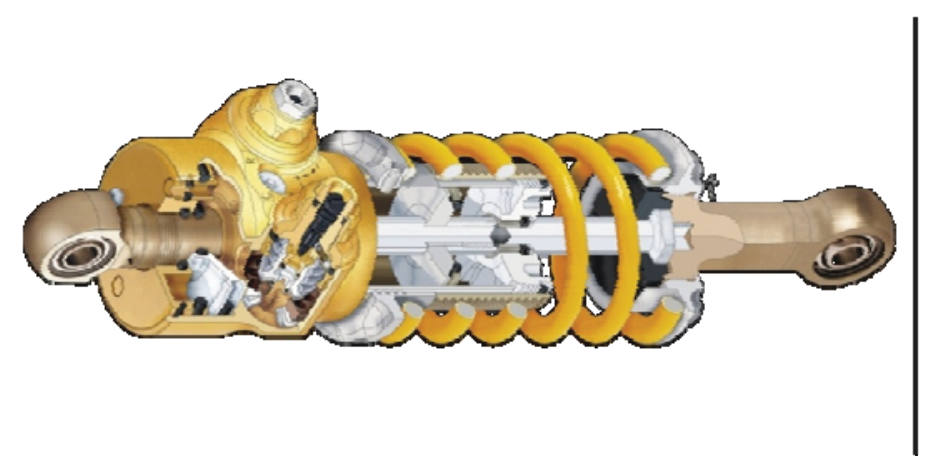

Figure 1-1. TTR cut away [3] 


\subsection{Thesis Organization, Project Phases}

The main objective of the thesis is to achieve a physical model of TTR which mathematically characterizes the real damper behavior and is validated based on the measurements performed on the shock absorber. Information is gathered from literature about the theory behind physical modeling of shock absorbers, and previous achievements in the same research field. Afterwards, the project is organized in the following steps.

Introduction to the shock absorber TTR

Getting familiar with the design and functionality of the damper to be modeled

- Design criteria

- General description, compression and rebound cycles

- Flow circuit at each of the cycles

- Hardware description, analyzing the real sample

- Understanding the whole flow cycle by relating the knowledge and the available sample of the damper

Introduction to AMESim

Getting familiar with the simulation software to be used, AMESim, as a multi-domain and multi-level physical modeling tool

- Training by LMS mainly on introduction to the 'Hydraulics', and 'Hydraulic Component Design' libraries, which are the most applicable ones in developing a suspension simulation model

- Studying the software progressive stages of the modeling procedure, Four modes of sketch design, sub-model selection, parameter setting, and simulation run

- Studying the logics behind some of the important modeling rules such as 'Causality'

$>$ Implementing the preliminary model

A basic model of TTR is conducted by first implementing the following four main sub-models of the system. The flow characteristic of each of the components is analyzed and the flow circuit in a complete damping cycle is studied. The sub-models are integrated to achieve a simple physical model of the damper which simulates the real damping behavior up to a satisfactory level.

- Main cylinder piston sub-model with a through-rod design

The cylinder is responsible for feeding the whole system without any piston rod displacement. The cylinder is basically modeled as two rigid chambers with variable volumes considering the pressure dynamics.

- High and Low Speed Adjusters sub-models

The adjusters are specific hydraulic valves which can be modified in terms of flow metering characteristics. The adjustment is done externally, based on a specific series of discrete numbers called 'clicks'.

- Check valve sub-model 
The check valve is responsible for separating the compression and rebound sides. It is equipped with a shim stack which makes the opening behavior gradual

- Gas reservoir or the accumulator sub-model

The accumulator connects the compression and rebound sides of the damper and is responsible for setting the system pressure level

$>$ Static validation of the preliminary model

Static measurements are done on the real damper by applying constant velocity to the piston rod and recording the stationary value of the damping force generated. Results are used to validate the implemented physical model damping behavior under the similar conditions.

$>$ Dynamic response of the simple model

Dynamic measurements are done on the real damper by applying sine wave velocity input to the piston rod. Statically validated model is tested under dynamic conditions to discover the weak points within the simulation results as well as the corresponding responsible sub-models. Large oscillations in the model response, as well as the low hysteresis predicted by the simulation model are the main problems. Solutions are suggested to improve the model dynamic characteristics.

$>$ Implementing the advanced model

The main cylinder piston, high speed adjusters, and the check valves are found to require improvements.

- Physical characteristics of leakage, friction, and elastic deformation are added to the cylinder piston sub-model in order to compensate for the hysteresis.

- A damping orifice is added to the high speed adjuster sub-model in order to cancel out the oscillations and its effect is proved mathematically. Leakage and friction phenomena are also added to the sub-model.

- An advanced model of the check valve is replaced by the simple one. The AMESim optimization tool is used to find the optimal parameter values for the sub-model which makes it to provide a similar flow bench behavior as the real check valve

$>$ Individual validation of the model components

Before analyzing the whole system dynamic behavior, the flow bench characteristics of the low speed, high speed, and check valves are investigated. Results are validated using the available measurements.

$>$ Dynamic validation of the advanced model

Validated components are gathered to form the advanced model of TTR. The model is validated by the dynamic measurements performed at the Öhlins dynamometer laboratory. Results are investigated and the effect of different 'click 'settings and input frequencies on the simulation model accuracy is analyzed.

Figure 1-2 shows the project phases in a flowchart demonstration. 


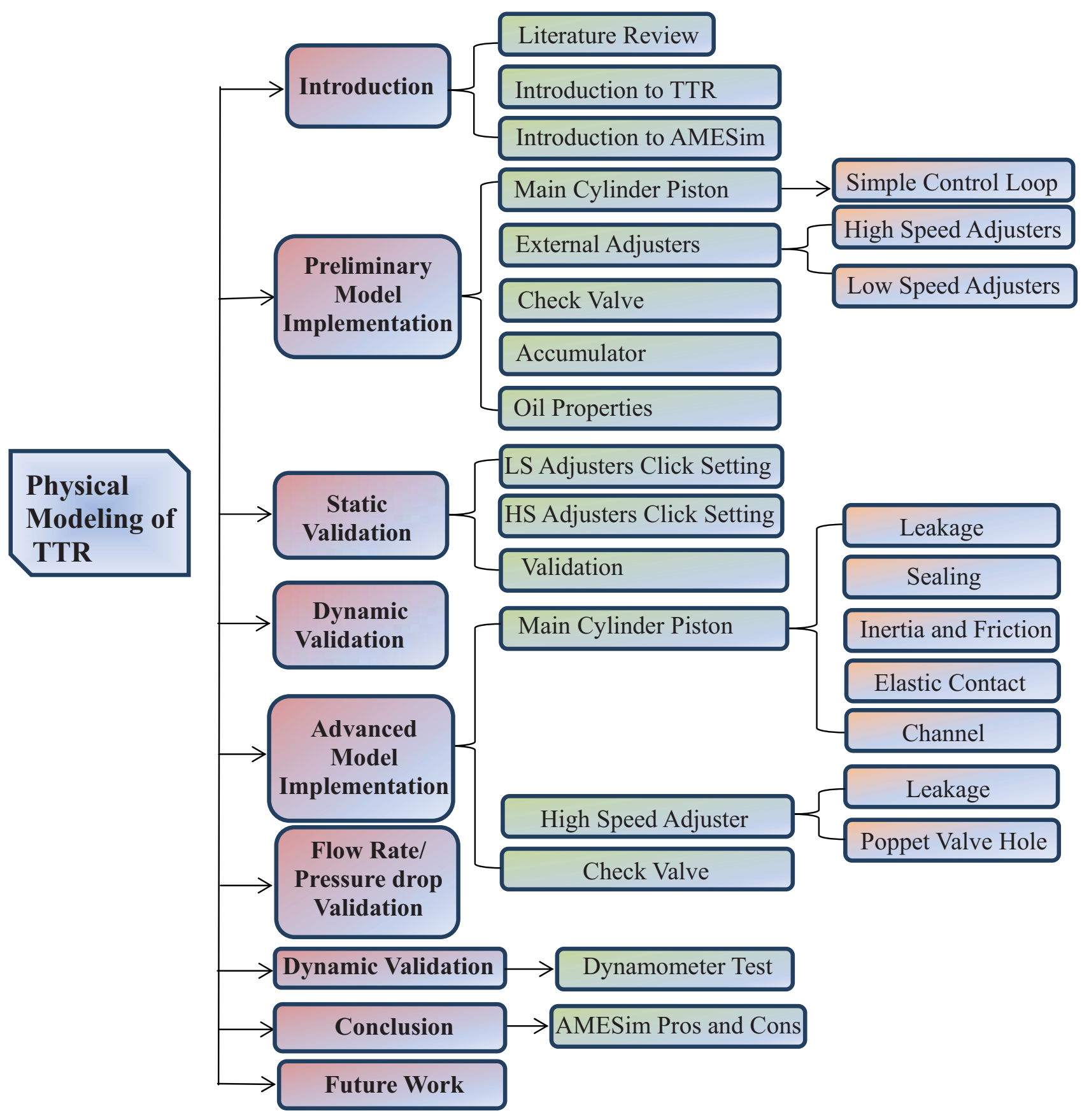

Figure 1-2. Thesis organization flowchart view 


\section{Introduction}

\subsection{Literature review}

When driving on the road, many factors such as the bumping, the speed and the steering may cause a relative vibration between sprung (quarter body) mass and unsprung (wheel) mass [6]. Shock absorber is an important part of a vehicle which directly affects its stability. It reduces the vibrations by turning the mechanical energy into heat through friction and dissipating it [6]. As mentioned before, shock absorber aims to achieve a satisfactory level of ride comfort and road handling simultaneously. A soft suspension provides good ride quality by reducing the effect of high frequency road variations. While a firm suspension is required to increase the force on tire and provide high drive controllability [8]. There exist three main types of shock absorbers: Passive, Semi-active, and active. In the current thesis a passive version of an advanced automotive shock absorber is modeled and simulated in the one dimensional simulation software, AMESim.

\subsection{Introduction to the TTR Shock Absorber}

Öhlins Racing is one of the worldwide known market leaders in the design and manufacturing of advanced racing suspensions for different vehicles and applications. In the current project one of the most advanced racing products of the company called TTR is modeled in a 1D simulation environment. The product is a 4-way fully independent externally adjustable damper. Adjustment is done externally for the Low/High speed valves on Compression/Rebound sides. TTR provides maximum damper response and generates relatively high damping force in short strokes. Furthermore, its through-rod design results in no piston rod displacement which can improve the damping performance of the shock absorber.

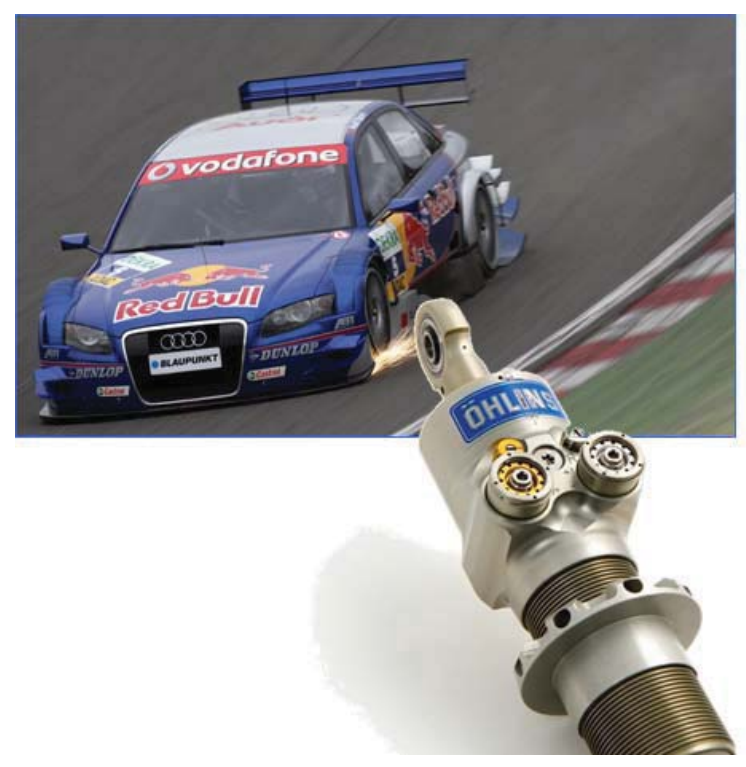

Figure 2-1. TTR racing shock absorber [4] 


\subsection{Introduction to AMESim}

AMESim, Advanced Modeling Environment for performing Simulations of engineering systems, is a one dimensional lumped parameter simulation tool which is used to model and analyze multi domain and intelligent systems and predict their multi-disciplinary performance [9].

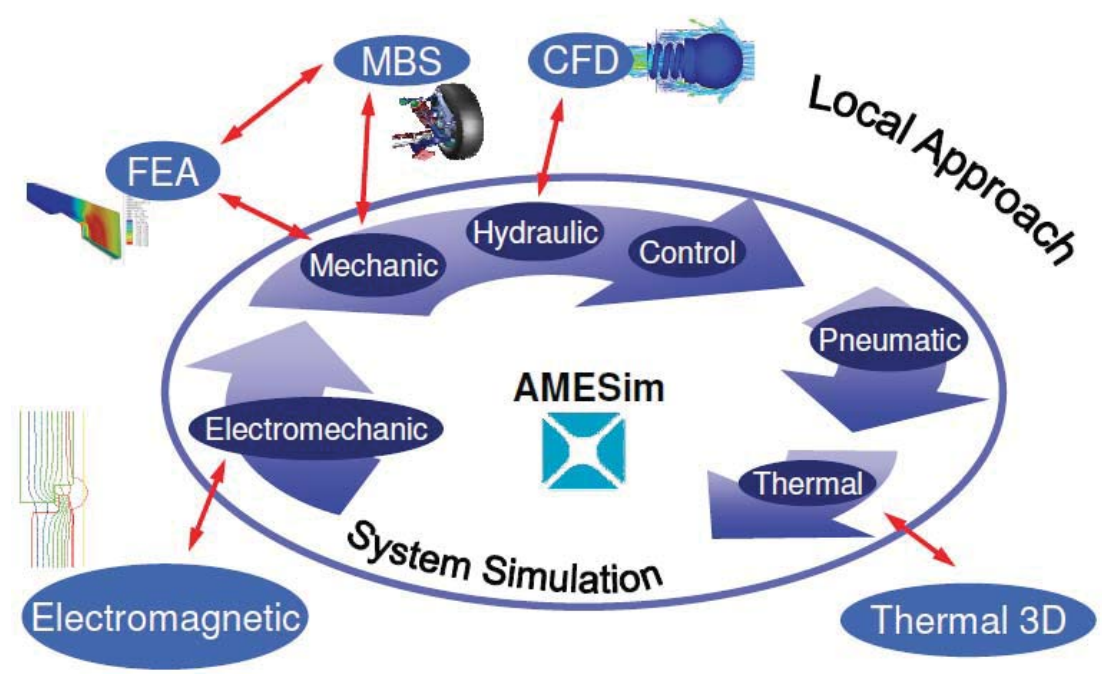

Figure 2-2. AMESim as a multi-domain simulation tool [11]

The modeling is done in four phases of sketch, sub-model setting, parameter setting, and simulation. In the sub-model setting user can choose a level of complexity for each of the model components. 


\section{Preliminary Model Implementation}

Using the basic sketches available for compression and rebound cycles, a preliminary model is going to be implemented in AMESim simulation software. In summary, a 4-way fully independent adjustable damper with through-rod design is going to be modeled.

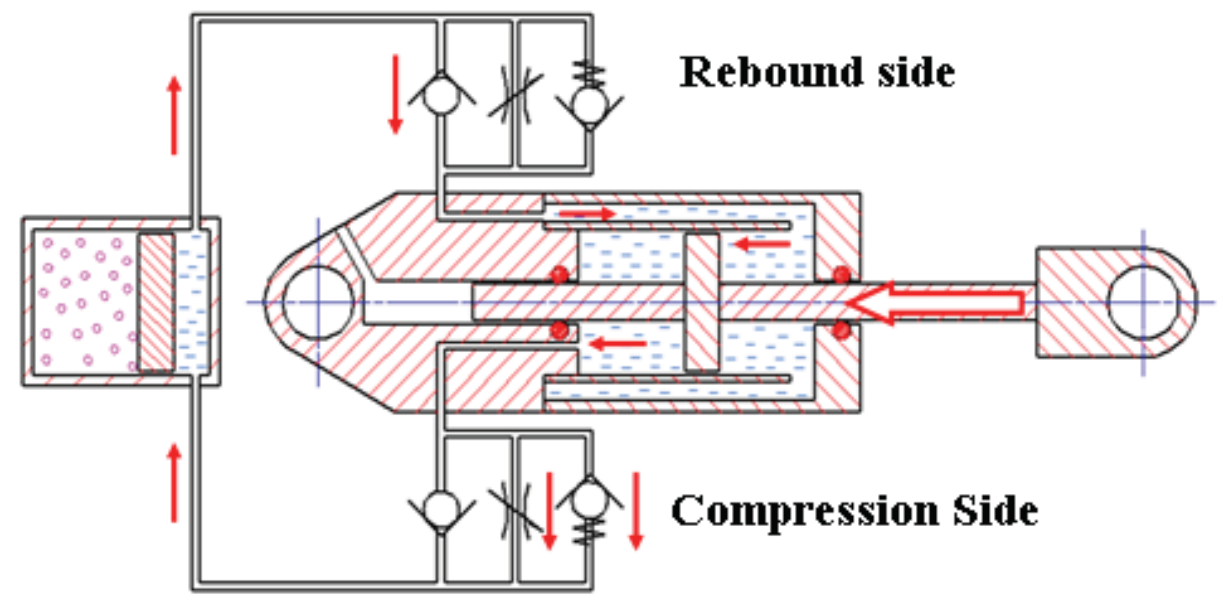

Figure 3-1. Compression Cycle [3]

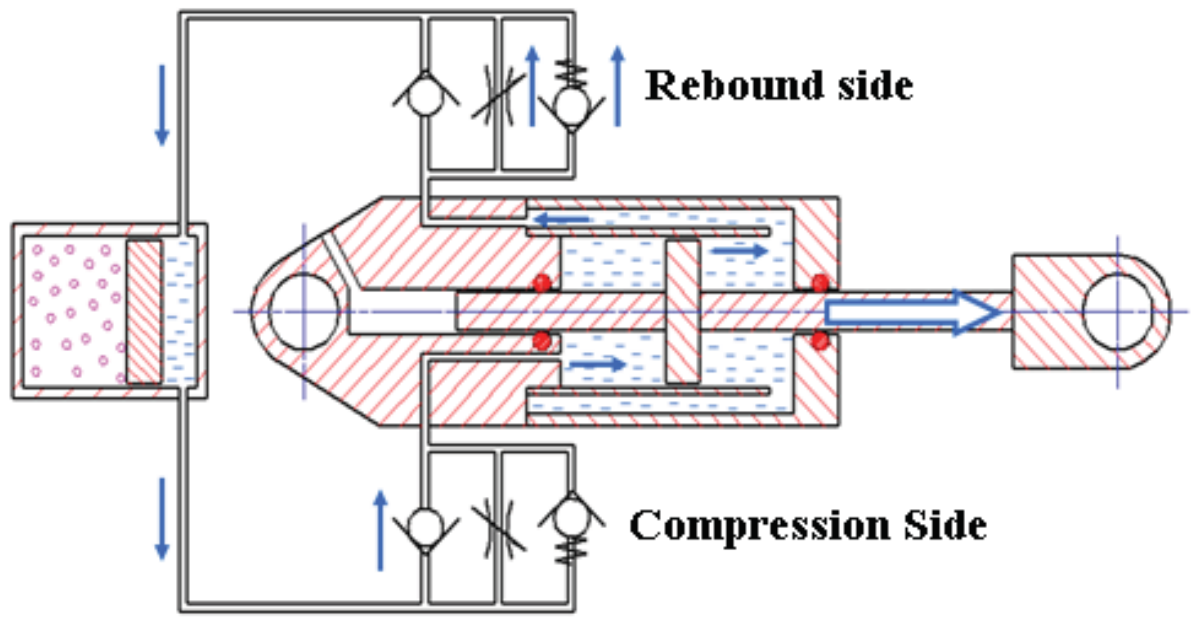

Figure 3-2. Rebound Cycle [3]

In general, the system is composed of four main parts:

- Main Cylinder: A through rod cylinder with two chamber volumes

- Compression Side: Composed of a low speed adjuster, a high speed adjuster, and a check valve, locating parallel to each other

- Rebound Side: Identical to the compression side

- Accumulator: A gas reservoir to set a pressure level for the system 
Figure 3-3 shows the schematic of the TTR damper. The input to the system is velocity applied to the main piston rod, and the output is the force generated in the rod.

System can generally undergo two cycles:

- Compression Cycle: Piston moves from right to left, flow from the first chamber goes through the compression side, the accumulator, the rebound side, and finally to the second chamber (Figure 3-1). As shown in Figure3-3, in the compression cycle, flow passes the high and low speed adjusters on the compression side and the check valve on the rebound side.

- Rebound Cycle: Piston moves in the opposite direction from left to right, flow from the second chamber goes through the rebound side, the accumulator, the compression side, and finally to the first chamber (Figure 3-2). As shown in Figure3-3, in the rebound cycle flow goes through the high and low speed adjusters on the rebound side and the check valve on the compression side.

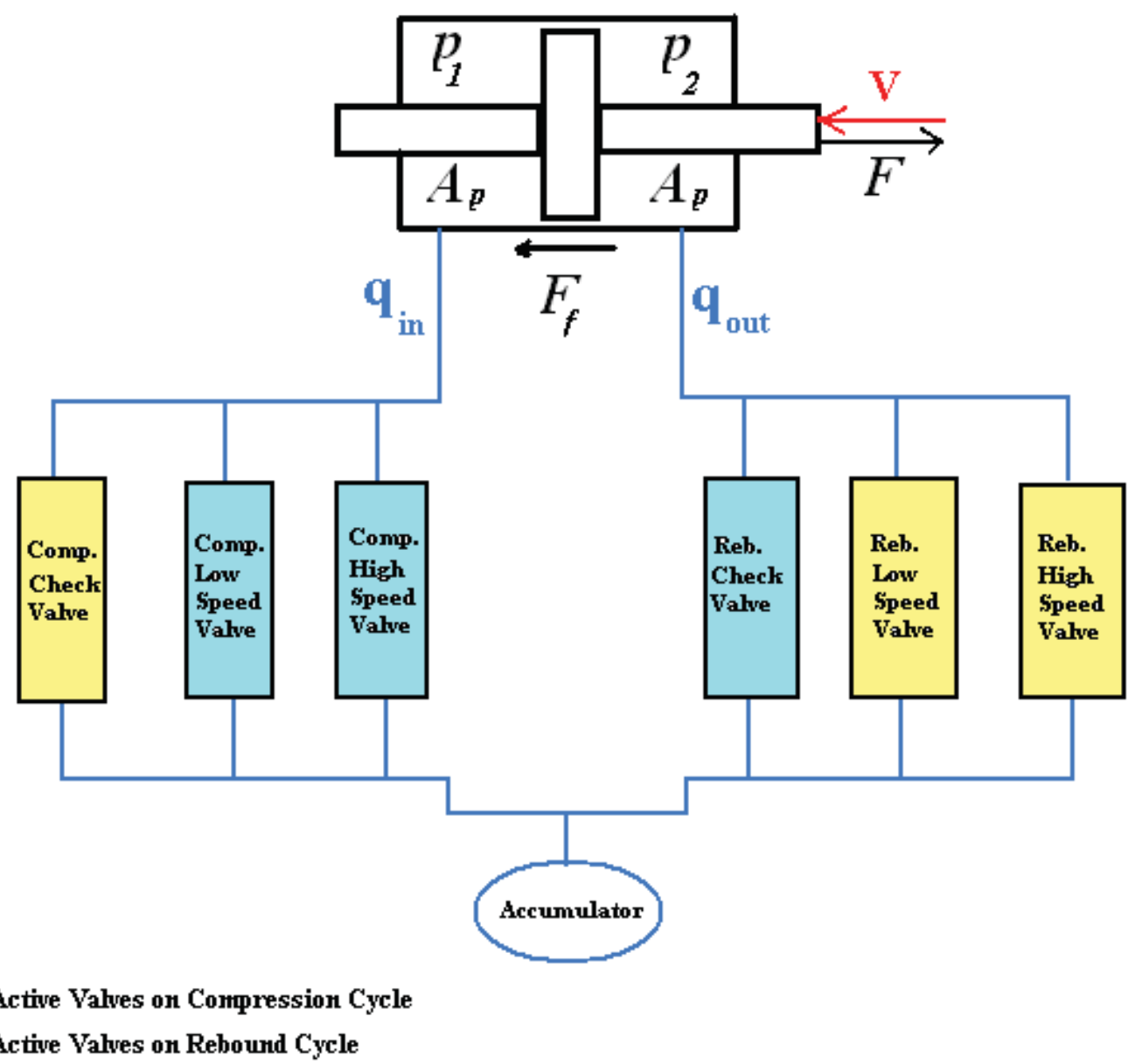

Figure 3-3. Simple schematic of the damper 


\subsection{Main Cylinder Piston Model}

The first part to be physically modeled is the main cylinder piston of the shock absorber. Flow is distributed from the main cylinder and all adjusters regulate the main piston flow. This results in maximum pressure area, minimum internal pressure, and finally less elastic deformation of the cylinder wall, which makes it possible to achieve high damping forces in short strokes.

Starting with the simplest level, model is composed of two identical cylinder chambers with fixed body and a through rod piston design. A benefit of having a through rod damper is the absence of piston rod displacement.

For each of the cylinder chamber components, a variable volume is considered which is responsible for simulating the pressure dynamics. The sub-model calculates the time derivative of pressure using the effective bulk modulus, net flow rate into the chamber, and the volume of the chamber.

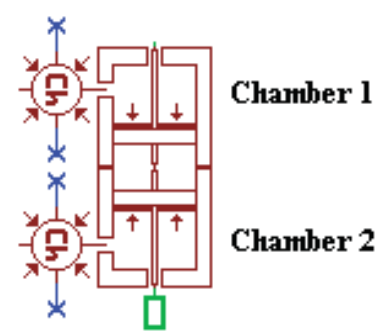

Figure 3-4. Simple model of the main piston

The cylinder chambers and volumes are from the 'Hydraulic Component Design' library. The input of the system is velocity and the output force, which can be measured on each part of the main rod. In order to have correct input and output a number of source and transducer components from the 'Mechanical (green)' and 'Signal, Control (red)' libraries of AMESim are needed to be used as in Figure3-4.

According to the product database, different versions of TTR with different dimensions are available. Table3-1, contains the parameter setting of the main cylinder used in this project both in modeling and measurements.

Table 3-1. Main piston parameter setting

\begin{tabular}{|l|l|l|l|}
\hline Piston with fixed body (top) & Piston with fixed body (bottom) & \\
\hline Piston diameter $(\mathrm{mm})$ & 36 & Piston diameter $(\mathrm{mm})$ & 36 \\
\hline Rod diameter $(\mathrm{mm})$ & 12 & Rod diameter $(\mathrm{mm})$ & 12 \\
\hline Chamber length at zero displacement $(\mathrm{mm})$ & 0 & Chamber length at zero displacement $(\mathrm{mm})$ & $\begin{array}{l}\text { Stroke } \\
\text { Length }\end{array}$ \\
\hline
\end{tabular}

There is no displacement restriction considered for the simple piston model. Therefore, in order to avoid physically impossible behaviors from the model, such as negative chamber length or volume, some limitations must be applied to the sub-model. Parameter called 'Chamber length at zero displacement' corresponds to the length of the chamber when the 
displacement of the input port is zero. In fact, it determines the stroke length during a simulation and must be tuned correctly based on the measurement conditions. As mentioned, wrong setting of this parameter leads to negative values of chamber length and chamber volume which is not physically possible. AMESim has a saturation level set to $\frac{V_{\text {dead }}}{100}$ which avoids the chamber volume to become negative. [2]

The value of the mentioned parameter depends on the initial piston position and the size of the stroke. Values of Table3-1 indicate that the piston is initially in the highest position and the length of the stroke is $25 \mathrm{~mm}$. Figure $3-5$ shows how the volume changes in two chambers during a complete stroke.

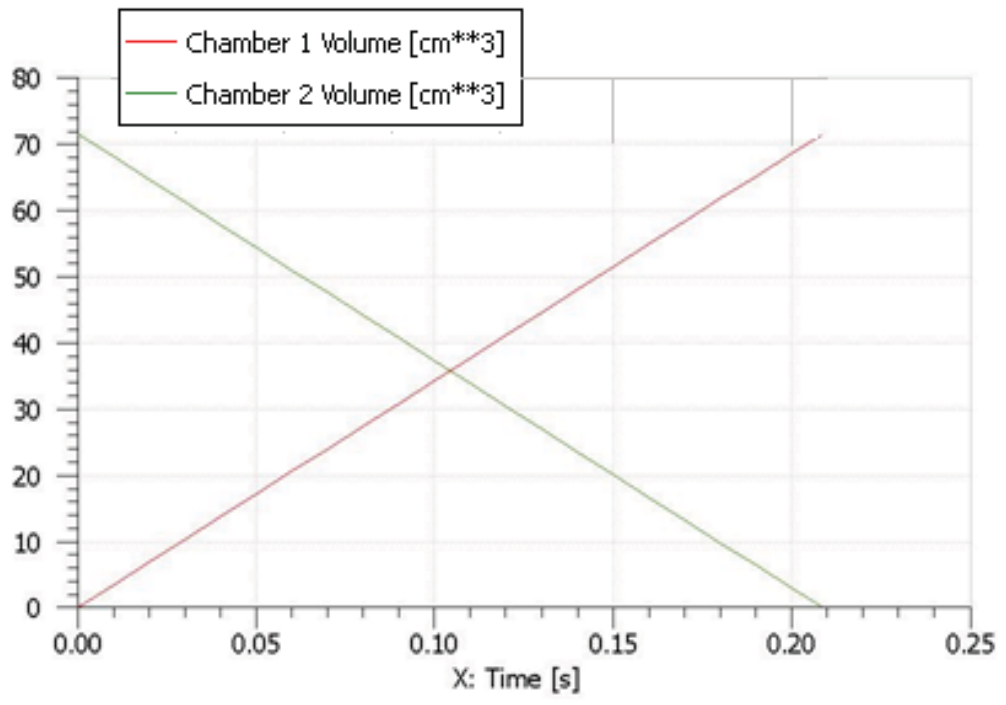

Figure 3-5. Main cylinder chambers volume versus time

\subsubsection{Velocity Input and the Simple Control Loop}

The main input of the shock absorber is velocity applied to the main piston rod. Therefore, the cylinder piston model is fed by a velocity source and the output of the system is the generated damping force. The force is measured by means of a linear velocity to force converter. The source, the variable converter, and the transducer are from the Mechanical library of the software, as shown by Figure3-6.

In order to be able to stop the input signal (the velocity) when the damper hits the bottom end of the cylinder, a small control loop is required to be added to the system. It also makes it possible to run different number of simulations with different input velocities at the same time (Batch Run). Otherwise, chamber length and volume may become negative because of the fact that the damper still has velocity when it is at its bottom end. This could cause some numerical problems to the software. 


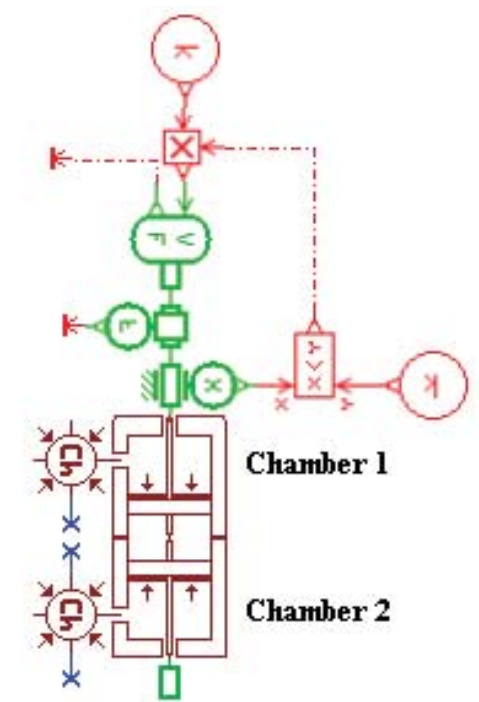

Figure 3-6. Velocity Input and the Simple control loop

The model measures the piston position with a displacement transducer, compares the value with a constant which is the maximum stroke length of the piston. Where the piston position exceeds the stroke value; the input velocity signal alters to zero, physically stopping the piston at the end of the cylinder chamber.

\subsection{External Adjusters}

TTR has four external adjusters in two groups of high and low speed. Each of the compression and rebound sides is equipped with a low and a high speed adjuster. The adjusters are special hydraulic valves, which can be modified in their oil flow metering characteristics, by means of external accessible screws. The adjustment is discrete, based on a specific number of 'clicks'. Setting different 'clicks' for the valves, results in different damping characteristics for the shock absorber. High speed adjusters are the poppet valves, hence their 'clicks' correspond to the pre-load over the poppet valve spring. Low speed adjusters are the fixed metering orifices, thus their 'clicks' vary opening area (diameter) of the orifice.

TTR is now modeled as a passive shock absorber. Therefore the clicks of the low and high speed valves are inputs of simulation and do not vary during a simulation. 


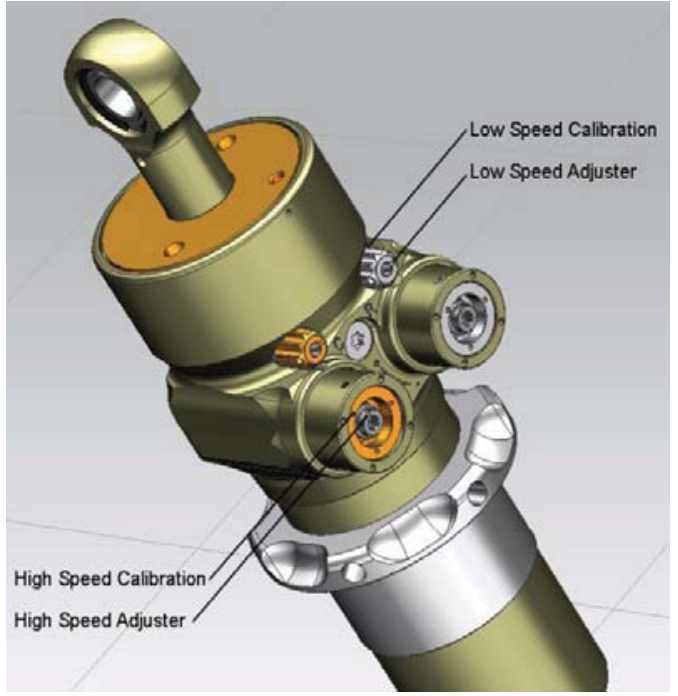

Figure 3-7. TTR external adjusters [3]

\subsubsection{High Speed Adjuster Model}

The high speed adjusters are conical poppet valves, pushed against their seats by preloaded coil springs in order to dictate a rapid opening to the valve dynamics. The preload is externally adjustable. The amount of spring preload determines the pressure difference across the main piston necessary to make the poppet valve open [1] and let the flow pass through the valve.
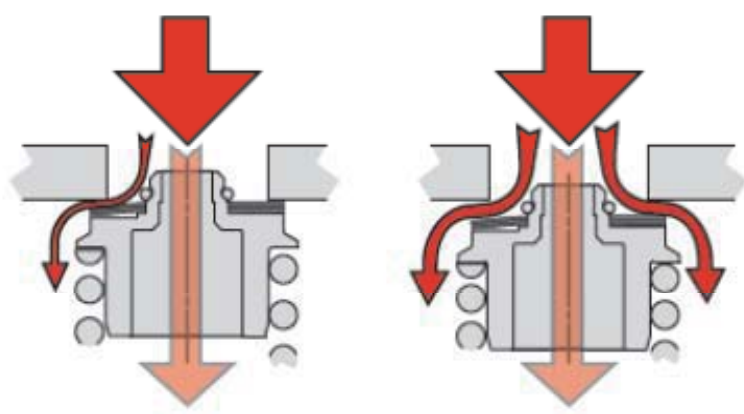

Figure 3-8. An illustration of the poppet valve opening characteristics [1]

The most critical issue in modeling the poppet valve is the conical poppet which dictates the flow behavior and therefore the damping characteristics. As shown in Figure3-9, depending on the position of the poppet with respect to the seat, three regions are considered separately.

- $X_{\text {lap }} \leq 0$, Spool region in overlap

- $0<X_{\text {lap }}<l_{c}$, Cone region in under lap

- $X_{\text {lap }} \geq l_{c}$, Rod region in under lap 


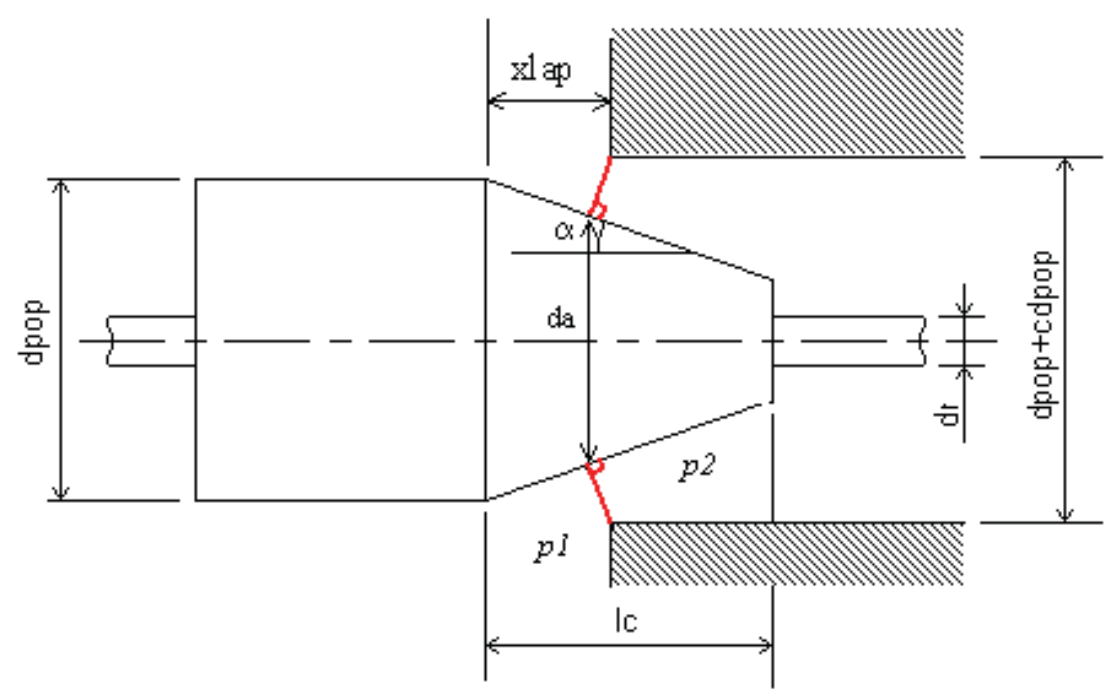

Figure 3-9. Schematic of the conical poppet model [2]

The flow area is calculated separately for each of the regions. The active diameter $\left(d_{a}\right)$ and the corresponding opening area of the poppet valve is calculated using the perpendicular distance from the poppet to the valve seat.

Figure 3-10 represents the simple model implemented for the poppet valves. It is composed of four sub-models: 'conical poppet' and 'piston with spring' from the HCD library and 'mass with friction and ideal end stops' and 'zero force sources' from the mechanical library.

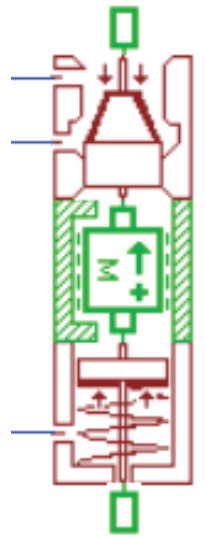

Figure 3-10. Poppet valve HCD model

According to the real valve, the spring is located inside the volume of the poppet, thus poppet and spring has the same volume. Therefore, variable volumes are added to the high speed adjuster model, connected to both poppet and spring volume, as shown in Figure3-11. 


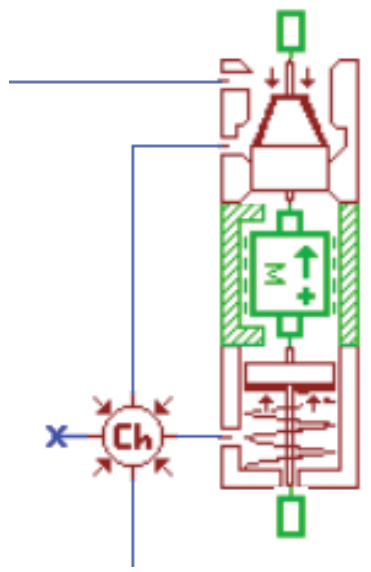

Figure 3-11. Poppet and spring with the same chamber volume

From the hardware side, there exist different versions of the poppet, shuttle guide, and spring which are considered as internal adjusters. For simplicity and consistency, a single version of each component is chosen and used for the whole simulation studies and measurements, although the model has the capability of changing these values to any other internal adjustment. Figure 3-12 illustrates a drawing of the mentioned components.
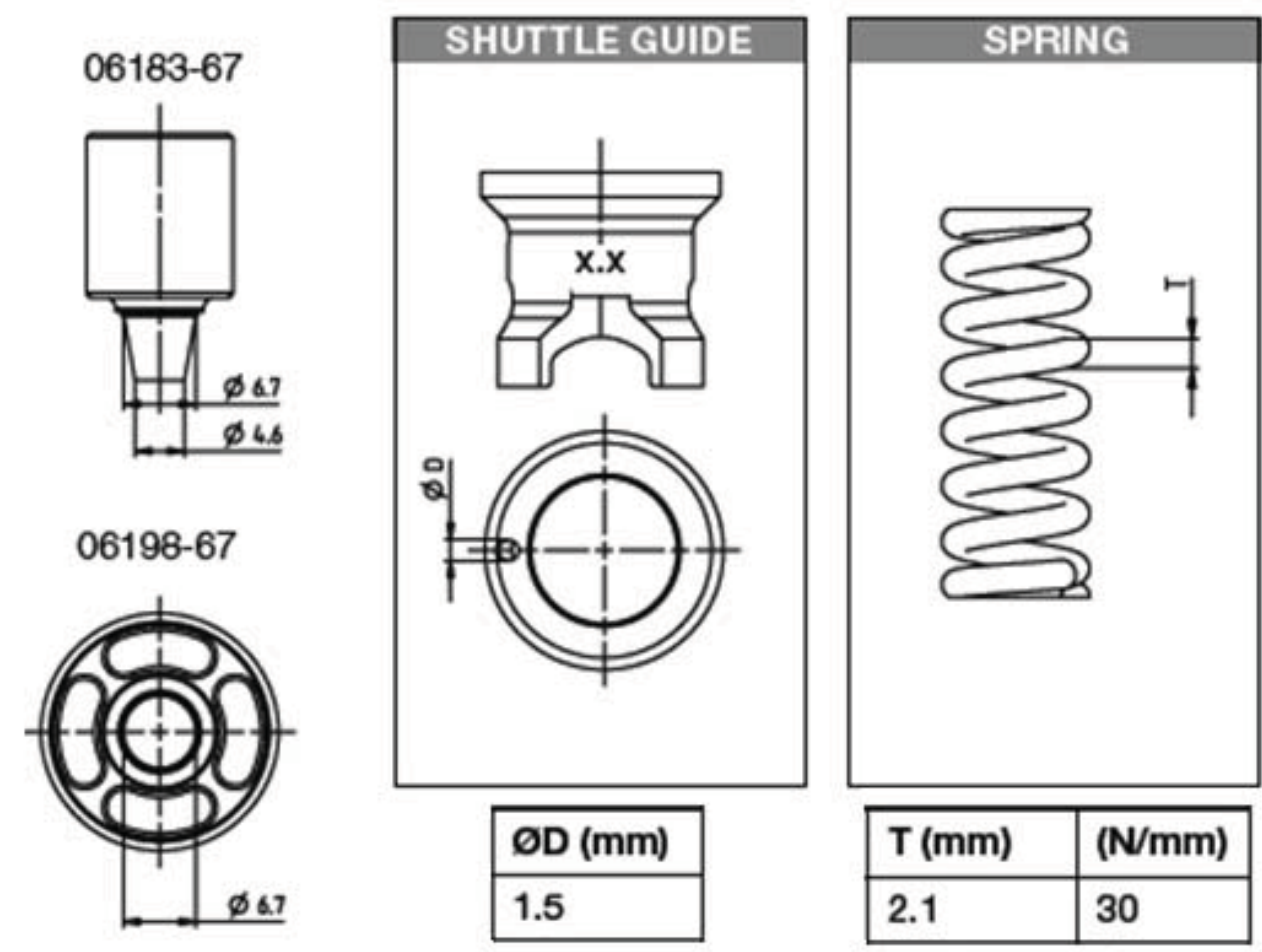

Figure 3-12. Drawing of the poppet valve sample [3]

Table 3-2 contains the values set for the poppet valve model parameters according to the geometry illustrated in Figure 3-12. 
Table 3-2. Poppet valve model parameter setting (confidential)

\begin{tabular}{|l|l|}
\hline \multicolumn{1}{|c|}{ Poppet with no seat } & Mass with friction and ideal end stops \\
\hline Diameter of poppet $(\mathrm{mm})$ & Mass $(\mathrm{kg})$ \\
\hline Cone length $(\mathrm{mm})$ & Coefficient of viscous friction $(\mathrm{N} /(\mathrm{m} / \mathrm{s}))$ \\
\hline Diameter of rod $(\mathrm{mm})$ & Windage coefficient $\left(\mathrm{N} /(\mathrm{m} / \mathrm{s})^{2}\right)$ \\
\hline Poppet half angle $(\mathrm{deg})$ & Coulomb friction force $(\mathrm{N})$ \\
\hline Clearance on the poppet diameter $(\mathrm{mm})$ & Stiction force $(\mathrm{N})$ \\
\hline & Lower displacement limit $(\mathrm{m})$ \\
\hline & Higher displacement limit $(\mathrm{m})$ \\
\hline & Inclination \\
\hline
\end{tabular}

\begin{tabular}{|l|}
\hline \multicolumn{1}{|c|}{ Piston with spring } \\
\hline Piston diameter $(\mathrm{mm})$ \\
\hline Rod diameter $(\mathrm{mm})$ \\
\hline Spring stiffness $(\mathrm{N} / \mathrm{mm})$ \\
\hline $\begin{array}{l}\text { Spring force at zero displacement }(\mathrm{N}) \\
\text { Spring Pre-load (click dependent) }\end{array}$ \\
\hline Chamber length at zero displacement $(\mathrm{mm})$ \\
\hline
\end{tabular}

For the piston covering the spring, to be able to calculate the correct length and volume of the hydraulic chamber, the chamber length when the input port displacement is zero must be specified. Therefore, the value is set such that the length and volume of the hydraulic chamber are never negative. Similarly the spring force must be specified when the displacement is zero.

\subsubsection{Low Speed Adjuster Model}

Low speed adjusters or bleed valves are externally adjustable orifices which their diameter is fixed after adjustment and does not vary with the pressure difference. As long as the piston is moving and the bleed valve is not fully closed, some oil will always flow through the bleed valve regardless of the poppet valve position.

The sub-model calculates the density and kinematic viscosity at the mean pressure $\left(\frac{P_{1}+P_{2}}{2}\right)$, using the bulk modulus estimation (described in 3.6). Consequently, the flow number and flow coefficient $\left(C_{q}\right)$ are calculated to be used in the orifice flow equation [2].

$$
q=C_{q} A \sqrt{\frac{2|\Delta P|}{\rho}} \operatorname{sign}(\Delta P)
$$

The sub-model has the ability to change its characteristics from laminar to turbulent flow, when passing the user specified transition value. The default value of the critical flow number recommended by AMESim is 1000 . The value can increase up to 50000 for very smooth surfaces and decrease to 50 for the rough ones [2]. 
Input parameters can either be the flow rate and pressure drop or the diameter and flow coefficient. The second alternative is used in this study. The schematic of the orifice together with the parameters table is shown in Figure3-13 and Table3-3.

The model of the bleed valve is the fixed orifice from the HCD library, configured in order to achieve the required flow restriction. The HCD sub-model compared to the HYD version, estimates the dynamic behavior of the valve more accurately.

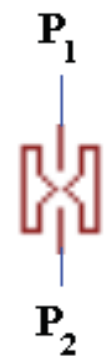

Figure 3-13. Bleed valve HCD model

Table 3-3. Bleed valve model parameter setting (confidential)

\begin{tabular}{|l|}
\hline \multicolumn{1}{|c|}{ Fixed Hyd. Orifice } \\
\hline Equivalent Orifice Diameter $(\mathrm{mm})$ \\
\hline Max. Flow Coefficient \\
\hline Critical Flow Number \\
\hline
\end{tabular}

\subsection{Check Valve Model}

The real check valve is made of a wave shim acting as a spring, which is responsible for the gradual opening of the valve. Flow goes through the shim until the check valve cracks. A simple spring loaded check valve model from the HYD library is used in the initial modeling phase, which considers no dynamics. The check valve opens if the pressure difference over it becomes larger than the cracking pressure, set by the spring.

\section{Out $-W(t)-$ In}

Figure 3-14. Check valve HYD model

$$
\boldsymbol{P}_{\text {in }}-\boldsymbol{P}_{\text {out }} \geq \boldsymbol{P}_{\text {crack }}
$$

This sub-model incorporates some mild hysteresis, so that the check valve opens a little above its nominal cracking pressure and closes a little below the cracking pressure. The default value of this hysteresis is zero. If the check valve, 'chatters', i.e. opens and closes rapidly, many discontinuities will be produced leading to a slow numerical solution, which can be solved by setting the hysteresis value to $1.0 \mathrm{e}-4$ [2].

Figure3-15, demonstrates the different flow regions of the check valve model, as well as the definitions required for the parameter setting. For the simple check valve component there are four parameters to be set, the crack pressure, the flow rate pressure gradient (grad), the 
nominal flow rate when the valve is fully open, and the corresponding pressure drop. There is no specific value available for these parameters and they have to be tuned based on measurements (7.3).

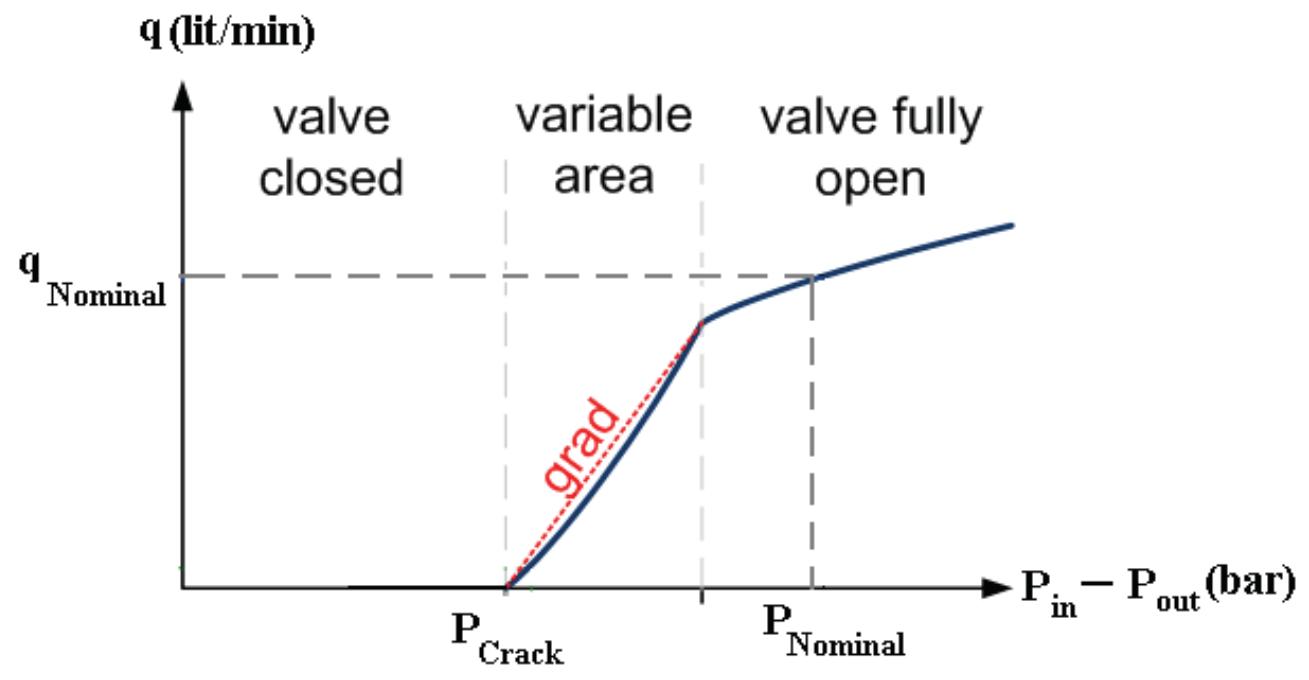

Figure 3-15. Check valve model, flow characteristics [2]

\subsection{Accumulator Model}

The accumulator (gas reservoir) is responsible for setting the system pressure level. The through-rod design of the TTR shock absorber helps to decrease the effect of the accumulator properties on the damping behavior. The system pressure level is fixed based on the initial pressure used in the accumulator properties. Consequently, the Low and High Speed Adjusters (LSA and HSA) zero click settings (i.e. the spring pre-load and orifice diameter at click0 which are also not available), are set.

For an accumulator sub-model from the HYD library of AMESim, the following parameters must be set:

- Gas pre-charge pressure $\left(P_{0}\right)$

- Accumulator volume $\left(V_{0}\right)$

- Initial pressure $\left(P_{i}\right)$

The combination of the above parameters is equivalent to the accumulator stiffness. The first two parameters are needed to be set using the real accumulator properties.

Suspension initially equilibrates the car weight, which yields to,

$$
\begin{gathered}
P_{i}=\frac{m g}{A_{\text {piston }}} \\
A_{\text {piston }}=\frac{\pi\left(d_{\text {piston }}^{2}-d_{\text {rod }}^{2}\right)}{4}
\end{gathered}
$$


Figure3-16 and Table3-4 show the schematic of the accumulator model as well as the parameters used for the accumulator model.

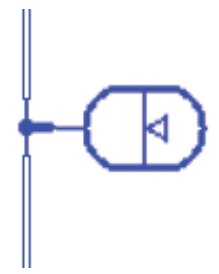

Figure 3-16. Accumulator HYD model

Table 3-4. Accumulator model parameter setting

\begin{tabular}{|l|c|}
\hline \multicolumn{2}{|c|}{ Hydraulic accumulator without inlet orifice } \\
\hline Gas pre-charged pressure (bar) & 5 \\
\hline Accumulator Volume $\left(\mathrm{m}^{3}\right)$ & 0,00032 \\
\hline Polytropic index & 1,4 \\
\hline Initial pressure (bar) & 32,527 \\
\hline
\end{tabular}

\subsection{Connecting Lines and Pipes}

Connecting lines between the model components are of great importance in AMESim simulations. Choosing a wrong sub-model for lines may cause negative influences on the simulation results, as well as unacceptably long simulation run time. In the current model almost all of the components are connected by direct connection sub-model. Only for the connection between the valves and the accumulator, the pipe sub-model considering the compressibility and friction is used (R-C-R), which is a lumped parameter sub-model of a hydraulic pipe.

The compressibility of the fluid and expansion of the pipe wall with pressure are taken into account by using an effective bulk modulus which can be calculated based on the wall thickness and Young's modulus for the wall material. The dimensions of the pipes are set according to the drawings of the real sample.

Table 3-5. Pipe model parameter setting

\begin{tabular}{|l|c|}
\hline \multicolumn{2}{|c|}{ Compressibility and friction hydraulic line } \\
\hline Diameter of pipe $(\mathrm{mm})$ & 10 \\
\hline Pipe length $(\mathrm{m})$ & 0,02 \\
\hline Wall thickness $(\mathrm{mm})$ & 2 \\
\hline Young's modulus of material (bar) & $2,06 \mathrm{e}+06$ \\
\hline
\end{tabular}




\subsection{Oil Properties}

The oil has bulk modulus of around 16000 bar and density of $865 \mathrm{~kg} / \mathrm{m}^{3}$ at $20^{\circ} \mathrm{C}$. Viscosity of the oil is temperature dependent and varies based on Figure3-17.

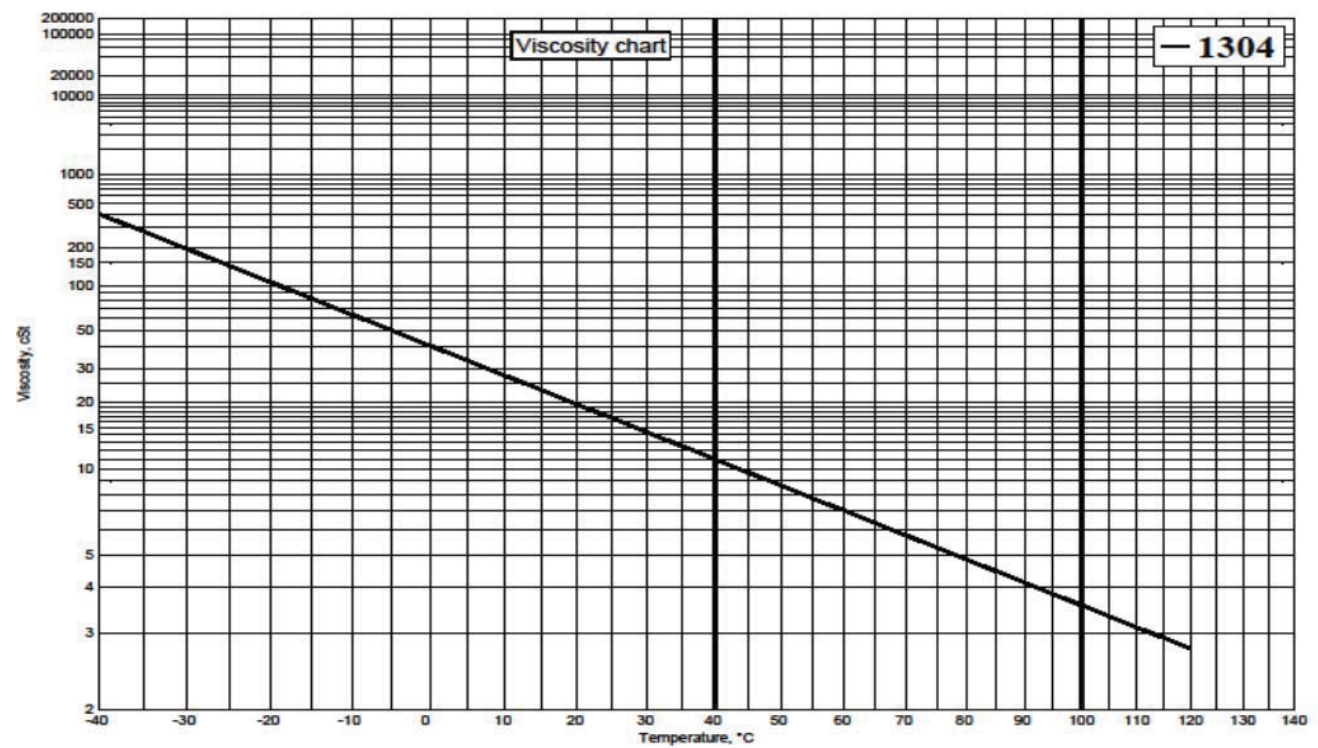

Figure 3-17. Viscosity of the oil as a function of temperature

Bulk modulus is generally defined as the resistance of oil to uniform pressure.

$$
B=-V \frac{d P}{d V}=\rho \frac{d P}{d \rho}
$$

The oil saturation pressure is the minimum pressure in which all of the air is dissolved in oil. For pressures above the saturation level, the software uses the Bulk modulus set by user. While, for pressures below saturation level, it uses the reduced Bulk modulus. It uses an expression which is an acceptable estimate of the commonly used 'Henry's Law' [2]. According to 'Henry's law', the fraction of not dissolved air decreases linearly with absolute pressure increase. Figure3-18 shows a comparison of the software expression and the 'Henry's Law'. 


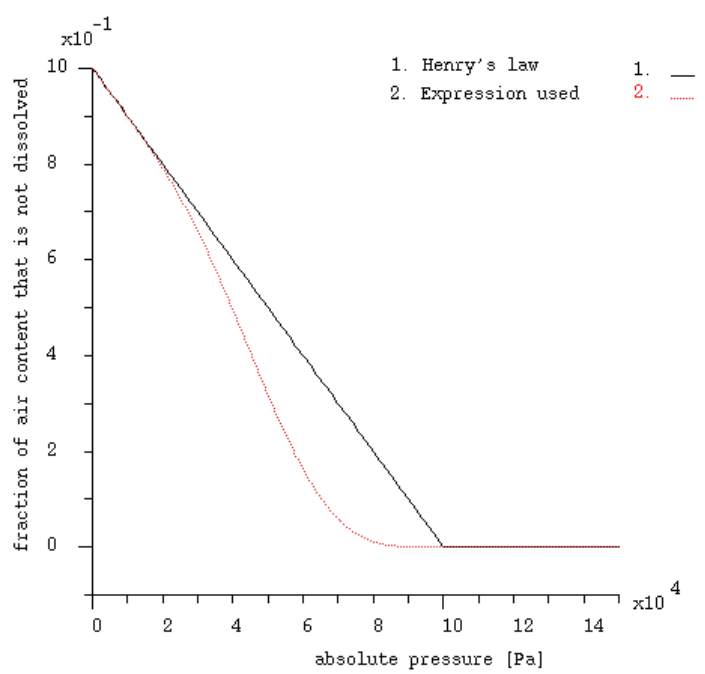

Figure 3-18. Henry's law compared to the software suggested expression for Bulk modulus [2]

Having the air fraction, the density and the corresponding bulk modulus are calculated as a function of pressure. Therefore, the accurate value of the bulk modulus is used at different pressure levels.

\subsection{Shock Absorber Preliminary Model}

Figure3-19 demonstrates the final version of the TTR preliminary AMESim model. As the real damper, the model is generally composed of four external adjusters, two on the compression and two on the rebound side. High and low speed adjusters are in parallel with check valves which are responsible for separating the compression and rebound sides. The accumulator is located between the high and low pressure sides of the damper. Therefore, the flow from the high pressure sides leads to the accumulator, the low pressure side valves, and finally the second chamber volume

The run status icon is a statistical tool used to discover the reasons of slow simulations. 


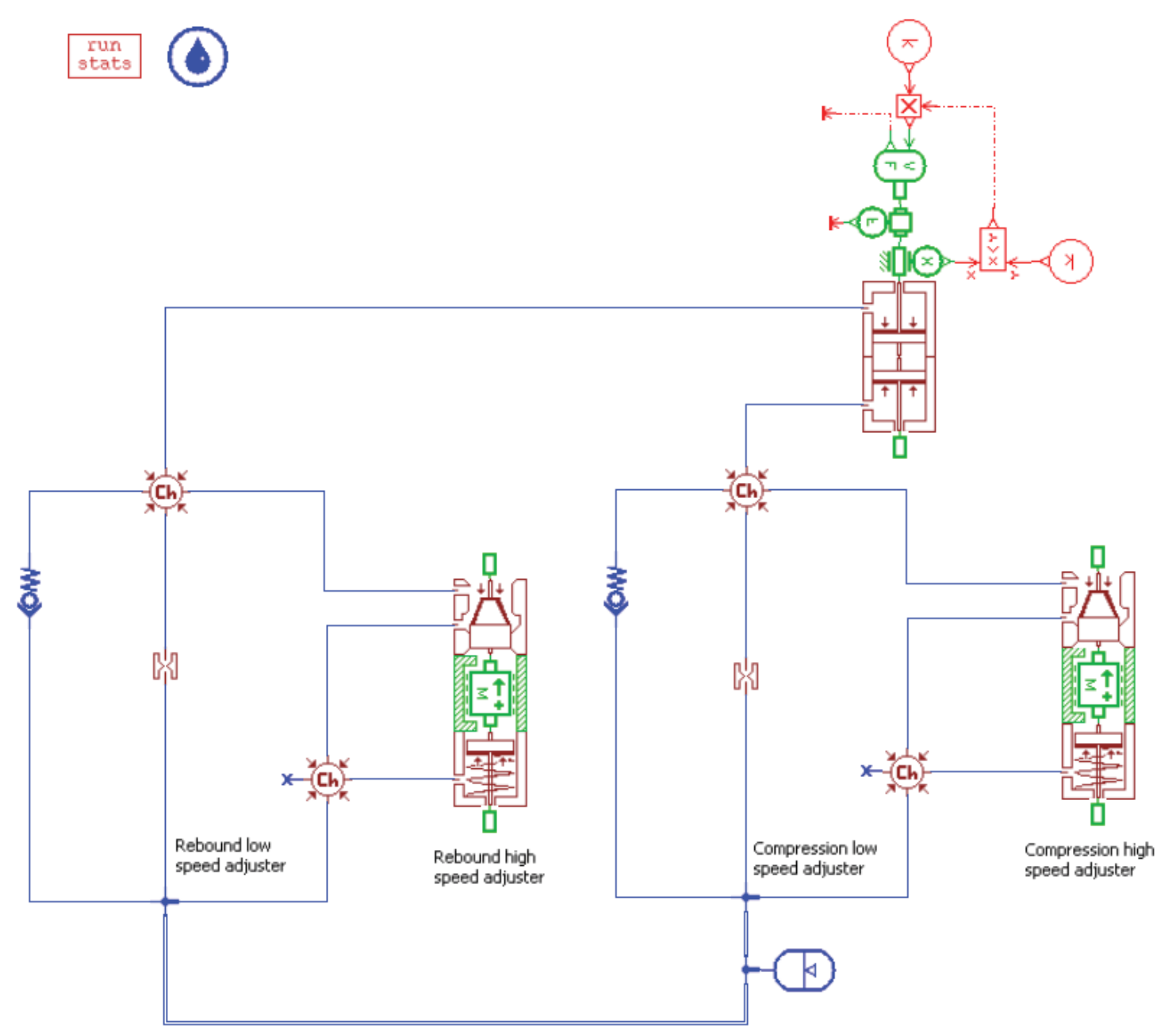

Figure 3-19. General sketch of the preliminary damper model 


\section{Preliminary Model Validation with Static Measurements}

The model has been statically validated, and static validation is one of the prerequisites for a model to be dynamically valid. Therefore, the static validation of the simple model is presented in this chapter. The main input of the model is the velocity input, explained in 4.2. Regardless of the input velocity, the model has two inputs in general, the opening of the orifice dictated by the Low Speed Adjuster click, and the preload over the spring set by the High Speed Adjuster click, explained in 4.3 and 4.4 respectively.

Since the corresponding opening diameter and spring pre-load for each click of the valves are not known, they need to be estimated by comparing the damping curves of simulation and measurements. Measurements are done on a TTR damper using the modern dynamometer available at Öhlins company laboratory. There exists a mathematical program called Valving Reference Program (VRP) which provides the measurements in terms of the damping curves (Force versus velocity). The preliminary AMESim model is going to be validated by comparing the achieved damping curves with the ones from VRP.

Before starting the validation, it is worthy to first introduce the general shape of a static damping curve.

\subsection{Static Damping Curve Characteristics}

Damping curves are diagrams of damping force versus velocity. Static damping curves are generally composed of three regions, as shown in Figure4-1.

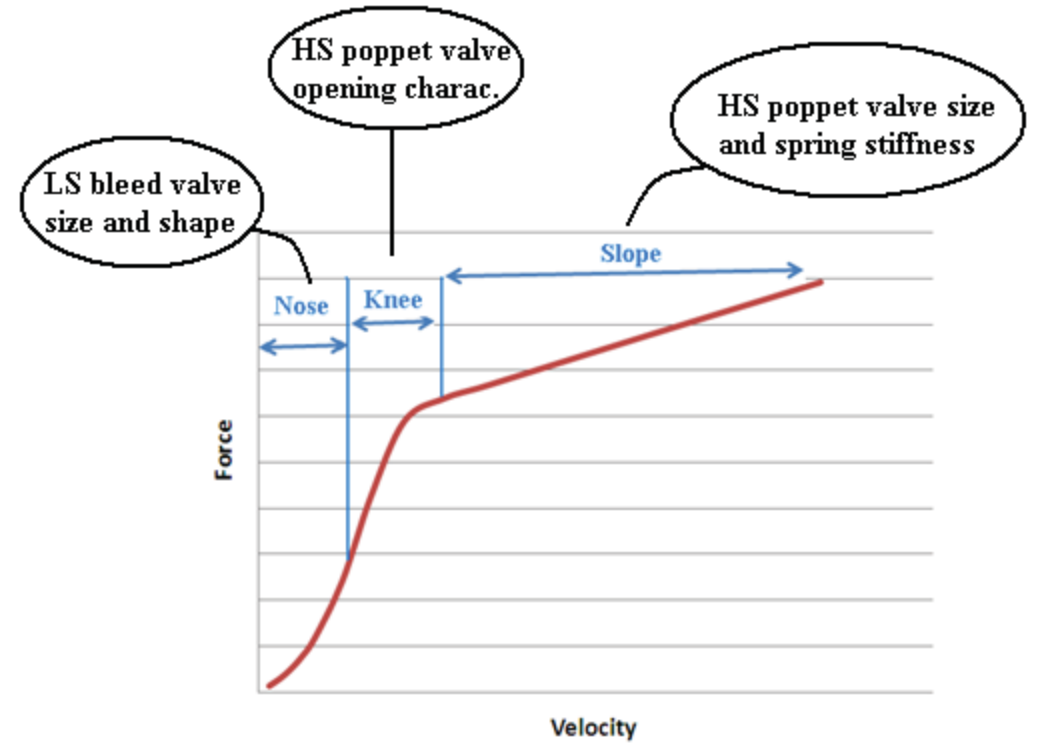

Figure 4-1. Static damping curve zones and the corresponding effective factors

The nose or the low speed zone is the low speed bleed valve affecting zone. The design and size of the bleed valve, i.e. the orifice opening, determines the characteristics and shape of the nose. Nose is followed by the knee zone which begins when the curve starts to level off into a radius. The shape of the knee is determined by the opening characteristics of the high speed poppet valves. Abrupt opening results in a sharp knee while a gradual one makes it 
smooth. The slope, or the high speed zone, starts where the curve blends into a straight line. Size of the poppet valves and the stiffness of the coil springs are the factors determining the slope.

The LS valves click setting measurements are done under the condition that the HS valves are fully closed and flow passes only through the low speed bleed valves. While for the HS valves click setting, the LS valves are set at click 30 which provides a medium opening of the orifice.

\subsection{Static Velocity Input}

The main input of the damper and consequently its simulation model is the velocity applied to the main piston rod. The velocity input characteristics determine if the tests are performed statically or dynamically.

During static measurements, the damper, with a specific click setting, is fed by a ramp followed by a constant input velocity. Damping force generated increases until reaching a constant level and the stationary value of damping force is recorded. Same procedure is done for 18 different constant speeds in the interval of $[0-0.5 \mathrm{~m} / \mathrm{s}]$.

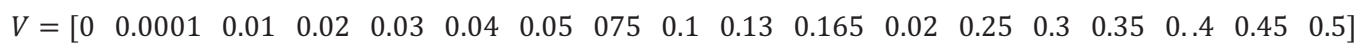

Therefore, a damping curve is constructed by connecting the 18 (Velocity, Force) points obtained from 18 tests. In order to fit the simulation model to the measurements, the model is also fed by the same velocities and the corresponding stationary force for each speed is recorded for all of the 18 simulation runs. Taking the advantage of 'Batch Run' tool in AMESim and also the simple control loop introduced in 3.1.1, 18 simulations are ran continuously and in a shorter time.

The system is fed by constant piston speed which yields to constant flow rate through the valves.

$$
\begin{aligned}
& A_{\text {piston }}=\frac{\pi\left(d_{\text {piston }}^{2}-d_{\text {rod }}^{2}\right)}{4} \\
& q=A_{\text {piston }} * V
\end{aligned}
$$

The stroke of the piston is $25 \mathrm{~mm}$ during the measurements. Thus, for each specific velocity, the corresponding time for simulation can be calculated by the simple relation,

$$
\text { Velocity }=\frac{\text { Displacement }}{\text { Time }}
$$

\begin{tabular}{|c|c|c|c|c|c|c|c|c|c|c|c|c|c|c|c|c|c|c|}
\hline $\mathrm{V}(\mathrm{m} / \mathrm{s})$ & 0 & 0.001 & 0.01 & 0.02 & 0.03 & 0.04 & 0.05 & 0.075 & 0.1 & 0.13 & 0.165 & 0.2 & 0.25 & 0.3 & 0.35 & 0.4 & 0.45 & 0.5 \\
\hline $\mathrm{t}(\mathrm{s})$ & 25 & 25 & 2.5 & 1.25 & 0.83 & 0.625 & 0.5 & 0.33 & 0.25 & 0.2 & 0.15 & 0.125 & 0.1 & 0.083 & 0.071 & 0.0625 & 0.056 & 0.05 \\
\hline$q(1 / \mathrm{min})$ & 0 & 0.054 & 0.54 & 1.086 & 1.63 & 2,17 & 2.71 & 4.07 & 5.41 & 6.94 & 8.96 & 10.86 & 13.57 & 16.28 & 19 & 21.71 & 24.43 & 27.14 \\
\hline
\end{tabular}

Table4-1 contains the flow rate and simulation final time for 18 different velocities.

Table 4-1. Flow rate and time of the static tests 


\subsection{Low Speed Adjusters External Click Setting}

The corresponding opening diameter for different clicks of the LS adjuster has to be found to obtain good measurements correlation. Each of the LS adjusters has approximately 50 clicks and the adjusting knob provides 10 clicks per turn. With $0.5 \mathrm{~mm}$ inclination of the thread, the opening increases by $0.05 \mathrm{~mm}$ per click. In addition, 0 click of the LS adjuster corresponds to a fully open condition for the bleed valve. Therefore, by increasing the click, the opening diameter decreases and consequently the damping force increases. Thus, if assuming the diameter of the orifice at click 0 to be $d_{0}$, it is predicted for the opening diameter, through measurements comparison, to follow a profile similar to Table4-2.

Table 4-2. Predicted orifice diameter for different clicks of LS valves based on the valve inclination

\begin{tabular}{|l|l|l|l|l|l|c|c|c|c|c|c|}
\hline Clicks & \multicolumn{1}{c|}{0} & \multicolumn{1}{c|}{5} & \multicolumn{1}{c|}{10} & \multicolumn{1}{c|}{15} & \multicolumn{1}{c}{20} & \multicolumn{1}{c|}{25} & \multicolumn{1}{c|}{30} & \multicolumn{1}{c|}{35} & \multicolumn{1}{c}{40} & \multicolumn{1}{c|}{45} & \multicolumn{1}{c}{50} \\
\hline $\begin{array}{l}\text { Orifice } \\
\text { diameter } \\
(\mathrm{mm})\end{array}$ & $d_{0}$ & $\begin{array}{l}d_{0} \\
-0.25\end{array}$ & $\begin{array}{l}d_{0} \\
-0.5\end{array}$ & $\begin{array}{l}d_{0} \\
-0.75\end{array}$ & $\begin{array}{l}d_{0} \\
-1\end{array}$ & $d_{0}$ & $d_{0}$ & $d_{0}$ & $d_{0}$ & $d_{0}$ & $d_{0}$ \\
\end{tabular}

Since $d_{0}$ is not known, the correct value of diameter for each click is first estimated by trial and error and then compared to the predicted profile. Figure 4-2, shows a comparison of the simulation result and measurement when only the LS valves are active.

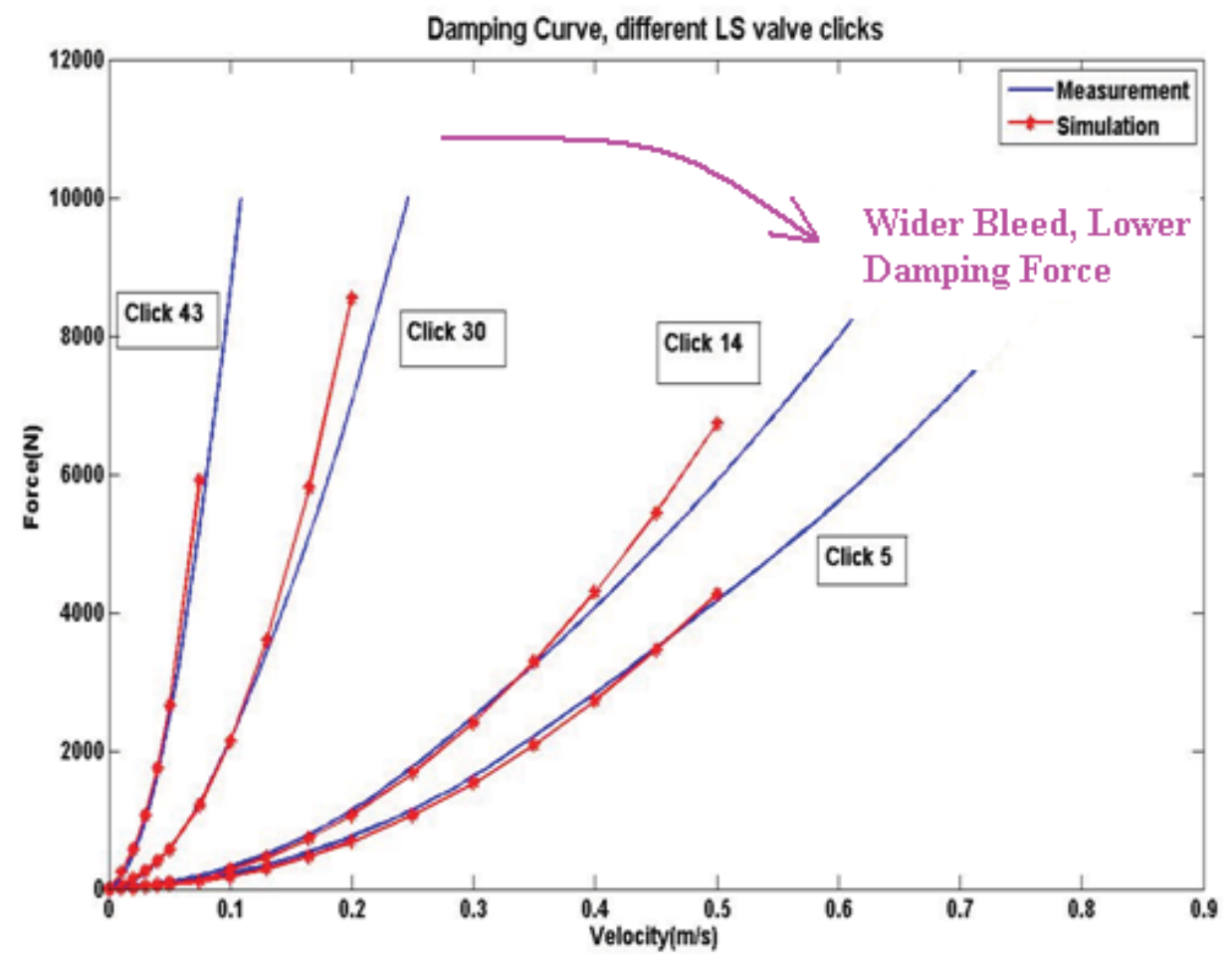

Figure 4-2. LS valve click setting, measurement and simulation comparison

As it comes from their name, the behavior of LS adjusters is mainly important in low range of velocities, where the HS valves are still closed. While at higher speeds poppet valves 
are open and their characteristic is dominant. Therefore, for the above comparisons, it is mostly crucial to have good agreement between measurements and simulation in lower velocities.

As shown in Figure4-2, the shape of the curve follows the orifice flow equation in which the flow is proportional to the square root of pressure difference. Furthermore, for lower clicks of the LS valve, the orifice opening is larger, which results in a lower flow restriction. Therefore, at a certain velocity, the generated damping force becomes smaller compared to the higher clicks.

Figure4-3 shows the mathematical explanation of the bleed valve damping behavior.

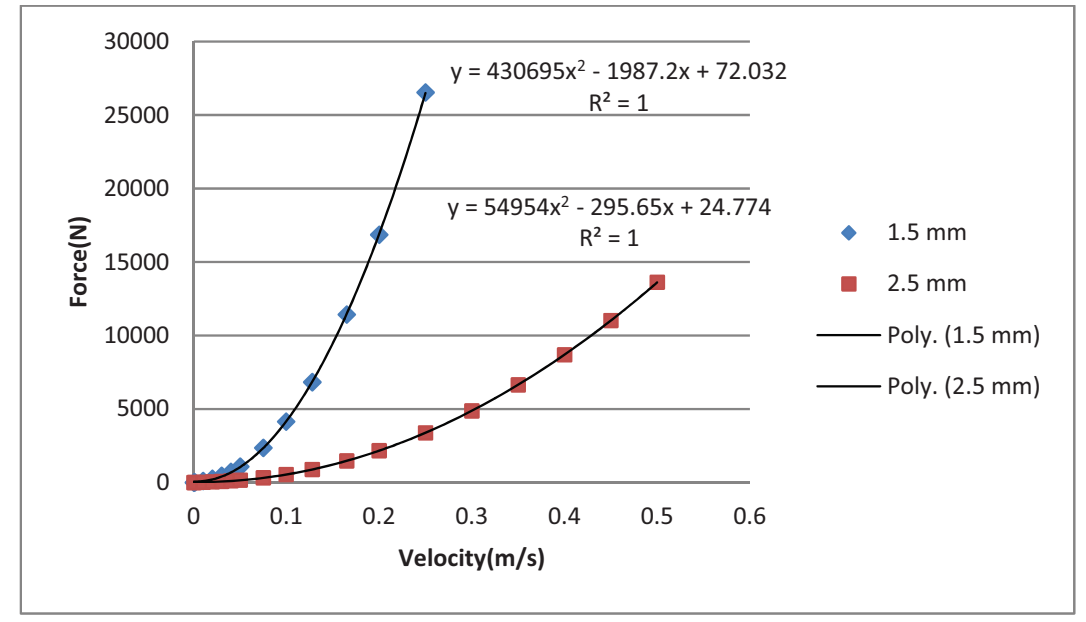

Figure 4-3. Bleed valve damping behavior

Figure4-3 shows the simulation results for two different orifice openings. It is clear that there is a second order relation between the generated damping force by the bleed valve and the velocity (reminding the orifice flow equation). In addition, as the orifice diameter increases, the coefficient of velocity decreases, and the curve becomes wider.

In order to find the correct opening diameter, a linear interpolation is performed for the points in Table 4-3 which are the approximate value of orifice diameters for a number of bleed clicks. As it is clear from the regression equation, with an acceptable accuracy, the opening varies linearly as the bleed clicks increases.

Table 4-3. Bleed valve clicks and the approximate orifice opening diameter

\begin{tabular}{|l|c|c|c|c|}
\hline LS Click & 5 & 14 & 30 & 41 \\
\hline Orifice diameter $(\mathrm{mm})$ & 2.8 & 2.4 & 1.5 & 1.1 \\
\hline
\end{tabular}




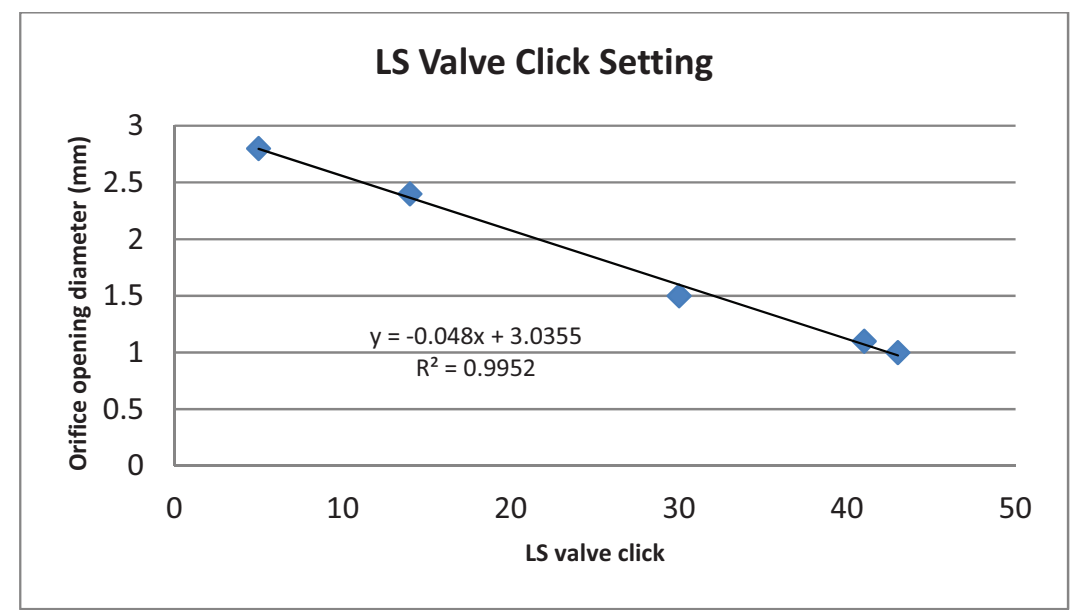

Figure 4-4. Linear interpolation for bleed valve click setting

According to the regression line equation, the orifice diameter decreases by $0.048 \mathrm{~mm}$ per click which is a good estimation for the $0.05 \mathrm{~mm}$ predicted value. Furthermore, the equation estimates the $d_{0}=3.04 \mathrm{~mm}$, which due to manufacturing accuracy is probably $3 \mathrm{~mm}$ in the real valve.

\subsection{High Speed Adjusters External Click Setting}

The next input of the model to be set is the corresponding pre-load of the high speed poppet valves spring for different clicks. In the measurements used, LS valves are set at click 30 both on the compression and rebound sides. The damping characteristics for different HS clicks are investigated, all at the same bleed setting.

The first step is to find the exact orifice opening diameter for click 30 of the bleed valves. As mentioned before, bleed damping behavior is dominant at low velocities. Therefore, in order to enhance the accuracy of the simulation, the difference between measurements and simulation result in the low speed range of the damping curve (Bleed valve dominant range, $V \leq 0.1 \mathrm{~m} / \mathrm{s}$ ) is going to be reduced. The procedure of finding a more precise opening diameter of the bleed orifices at click 30 is discussed below. The poppet valves are set at click 40 in the following graphs, although their effect at low speeds is not significant. 


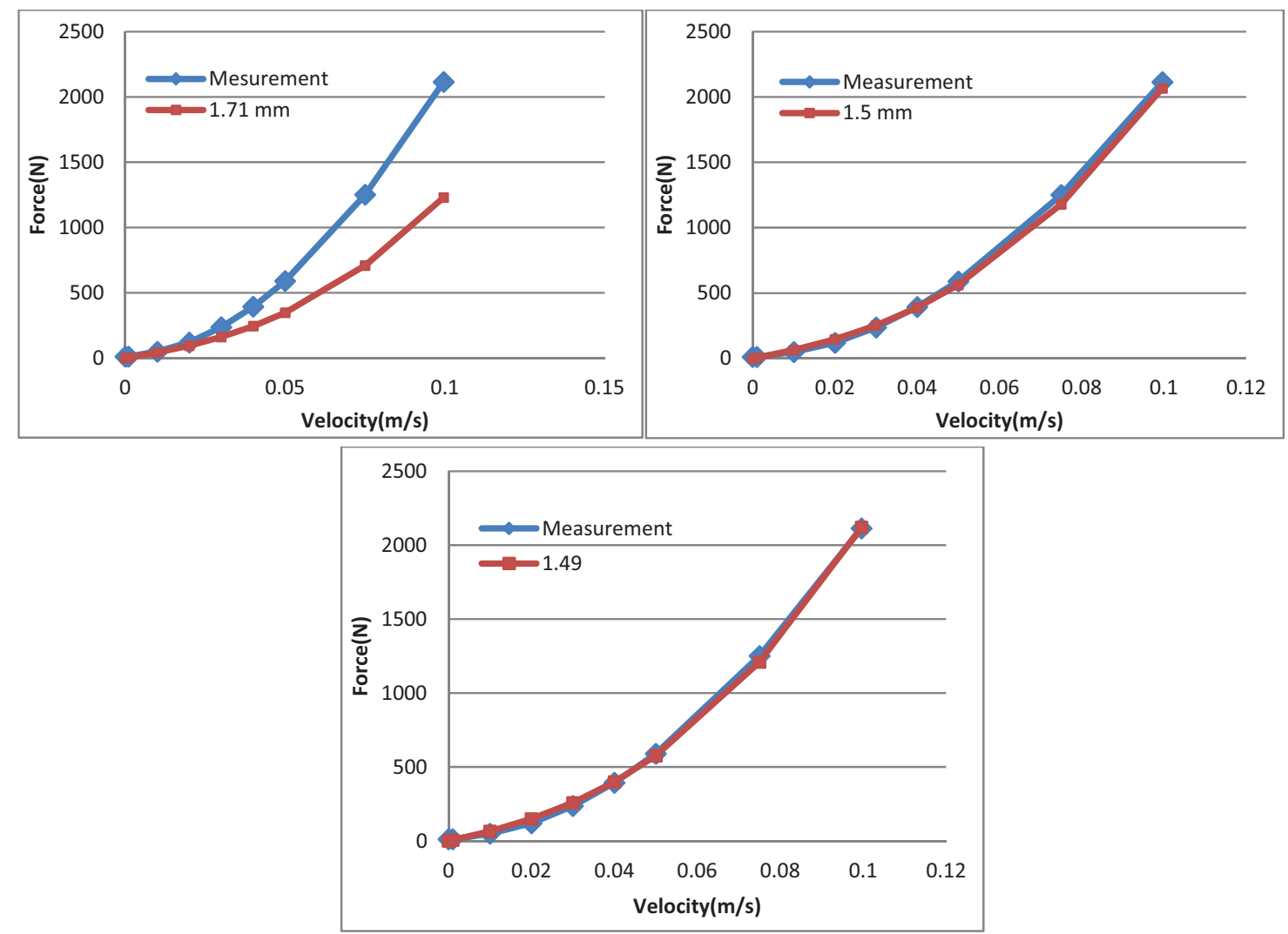

Figure 4-5. Damping curve at low speeds to find the exact equivalent orifice diameter at click 30 of bleeder

In order to enhance the accuracy of the simulation results, a more precise value for the orifice diameter at click 30 is found in Figure4-5. As it is clear $1.49 \mathrm{~mm}$ opening diameter best matches the measurement recorded data and is going to be used for the rest of the validation studies including both bleed and poppet valves.

Knowing the exact bleed characteristics, it is possible to find the equivalent spring preload external adjusting for different clicks of the HS valves. For the poppet valves, the knob provides 8 clicks per revolution. Since the inclination of the thread is equal to $0.8 \mathrm{~mm}$, the preload on the spring increases by $0.1 \mathrm{~mm}$ per click. Substituting $K=30 \mathrm{~N} / \mathrm{mm}$, as spring stiffness and $x=0.1 \mathrm{~mm}$, as the displacement in the basic spring force law,

$$
\boldsymbol{F}=\boldsymbol{K} \cdot \boldsymbol{x}
$$

the preload is predicted to increase by $3 \mathrm{~N}$ per click.

0 click of the poppet valve is fully counter clock wise with minimum force and minimum preload over the spring. Assuming the preload of click 0 to be $F_{0}$,

Table 4-4. Predicted spring pre-load for different clicks of HS valves based on the valve inclination

\begin{tabular}{|l|c|c|c|c|c|c|c|c|c|}
\hline Clicks & 0 & 5 & 10 & 15 & 20 & 25 & 30 & 35 & 40 \\
\hline Preload(N) & $F_{0}$ & $F_{0}+15$ & $F_{0}+30$ & $F_{0}+45$ & $F_{0}+60$ & $F_{0}+75$ & $F_{0}+90$ & $F_{0}+105$ & $F_{0}+120$ \\
\hline
\end{tabular}


The value of $F_{0}$ is directly dependent to the system pressure level, defined by the accumulator sub-model. With the system initial pressure defined in 3.4, in order to estimate the $F_{0}$ value, the damping characteristics of the poppet at the highest click (40), is simulated and compared to static measurements. Figure 4-6 demonstrates the damping characteristics at click 40 of the poppet valve and 30 of the bleed. To catch the same behavior of measurements, two parameters of spring pre-load and orifice diameter need to be set. As it is clear, for velocities below $0.1 \mathrm{~m} / \mathrm{s}$ (before knee), the force generated by the low speed valve is dominant, for which $1.49 \mathrm{~mm}$ opening diameter of the orifice resulted in the best match. Damping force in this range of velocities is totally independent of the poppet valve setting. Although for higher velocities, it is the poppet valve which dictates the shape of the damping curve. These results are in perfect agreement with theory and demonstrate the validity of the simulation model.

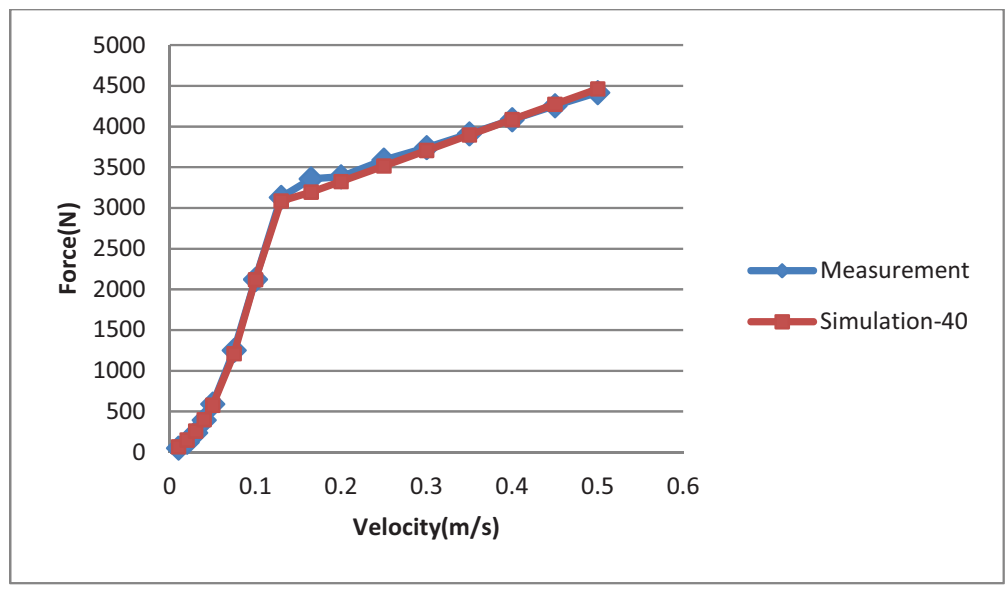

Figure 4-6. Damping curve for click 30 of LS and 40 of HS valves

The spring pre-load at click 40 is estimated to be $250 \mathrm{~N}$ in order to achieve the good agreement in Figure4-6. Table4-5, demonstrates the corresponding spring pre-load for the rest of the high speed adjusters clicks, estimated by measurements.

Table 4-5. Poppet valve clicks and the approximate spring pre-load

\begin{tabular}{|c|c|c|c|c|c|c|c|c|c|}
\hline Clicks & 0 & 5 & 10 & 15 & 20 & 25 & 30 & 35 & 40 \\
\hline Simulation & -250 & -238 & -222 & -208 & -193 & -178 & -162 & -147 & -132 \\
\hline
\end{tabular}

In order to find the pre-load in the rest of the clicks a linear interpolation is done for the points in Table4-5. As it is clear from the regression equation, with an acceptable accuracy, the opening varies linearly with the click changes. 


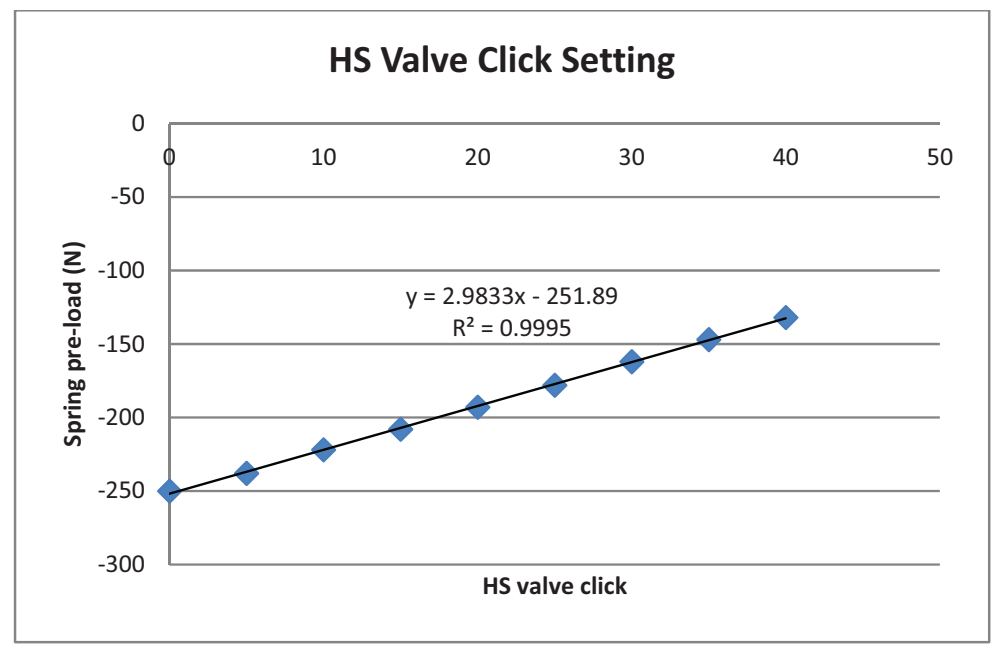

Figure 4-7. Linear interpolation for poppet valve click setting

According to the regression line equation, the spring pre-load increases by $2.98 \mathrm{~N}$ per click which is a good estimation for the $3 \mathrm{~N}$ predicted value. Furthermore, the equation estimates the $F_{0}=-251.89 \mathrm{~N}$, which is accurate in the system pressure level determined by this accumulator initial pressure.

\subsection{Model Validation with Static Measurements}

As mentioned before, in the measurements available low speed bleed valves are always at click 30 , which corresponds to $1.49 \mathrm{~mm}$ orifice diameter, and tests are repeated for nine different clicks of the high speed valves from 0 to 40, with 5 click steps. Figure4-8 shows the result for the lowest and highest clicks, and the rest of diagrams are presented in Appendix A. 


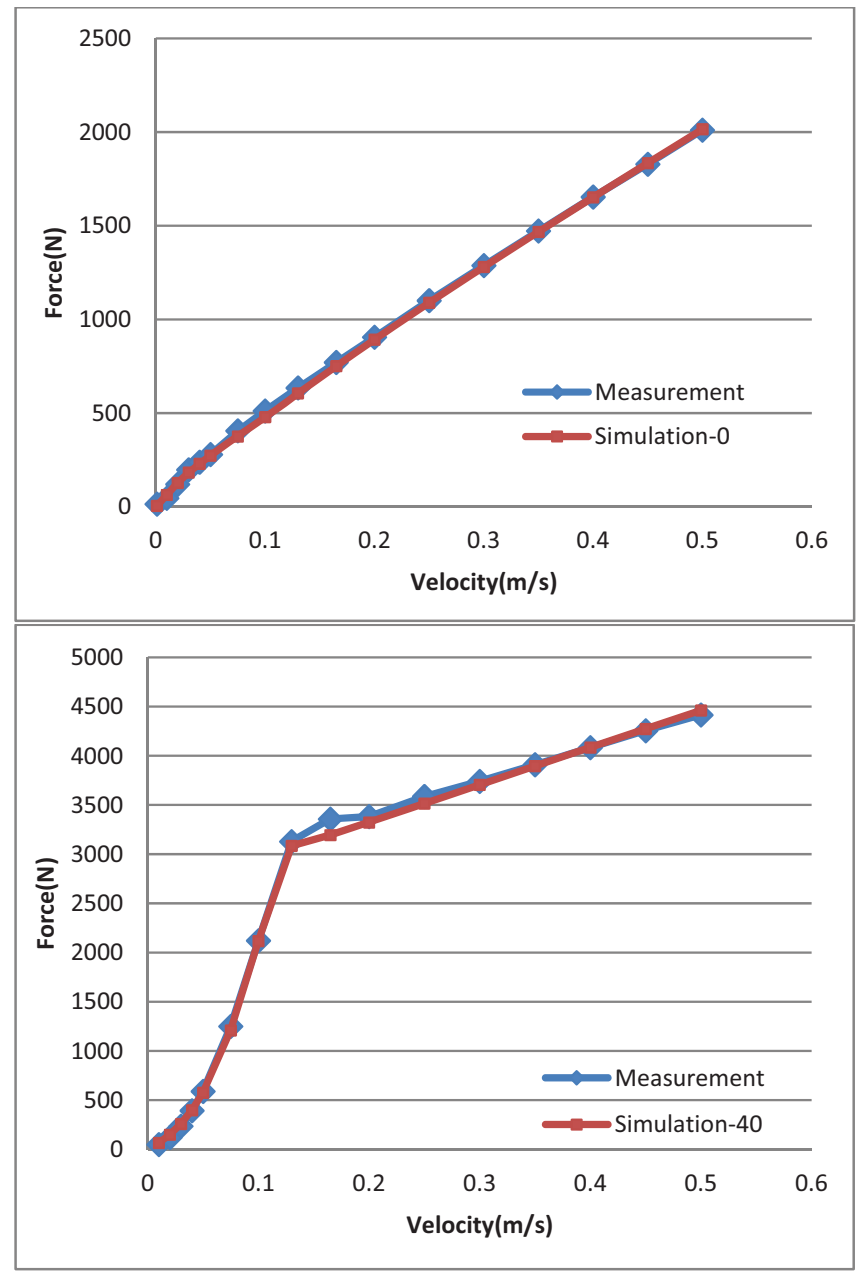

Figure 4-8. Static Validation in different HS click 0-40

As mentioned earlier, static damping curves are generally composed of three parts: nose (low speeds), knee, and slope (high speeds). Design and opening size of the bleed valves determine the characteristic and shape of the nose zone. While the knee shape is dependent on the poppet valves opening characteristics to be abrupt or gradual. Abrupt opening results in a sharp knee while a gradual one makes it smooth. The slope zone is dependent on the poppet valves size and the coil spring stiffness. Applying a smaller value for the spring stiffness reduces the slope level. Since these factors are fixed in different simulations, the slope is also constant in different valve pre-loads. 


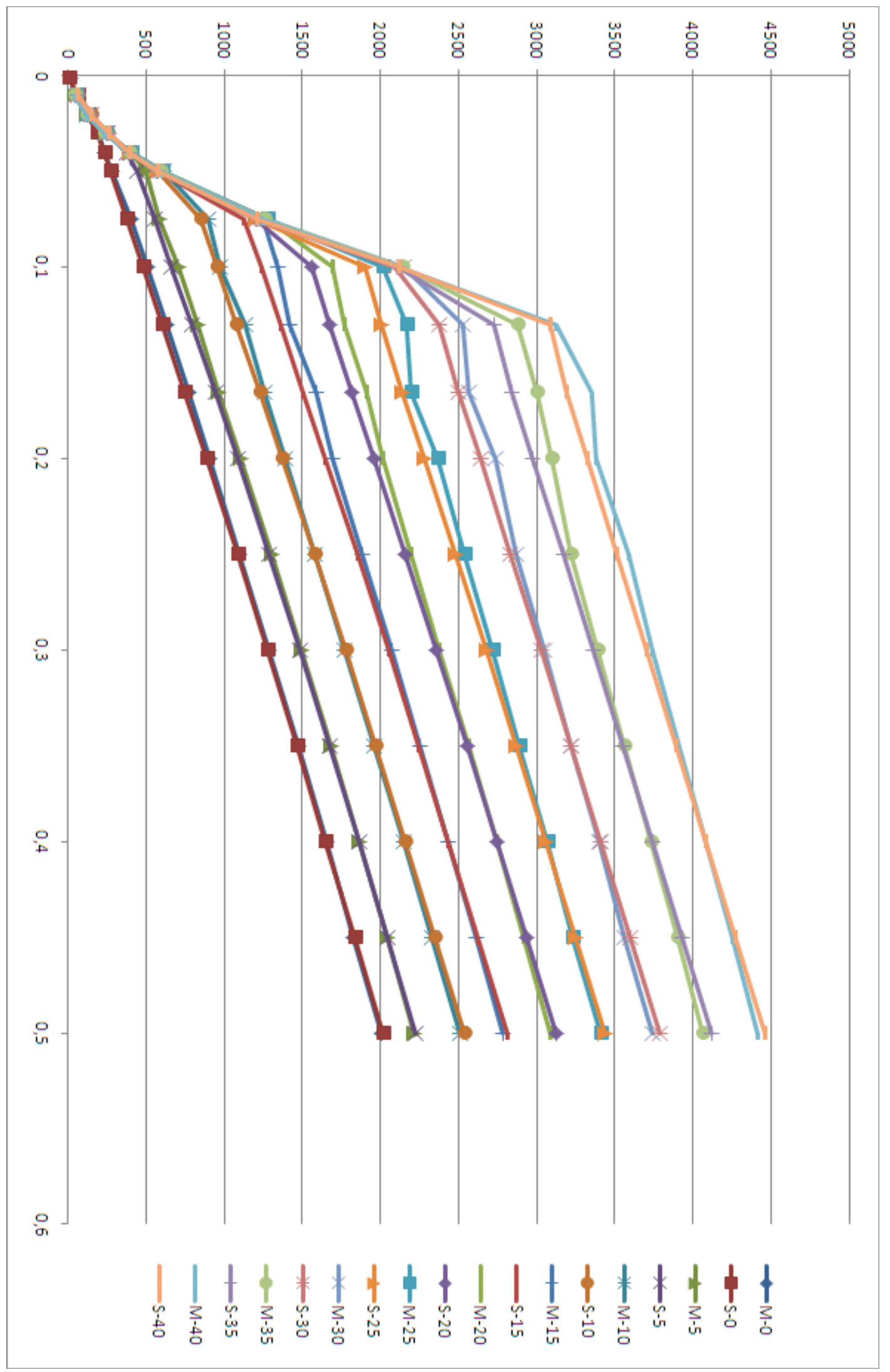

Figure 4-9. Static model validation, combined plot 
Figure4-9 gathers all of the curves for different clicks in a larger scale. The constant orifice diameter (bleed click) results in the similar 'Nose' shape for all of the curves. In addition, the constant poppet size and spring stiffness results in similar 'Slope' for all of the curves. The only variable parameter is the spring pre-load (poppet valve click), which increases the damping force level for higher clicks. The agreement is almost perfect especially for lower clicks. For higher clicks there is a difference in 'Knee' zone of the curve. As mentioned in (4.1), the opening characteristic of the poppet valve is responsible for the knee shape. The simulation model provides a fairly sharp knee which is reasonable according to the almost simple model of the damper. Therefore in order to achieve better agreement, a more advanced model of the poppet valve is required. The oscillatory behavior of the measurements in the knee region can highly depend on the measurement conditions and usually varies from one to another test. On the other hand, it can be due to friction which is not yet considered in the simulation model. 


\section{Simple Model Dynamic Behavior}

The statically validated model requires to be dynamically validated. This chapter presents the response of the simple model to a dynamic input, in order to investigate the weak points and think of solutions to improve the model.

\subsection{Dynamic Damping Curve Characteristics}

In static conditions, stationary piston velocity feeds the system, while in the dynamic case neither the velocity nor the flow is constant. The dynamic behavior of a system can be studied in two domains of time and frequency. Before going through the model dynamic response, it is beneficial to first get familiar with the characteristics of a dynamic damping curve.

Figure 5-1 shows an example of the damper respond to a complete sine wave cycle as velocity input. The cycle is divided into four different phases.

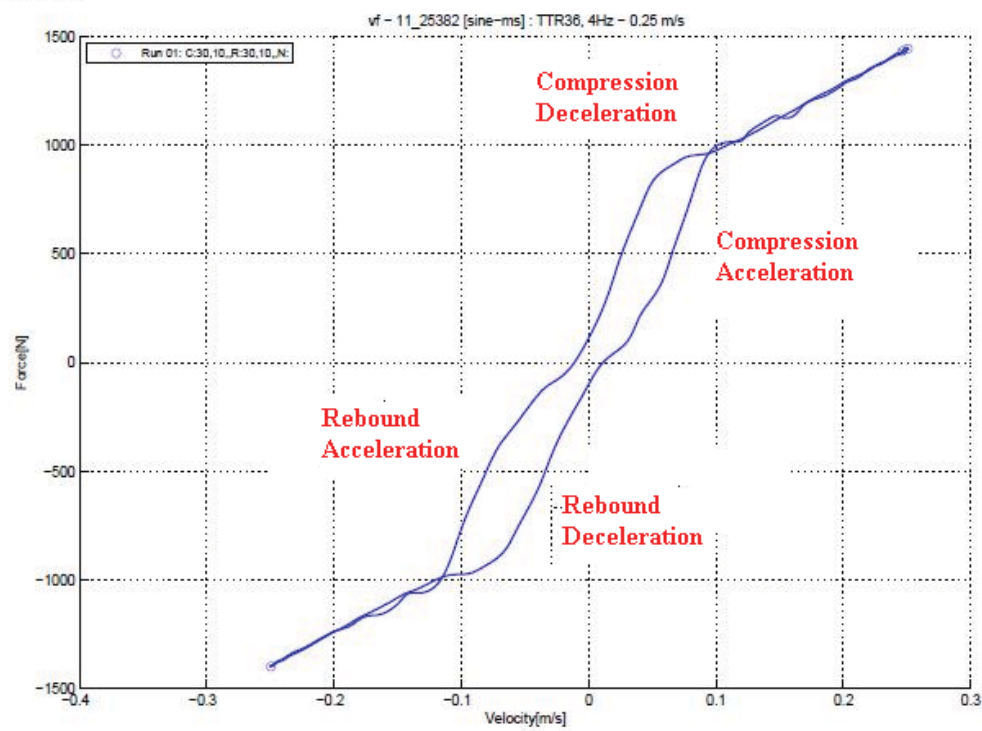

Figure 5-1. Phases of the dynamic damping curve

According to Figure5-1, the acceleration force values are lower compared the deceleration ones around zero velocity, where the movement changes direction. This separation at low velocity is called 'Hysteresis'. Hysteresis is one of the crucial issues of the curve.

A common problem in transducers is the Hysteresis error which causes different outputs from the same measured quantity. The error is either due to energy dissipation sources such as friction, or magnetic materials which the first one is the hardest to be controlled and calibrated. Therefore, in order to increase the accuracy of a simulation model results, friction must be first estimated and then compensated. Repeatability in the hysteresis behavior is a useful factor which makes the compensation easier [10]. 


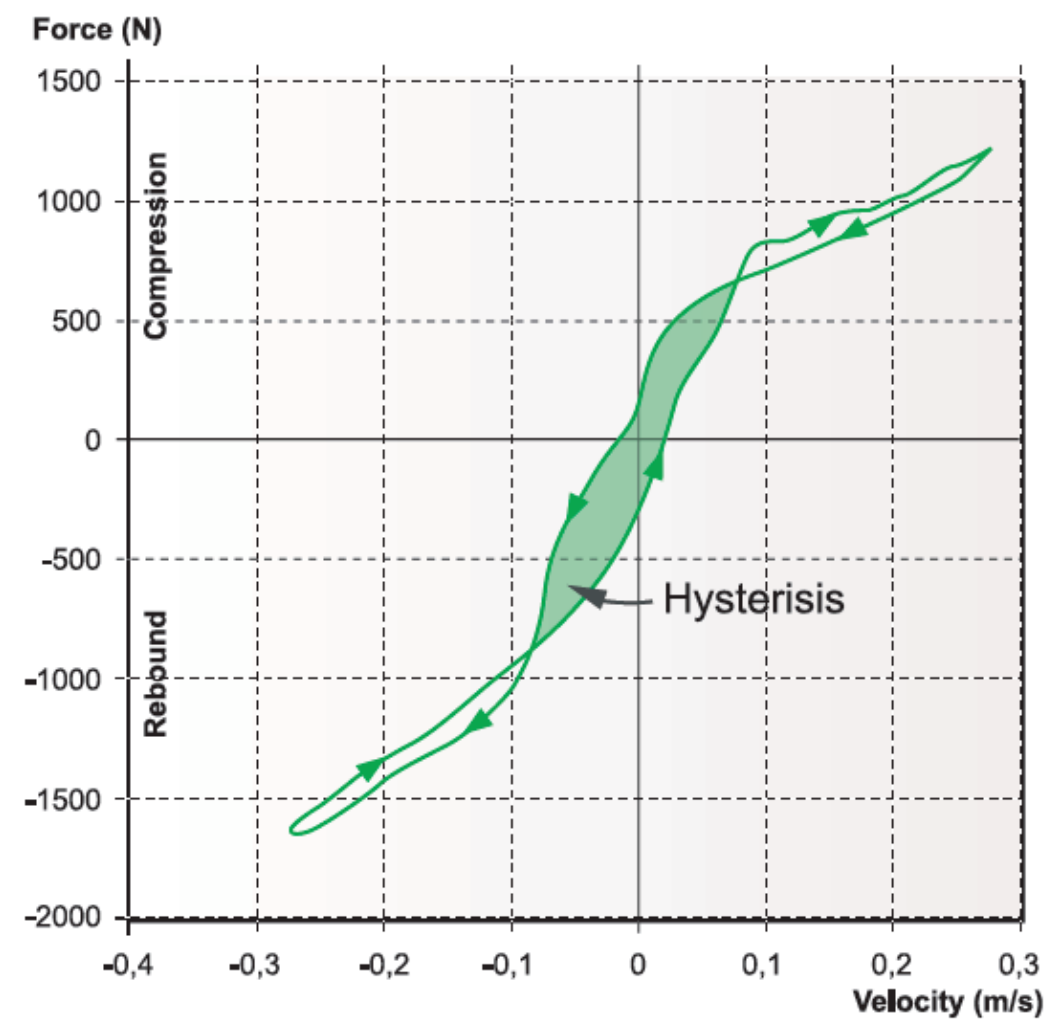

Figure 5-2. Hysteresis definition during a complete sine wave cycle [1]

In order to catch this natural behavior in simulation model, friction, leakage, elastic deformation, and mechanical free play which are the main sources of energy loss, must be introduced to the model.

Similar to the static damping curve, Figure4-1, the dynamic curve can also be divided into specific zones. Figure5-3 shows the zones as well as the effective damper components which their behavior is dominant in each zone. In the low speed rang the bleed valves and in the high speed range the poppet valves determine the damping characteristics. 


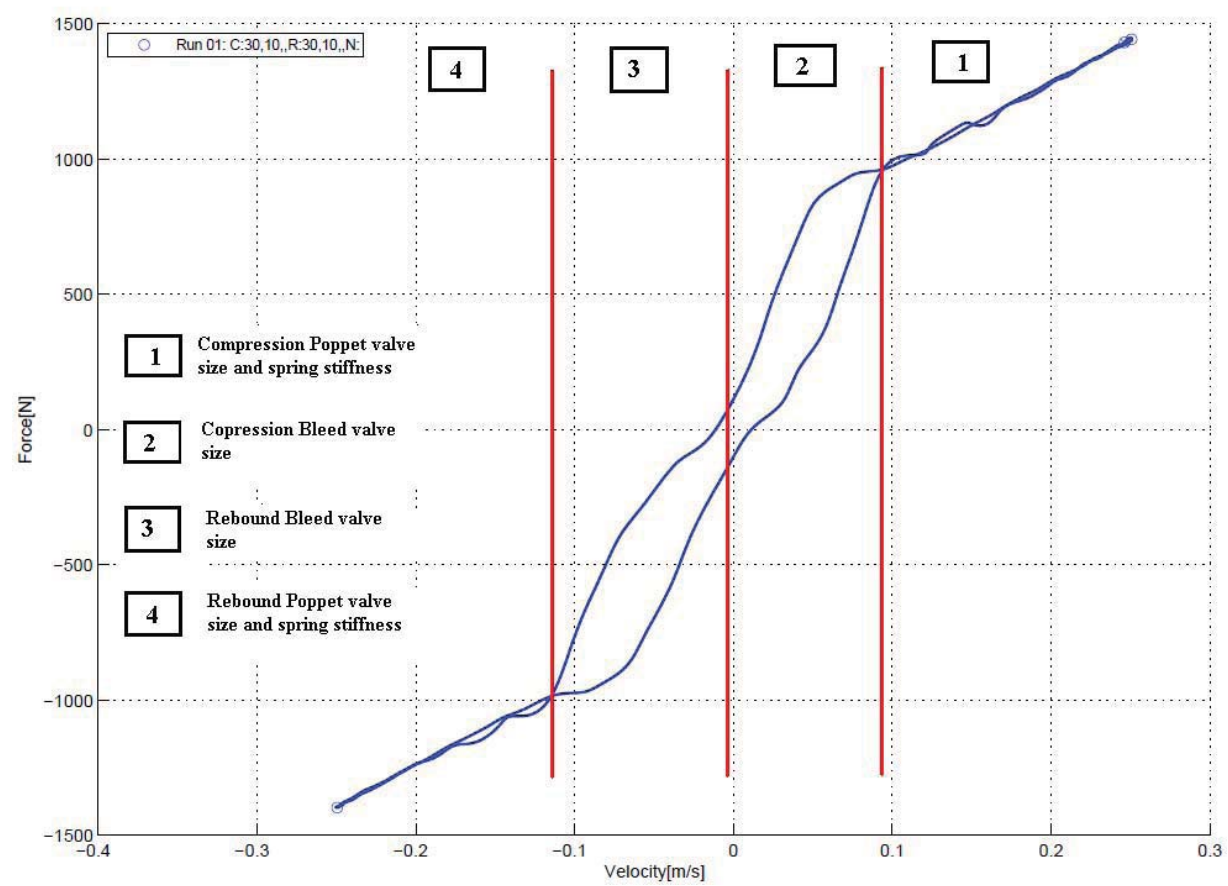

Figure 5-3. Dynamic damping curve zones and the corresponding effective factors

\subsection{Dynamic Velocity Input and Flow Distribution}

During the static simulations, the input of the model is a constant velocity, while in the dynamic part the input is changed to a sine wave source connected to a velocity converter. This allows investigating the system response on the rebound cycle as well as the compression cycle. Time step is reduced to 0.001 second to be able to observe the curves more accurately. The sine input for all of the following measurements and simulations has the amplitude of $0.25 \mathrm{~m} / \mathrm{s}$, and the frequency changes in the range of $4-24 \mathrm{~Hz}$. Figure $5-4$ illustrates a cycle of the input with $4 \mathrm{~Hz}$ frequency.

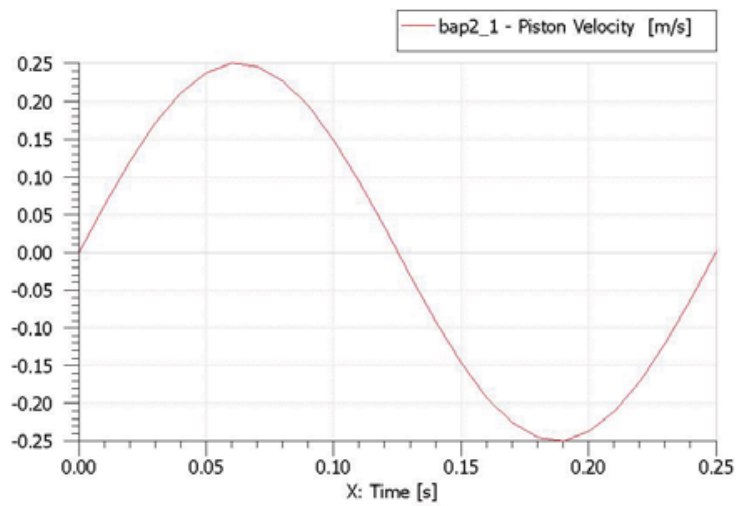

Figure 5-4. An example of the dynamic model input velocity 
Table 5-1. Signal source parameter setting

\begin{tabular}{|l|c|}
\hline \multicolumn{2}{|c|}{ Sine signal source } \\
\hline Sine wave fequency $(\mathrm{Hz})$ & Variable \\
\hline Mean level & 0 \\
\hline Sine wave amplitude & 0,25 \\
\hline Phase shift & 0 \\
\hline
\end{tabular}

An example of the flow rates through each of the valves during a complete sine wave cycle is shown in Figure5-5.

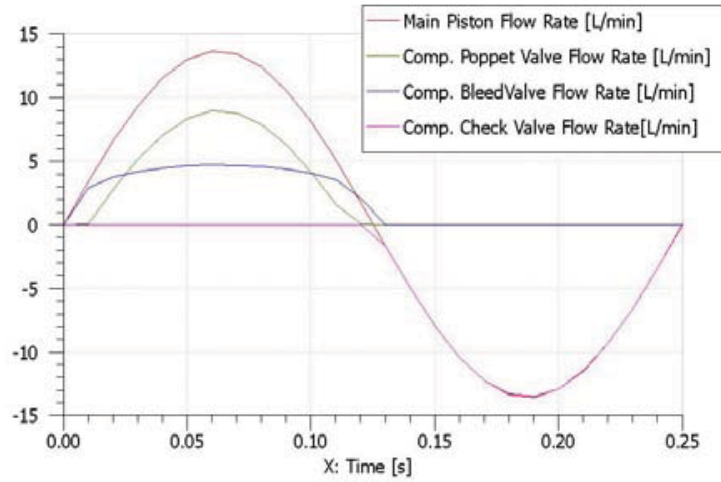

(a)

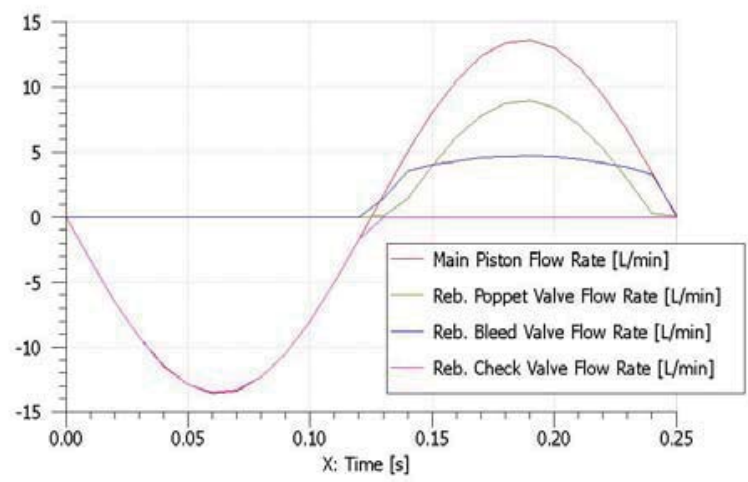

(b)

Figure 5-5. Flow distribution on (a) compression side, (b) rebound side

Referring to Figure5-5, during the compression cycle, $0 \leq t \leq 0.125 \mathrm{~s}$, the flow goes through the 'compression' poppet and bleed valves as well as the 'rebound' check valve. While in the rebound cycle, $0.125 \leq t \leq 0.25 \mathrm{~s}$, the flow goes through the 'rebound' poppet and bleed valve as well as the 'compression' check valve. 


\subsection{Dynamometer Tests}

Figure5-6 depicts a dynamometer equipped with a damper, showing the transducers and technical units.

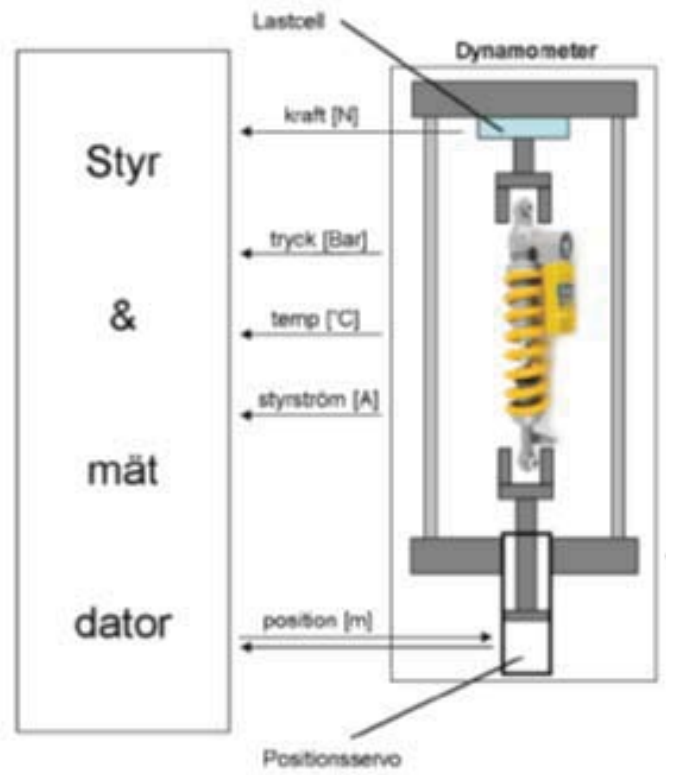

Figure 5-6. Schematic diagram of the dynamometer rig and how it communicates with the ECU unit [4]

According to literature [1], most of the industrial oil properties are temperature dependent. The variation of properties is mainly observable when temperature changes in the range of $25-50^{\circ} \mathrm{C}$. While in the range of $50-80^{\circ} \mathrm{C}$, it presents an approximately constant behavior. Therefore, in order to minimize the temperature effect, the shock absorber is first warmed up until reaching $60^{\circ} \mathrm{C}$, and then the tests are conducted. Moreover, if passing $80^{\circ} \mathrm{C}$, it is first cooled down before performing the next test.

\subsection{Dynamic Response of the Simple Model}

The normal operational click setting of the damper is chosen as the case study to investigate the accuracy of the simple simulation model. Therefore, both of the LS and HS valves produce medium force at clicks 30 and 10 respectively. The input velocity has amplitude of 0.25 and four frequencies of 4, 8, 16, $24 \mathrm{~Hz}$. Results for the nominal and high frequencies are shown in Figure5-7 and the rest of the frequencies are presented in Appendix A. 

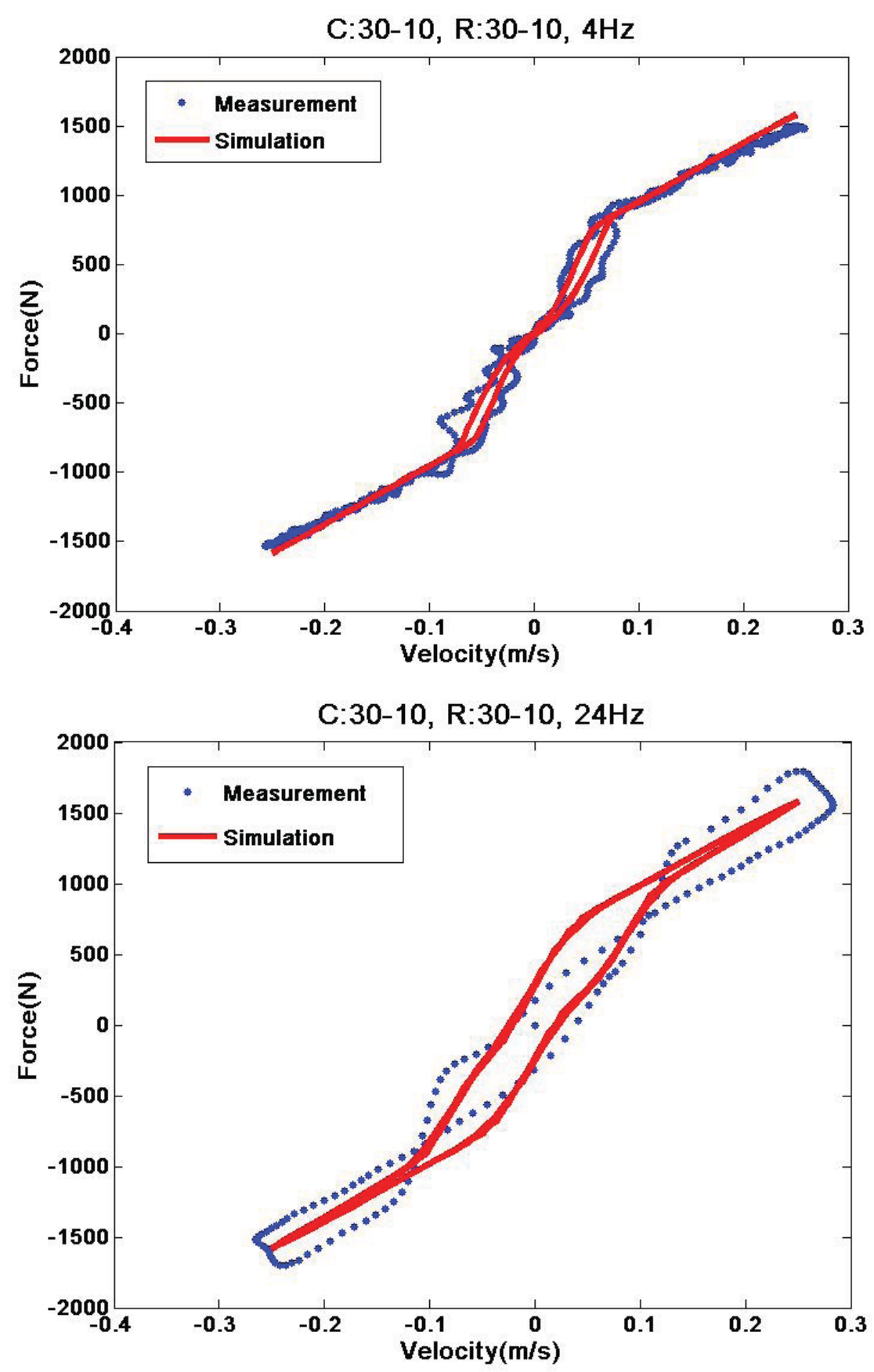

Figure 5-7. Dynamic response of the simple model

According to Figure5-7, the simple model response is in fairly good agreement with the measurements. The major problem is in the relatively low hysteresis level estimated by the simulation model, compared to the real behavior. Leakage, friction, and elastic deformation of the main cylinder are the most important factors in the hysteresis phenomenon. Therefore, the simple model requires some improvements in the main cylinder piston part in order to predict the real hysteresis more accurately. 
As shown in Figure5-7, as the frequency increases, the agreement reduces drastically. In addition to the hysteresis problem, the model shows weak ability in simulating the slope zone of the damping curve. According to Figure5-3, since the high speed poppet valves are the effective components in slope section characteristics, their simple model must be improved in order to achieve a better agreement. 


\section{Advanced Model Implementation}

Similar to any mechanical model, there is always a considerable difference between the ideal mathematical behavior of a model and the real one which happens under the operational conditions. After achieving a model which fully describes the static behavior of the ideal damper, vital details are going to be added to the model to enhance its ability in simulating the real behavior of TTR in different phases of the damping cycle. The current model shows a reasonable behavior in stationary condition, therefore, the next step in validating the model is to improve its dynamic behavior. Here is a short list of suggested functions which can be added to the model in order to investigate their influence on improving the damping curves.

- Leakage in the main cylinder and poppet valves

- Friction in the main cylinder and poppet valves

- Elastic deformation of the cylinder body due to the high internal pressure

\subsection{Main Cylinder Piston Advanced Model}

According to the dynamic response of the simple model (5.4), in order to improve the dynamics of the simulation model, a more advanced model of the main cylinder and piston is required. Therefore a number of components are added to model and their influence on the dynamic response is investigated.

\subsubsection{Leakage Model}

The component called 'Leakage and viscous friction' is added to the main cylinder model from the HCD library. The so-called component is a sub-model which calculates the hydraulic leakage flow rate and the corresponding viscous friction force. The flow path is assumed to be between the main piston and the cylindrical sleeve. The length of this clearance flow path is assumed to be constant. The leakage flow rate is calculated using the density and absolute viscosity as a function of pressure [2].

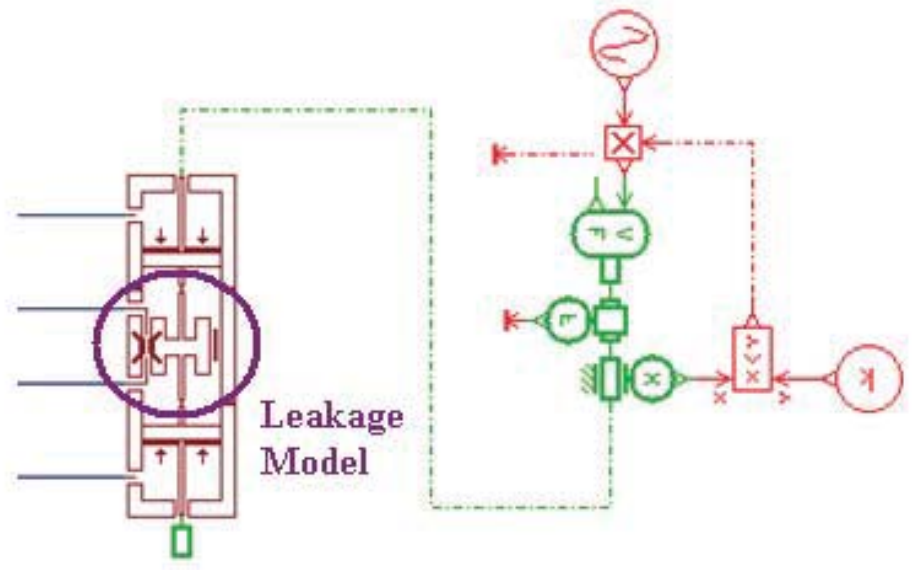

Figure 6-1. Main piston leakage, HCD model 
Table 6-1. Main piston leakage model parameter setting

\begin{tabular}{|l|c|}
\hline \multicolumn{2}{|c|}{ Main piston leakage and viscous friction } \\
\hline External piston diameter $(\mathrm{mm})$ & 36 \\
\hline Clearance on diameter & 0,036 \\
\hline Length of contact $(\mathrm{mm})$ & 25 \\
\hline
\end{tabular}

In case of uncertainty in the clearance value, 1/1000 of the piston diameter is suggested by AMESim as an initial guess, which is used here.

In the normal $4 \mathrm{~Hz}$ frequency test, the leakage flow rate reaches $0.00453 \mathrm{lit} / \mathrm{min}$ at most, which is almost negligible compared to the main flow. Therefore, its effect is not significantly observable in the damping curves especially at low frequencies.

\subsubsection{Inertia and Friction Model}

The next step to make the model closer to real dynamic behavior is to consider the friction forces which are mainly responsible for the hysteresis. Solution is to add "mass with friction and end stops" to the main piston model. Mass component represents the onedimensional motion of a two port mass under the action of two external forces and frictional forces. The displacement is limited to a specified range defined by ideal end stops.

Due to 'Causality' characteristics of AMESim, a mass component with friction cannot be inserted to the main piston model directly, due to input and output mismatches. Since the mass component requires force as input on both of the ports, while the input of the damper model is a motion on piston rod which corresponds to a certain velocity, some modifications need to be done. Therefore, instead of a single mass, a combination of a mass and a springdamper component is added to the model, which is described in 6.1.3.

Table6-2 contains the parameter setting for the main piston mass sub model.

Table 6-2. Main piston inertia and friction model parameter setting

\begin{tabular}{|l|c|}
\hline \multicolumn{2}{|c|}{ Mass with friction and ideal end stops } \\
\hline Mass $(\mathrm{kg})$ & 0.05 \\
\hline Coefficient of viscous friction $(\mathrm{N} /(\mathrm{m} / \mathrm{s}))$ & 0 \\
\hline Windage coefficient $\left(\mathrm{N} /(\mathrm{m} / \mathrm{s})^{2}\right)$ & 0 \\
\hline Coulomb friction force $(\mathrm{N})$ & 10 \\
\hline Stiction force $(\mathrm{N})$ & 10 \\
\hline Lower displacement limit $(\mathrm{m})$ & -0.025 \\
\hline Higher displacement limit $(\mathrm{m})$ & 0.025 \\
\hline Inclination & 0 \\
\hline
\end{tabular}

Mass has four friction parameters which none of the quantities can be negative. The stiction force (Static Friction) is the maximum friction force when the mass is at rest and the Coulomb friction force is the dry friction force when the mass is in motion (assumed constant). Stiction level cannot be less than the Coulomb friction. If the stiction force is a lot bigger than the Coulomb friction force, the motion can be very jerky. Both viscous friction (proportional to speed) and windage (proportional to speed squared) add damping which 
results in a quicker steady state [2]. Values of windage and viscous friction are set to zero because the leakage sub-model considers their effect on damping characteristics.

Since there is no value available for the friction terms, they need to be tuned by the measurements. The static friction is the value of the force acting on the piston rod when there is no damping force generated by the shock absorber (i.e. very large opening of the bleeders and removing all flow restrictions).

The force value at the very beginning of a measurement where the velocity is almost zero, gives the static friction. This value is found to be $10 \mathrm{~N}$ from the measurements at $0.001 \mathrm{~m} / \mathrm{s}$, and is applied for the stiction and Coulomb friction parameters. Figure6-2 illustrates the damping curve when LS valves have very large openings and there is no damping force generated by the model. It is clear that the only present force is the static friction which is almost constant with respect to velocity expectedly.

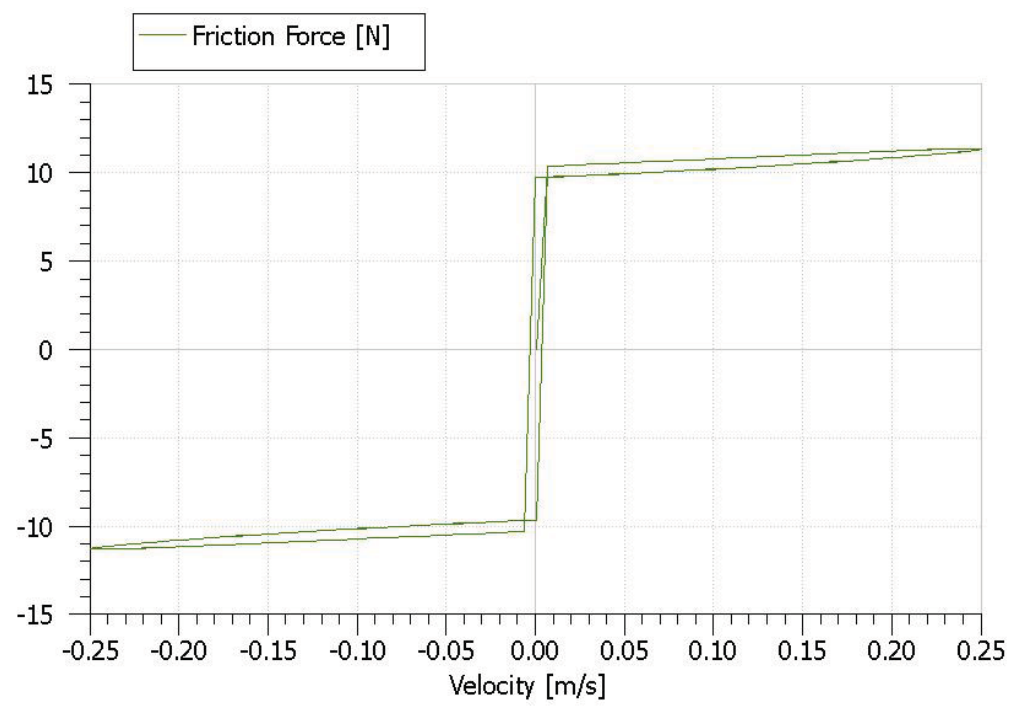

Figure 6-2. Friction force tuned by measurements

\subsubsection{Elastic Contact Model}

The dynamic behavior of the shock absorber presents some hysteresis at low speeds. One of the sources of hysteresis is the leakage and free play in mechanical structure. The other one is the elastic deformation of the cylinder wall in high pressures. The deformation is caused by expansion/compression of the damper body. The deformation adds more compliance to the model and highlights the effect of leakage flow which results in a larger hysteresis.

The phenomenon is added to the model by using the "Mechanical Spring and Damper" component from the AMESim HCD library. Parameters of the component need to be tuned by the measured damping curves. Table 6-3 contains the selected values after a large number of trial and errors. 
Table 6-3. Elastic contact HCD model parameter setting (confidential)

\begin{tabular}{|l|}
\hline \multicolumn{1}{|c|}{ Mechanical spring and damper } \\
\hline Spring force with both displacements zero $(\mathrm{N})$ \\
\hline Spring rate $(\mathrm{N} / \mathrm{m})$ \\
\hline Damper rating $(\mathrm{N} /(\mathrm{m} / \mathrm{s}))$ \\
\hline
\end{tabular}

Now the main piston model is composed of the following components each responsible for a specific physical characteristic in damping behavior.

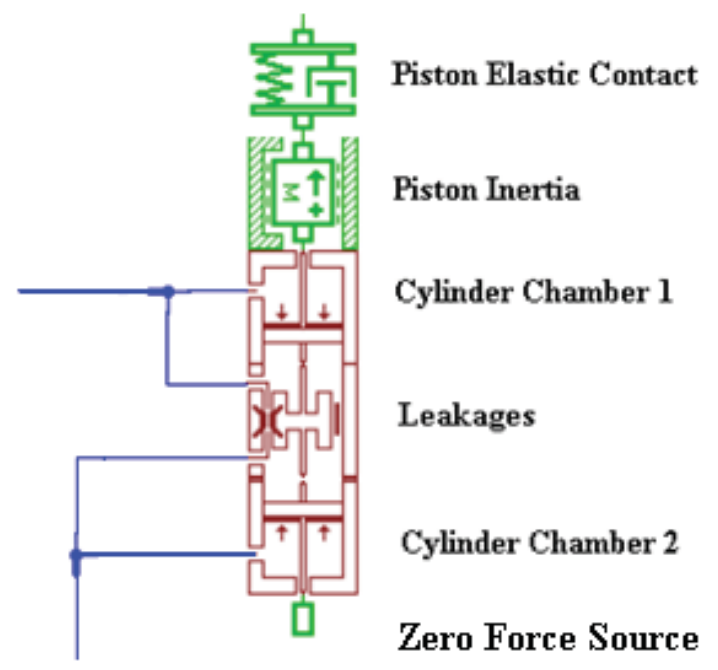

Figure 6-3. Main cylinder advanced model

\subsubsection{Channel Model between the Inner and Outer Tube}

The rebound chamber is connected to the low pressure accumulator side through an annular pipe between the inner and outer tube of the main cylinder. In the advanced simulation model it is assumed to be an annular orifice as shown in Figure6-5.

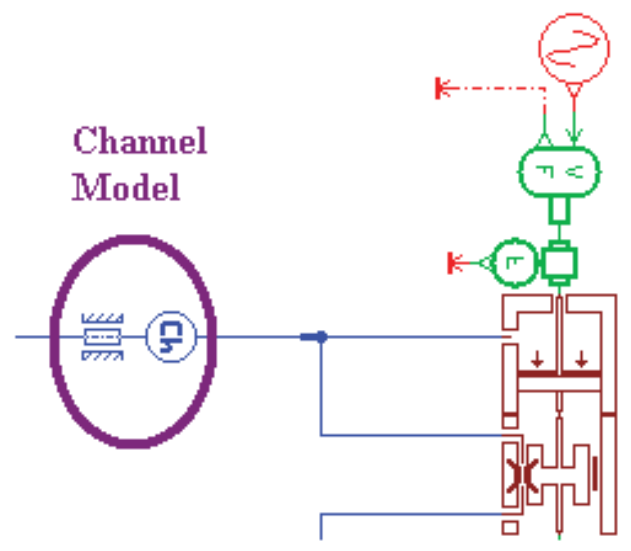

Figure 6-4. Model of the channel between the inner and outer tube of the main cylinder 
In order to set the parameters of the sub-model added, a schematic of the orifice geometry is sketched below.

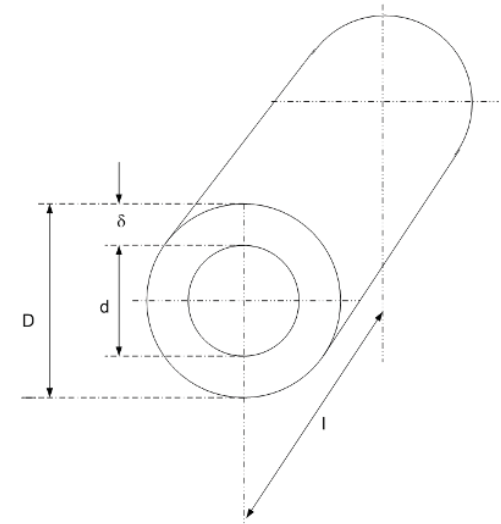

Figure 6-5. Concentric orifice geometry [2]

Therefore, according to the dimensions of the main cylinder tubes and the stroke size used in measurements, the following values are set for the orifice parameters.

Table 6-4. Channel model parameter setting

\begin{tabular}{|l|c|}
\hline \multicolumn{2}{|c|}{ Fixed Hyd. Concentric Orifice (laminar resistance) } \\
\hline Length $(\mathrm{mm})$ & 25 (Stroke Length) \\
\hline Inner Diameter $(\mathrm{mm})$ & 36 \\
\hline Outer Diameter $(\mathrm{mm})$ & 37.75 \\
\hline
\end{tabular}

The added sub-model slightly increases the damping force.

Figure6-6 compares the damping curves achieved by the simple model and the advanced cylinder piston model. It is clear that the problem of low hysteresis has been solved by adding the leakage, friction and elastic contact components. The improvement is even clearer at higher frequencies. 


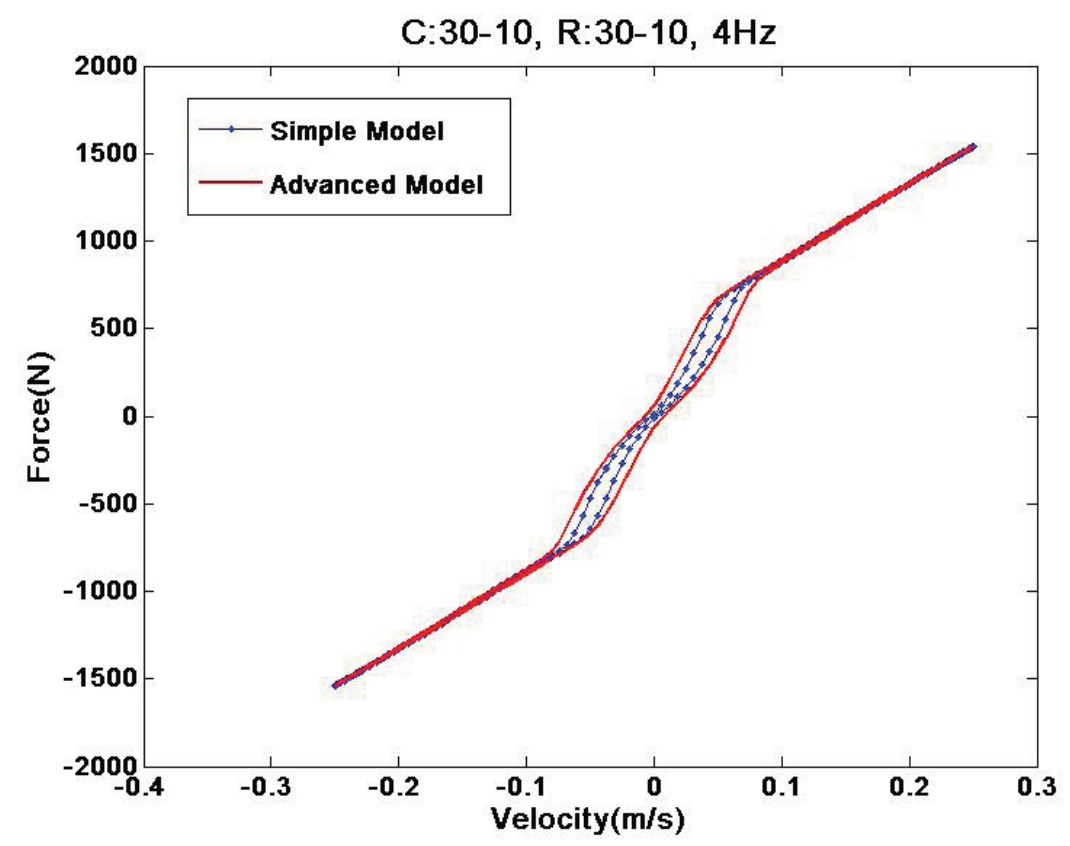

Figure 6-6. Effect of the advanced cylinder model on improving the hysteresis

\subsection{High Speed Adjusters Advanced Model}

The next part of the model which requires some dynamic improvements are the HS adjuster, which have a crucial role in changing the damping curve characteristics.

\subsubsection{Leakage Model}

The same sub-model as mentioned in 6.1.1 is used to simulate the leakage phenomena in the HS valves. This time the model calculates the leakage flow between the cylindrical spool and sleeve. Figure6-7 depicts the location of the sub-model as well as its connection to the rest of the components.

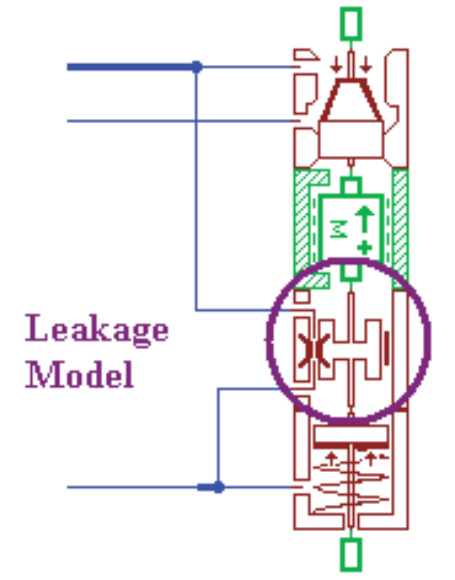

Figure 6-7. Poppet valve leakage, HCD model 
Same parameters are set this time considering the HS adjuster geometry. The maximum leakage flow rate for a $4 \mathrm{~Hz}$ velocity input frequency is 0.0001531 it $/ \mathrm{min}$, which shows the very low contribution of it in the main flow behavior.

Table 6-5. Poppet valve leakage model parameter setting (confidential)

\begin{tabular}{|l|}
\hline \multicolumn{1}{|c|}{ Main piston leakage and viscous friction } \\
\hline External piston diameter $(\mathrm{mm})$ \\
\hline Clearance on diameter \\
\hline Length of contact $(\mathrm{mm})$ \\
\hline
\end{tabular}

\subsubsection{Poppet Valve Orifice Model}

According to the real TTR design, in order to enhance the damping characteristics, a small orifice on the shuttle guide of the valve is manufactured. The orifice can have three different diameters of $1,1.5$, or $2 \mathrm{~mm}$, according to the different versions. The poppet valve orifice acts as a fixed dynamic connection between the low pressure side of the valve (reservoir, accumulator) and the cavity on the back side of the valve. This solution increases the damping effects on the moving element, i.e. the poppet. A schematic of the holes' location is shown in Figure6-8.

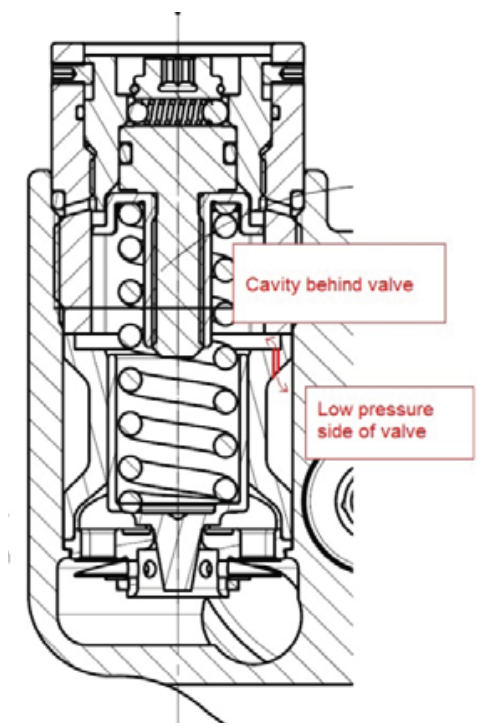

Figure 6-8. Schematic of the poppet valve hole location

A shuttle guide with $1.5 \mathrm{~mm}$ hole diameter is used in the measurement data available, which is modeled through a fixed orifice. The orifice diameter in the simulation model can vary in a specific range, due to manufacturing accuracy. The hole is added to the simple model of the poppet valve as a fixed orifice from HCD library, as shown by Figure6-9. 

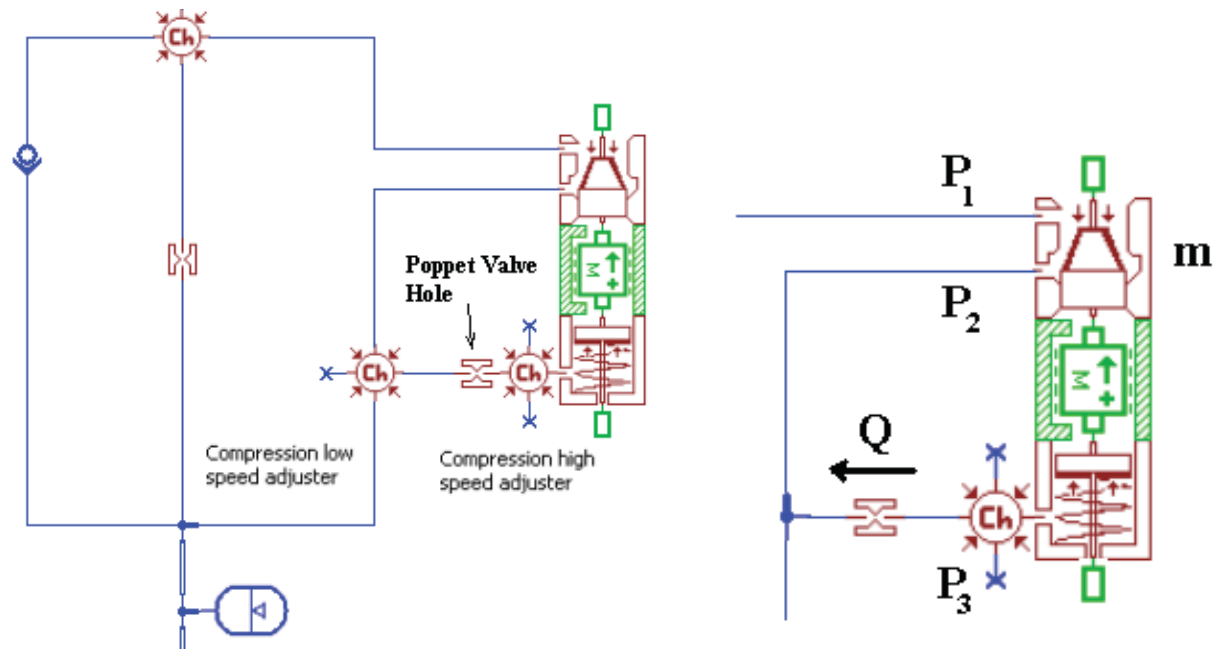

Figure 6-9. Poppet valve hole considered as a fixed orifice in model

Dynamics of the valve is studied, in order to investigate the effect of the orifice on damping characteristics. Force equilibrium and orifice laminar flow equations are applied to the system. Linearization followed by the Laplace transformation appears a damping term which is the result of the added orifice.

$$
\begin{aligned}
& K x+F_{0}=F_{s} \\
& m \ddot{x}=P_{1} A_{1}-P_{3} A_{3}-F_{s} \\
& Q=K_{\text {lam }}\left(P_{3}-P_{2}\right) \\
& A_{3} \dot{x}=K_{\text {lam }}\left(P_{3}-P_{2}\right)
\end{aligned}
$$

Introducing $P_{3}$ from (6-4) to (6-2) results in the poppet valve equation of motion.

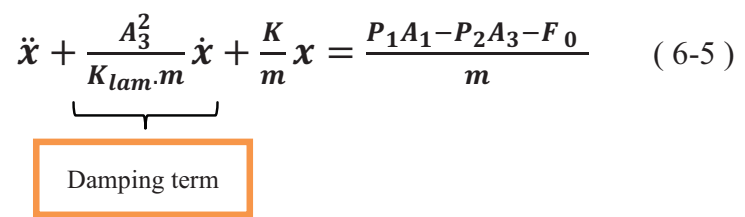

As shown in (6-5), a smaller orifice opening results in higher damping.

To see if the added orifice changes the static behavior of damping or not, it is worthy to take a short step back and investigate the effect of the new component on the static behavior. The input of the system is constant speed with 16 different values and the stationary force generated is extracted and plotted (LS and HS clicks of 30 on both compression and rebound sides). 


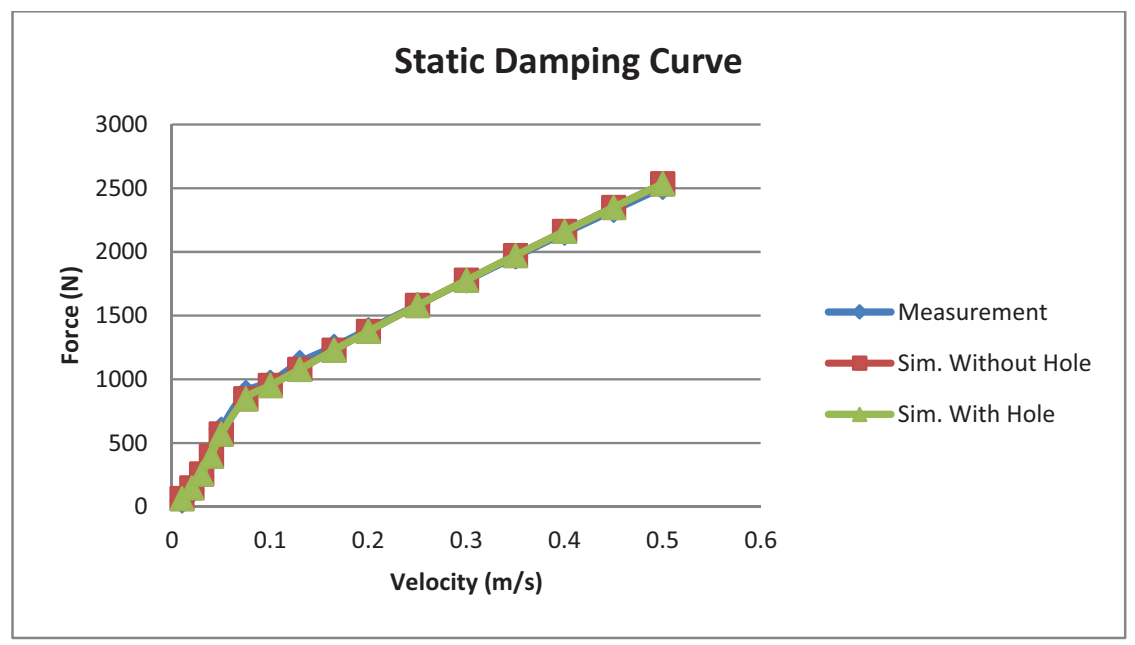

Figure 6-10. Effect of the poppet valve hole on the static behavior

The new model gives the same static behavior as the one without the hole, but the point is that before introducing the hole to the valve model, the system had large oscillations.

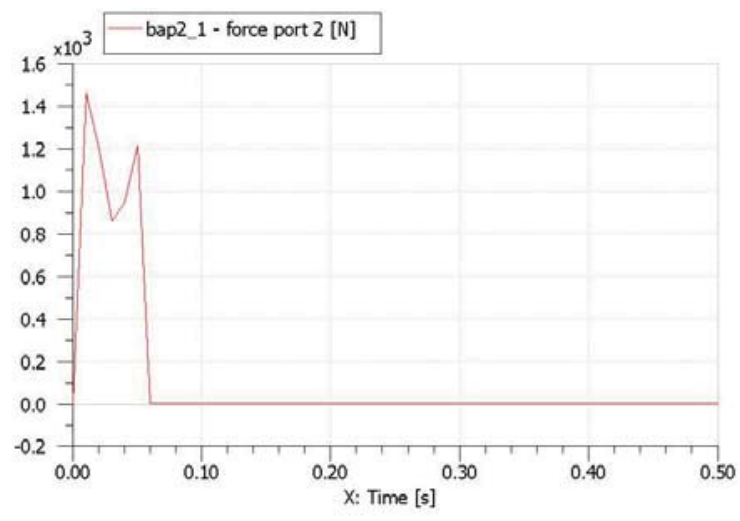

(a)

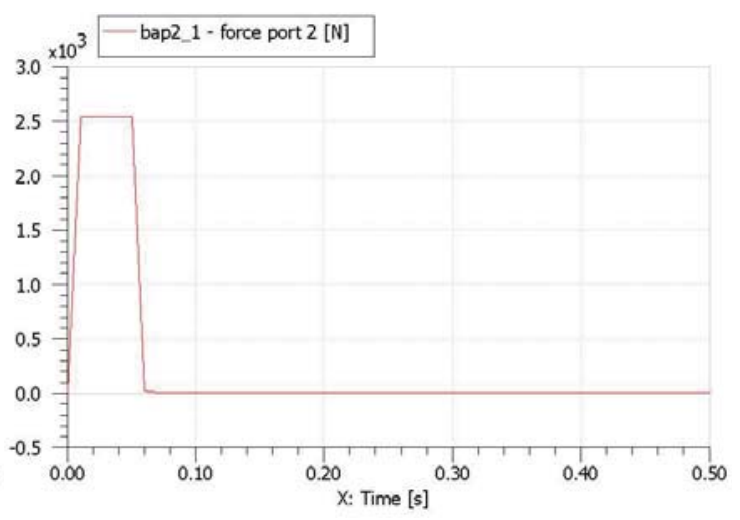

(b)

Figure 6-11. Static damping force (a) without poppet valve hole, (b) with poppet valve hole

The oscillations were initially eliminated by decreasing the mass of the valve to a fictitious value of $1 \mathrm{e}-5$. The hole adds damping to the system, which results in a smooth behavior, when considering the real mass of the valve. Figure6-11 shows the effect of the hole on the damping force behavior, for the real mass of the valve. System is fed by $0.5 \mathrm{~m} / \mathrm{s}$ constant speed.

Therefore, the significant effect of the hole on the static behavior is that it adds damping and allows predicting higher damping force. As a consequence, the real mass for the poppet valve can be implemented.

The influence of the hole on the dynamic behavior is of greater interest. Therefore, the input of the system is changed to a sine wave. 


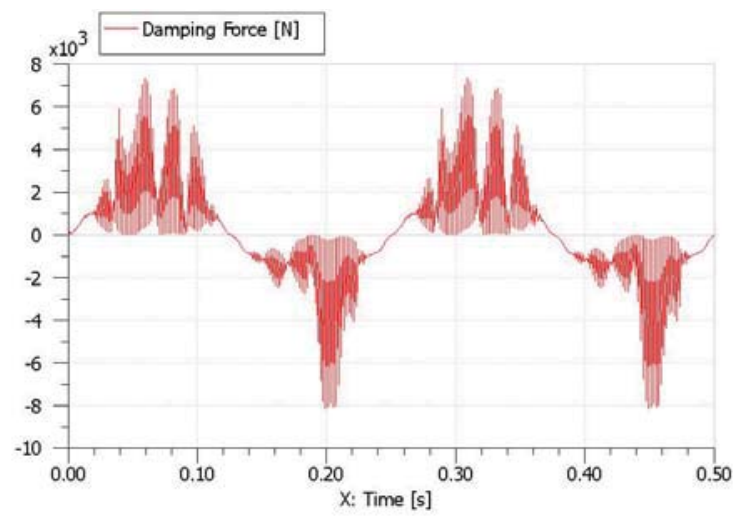

(a)

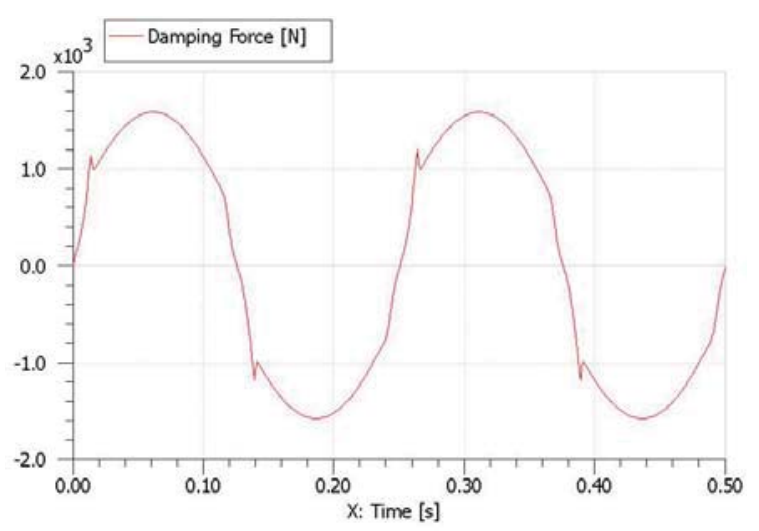

(b)

Figure 6-12. Dynamic damping force (a) without poppet valve hole, (b) with poppet valve hole

As expected, the hole damps the oscillations and a small overshoot is left, which its amplitude is related to the hole diameter. By increasing the diameter (up to an optimal value), flow restriction decreases, and the overshoot becomes smaller.

Figure6-13 compares the damping curves achieved by the simple model and the advanced cylinder piston and poppet valve models, at a higher frequency. In addition to the hysteresis improvement, an overshoot at the beginning of the slope zone, due to the poppet valve orifice, is appeared which improves the accuracy of the simulation model.

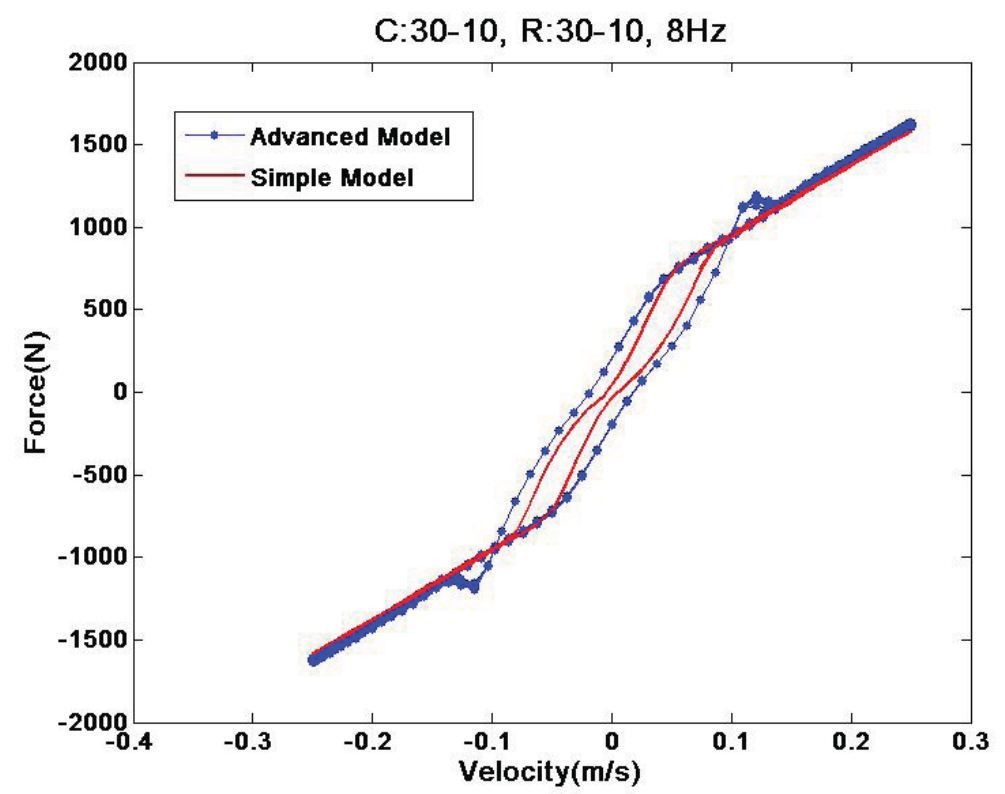

Figure 6-13. Effect of the advanced cylinder and poppet valve models on damping curve 


\subsection{Check Valve Advanced Model}

As mentioned in the simple model implementation section, a simple HYD component with not specifically defined parameters is used for the damper check valves. In order to simulate the dynamics of the valves more accurately, a HCD model is designed and its parameters are tuned to available measurements, using the AMESim optimization tool (7.3).

The crack pressure and flow rate pressure gradient are the basics to set the advanced model parameters using the HCD library. Check valve is going to be modeled by a conical spool, a pre-loaded spring, and an inertia component.

\section{HCD Model}
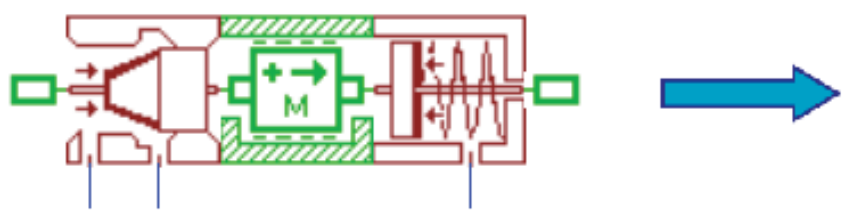

\section{HYD Model}

\section{Check valve conical spool

\begin{abstract}
inertia spring
\end{abstract} \\ Check valve Check valve}

Figure 6-14. Check valve HYD model replaced by HCD

In the check valve advanced model, the spring preload defines the opening of the valve, the spring rate defines the pressure gradient, and finally the higher end stop of the mass defines the saturation level of the valve.

According to Figure6-15, the pre-load of spring needs to be adjusted so that the valve opens at the crack pressure $\left(F_{0}\right)$. The spring rate has to be adjusted so that when the valve is fully open $\left(x_{\max }\right)$, it provides the maximum flow rate at maximum pressure. In order to connect force to pressure, flow area is needed to be calculated. Considering $\mathrm{x}$ as the valve opening and the annular groove of the spools [5],

$$
\text { Flow area }=\pi D x
$$
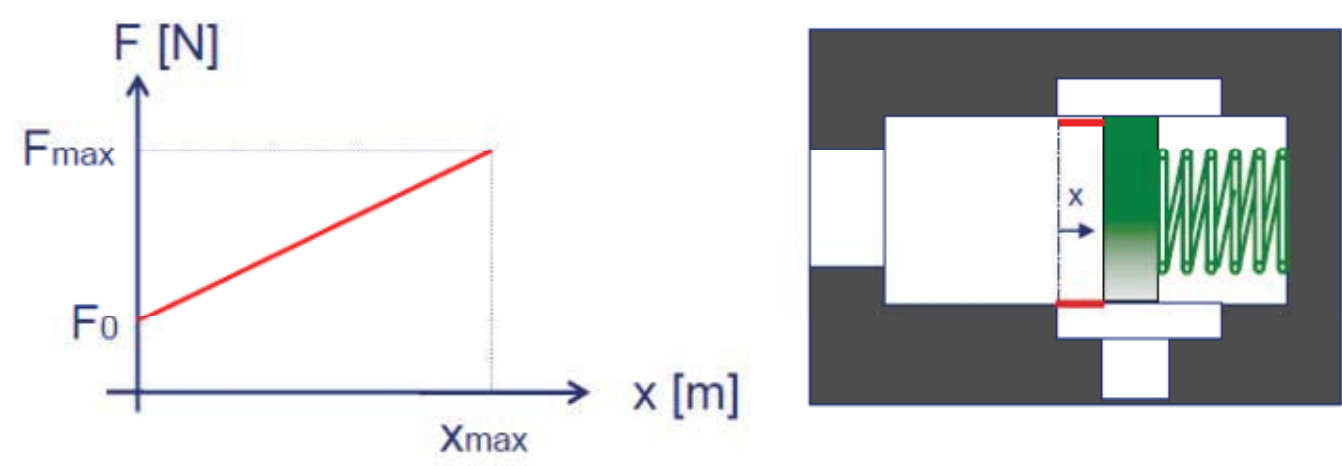

Figure 6-15. Check valve characteristics [5] 
The valve saturation, can be a result of different geometrical constraints such as mechanical stroke limiter, or flow restrictions e.g. by an inlet or outlet orifice. The saturation can be modeled by mechanical end stop defined in the mass element, maximum under lap defined in the spool element, or outlet or inlet orifice diameter. The first choice is used for the current model. As it is clear many parameters need to be set for the new check valve model, for which the AMESim optimization tool together with the measurement data is the best solution. The optimization results as well as the final selected parameters are presented in section 7.3.

\subsection{Shock Absorber Advanced Model}

Figure6-16 presents an overall sketch of the advanced model. The dynamics behavior has improved in different sections of the model. Leakage is added to the main cylinder and high speed valves in order to consider its contribution in the generated damping force. Cylinder body is considered to have elastic deformation when pressure rises. Furthermore, the damping orifice is added to poppet valves model in order to damp the undesired oscillations.

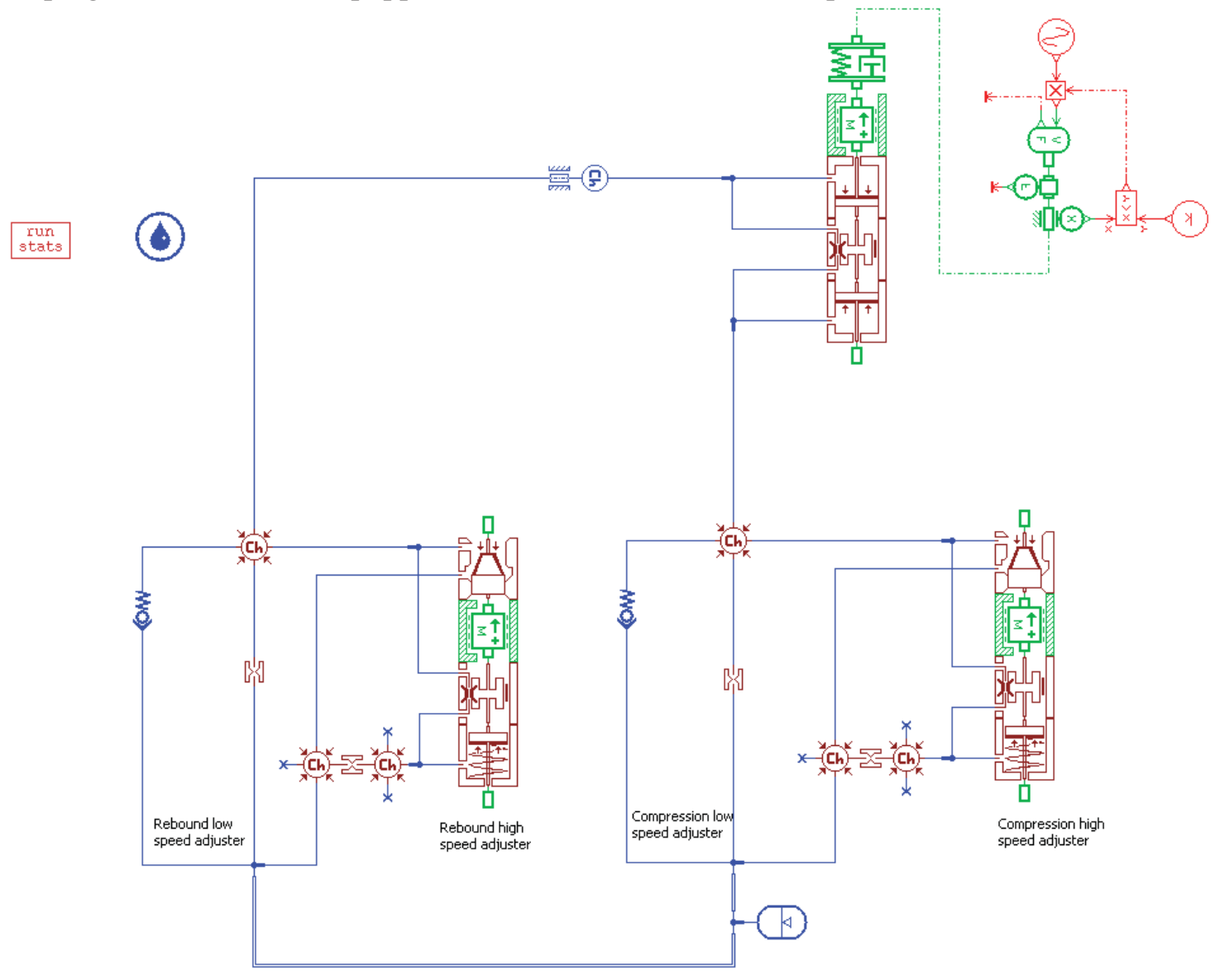

Figure 6-16. General sketch of the advanced damper model 


\section{Flow Rate versus Pressure Drop Validation}

The correct modeling of the real damper behavior is achieved by comparing numerical results, from separate model components, with measurements on different parts of the damper, using the advanced instruments available at Öhlins company. In order to validate the simulation model of the damper, it is a logic idea to first examine the components accuracy and then investigate the general behavior. One of the important tests which can be conducted for this purpose is the 'Flow bench' test in which the pressure drop over a component is plotted as a function of the flow passing through it.

The measurements are done on the poppet and bleed valves as well as the check valve, and results are compared to the ones from the simulation model. Measurement data is filtered in MATLAB up to an acceptable level (Appendix C).

\subsection{Low Speed Adjusters}

The flow through the bleed valve is measured by a flow sensor and is plotted as a function of pressure drop, which is measured across the valve by means of a pressure transducer. Figure7-1 depicts the AMESim bleed model setup, which replicates exactly the flow bench setup.

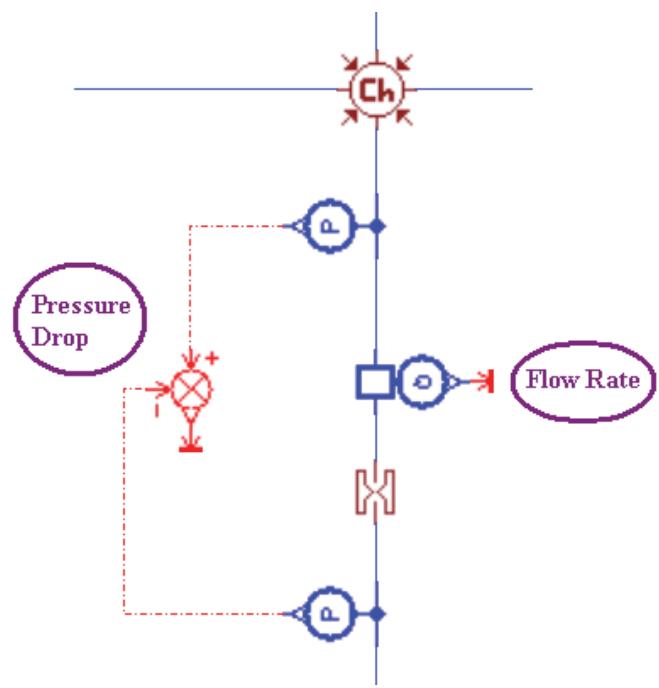

Figure 7-1. Measuring flow rate and pressure drop over the bleed valve

Simulation results are compared to the measurements for the highest and lowest available clicks of the LS valve and the plots for the rest of the click settings are presented in Appendix A. 

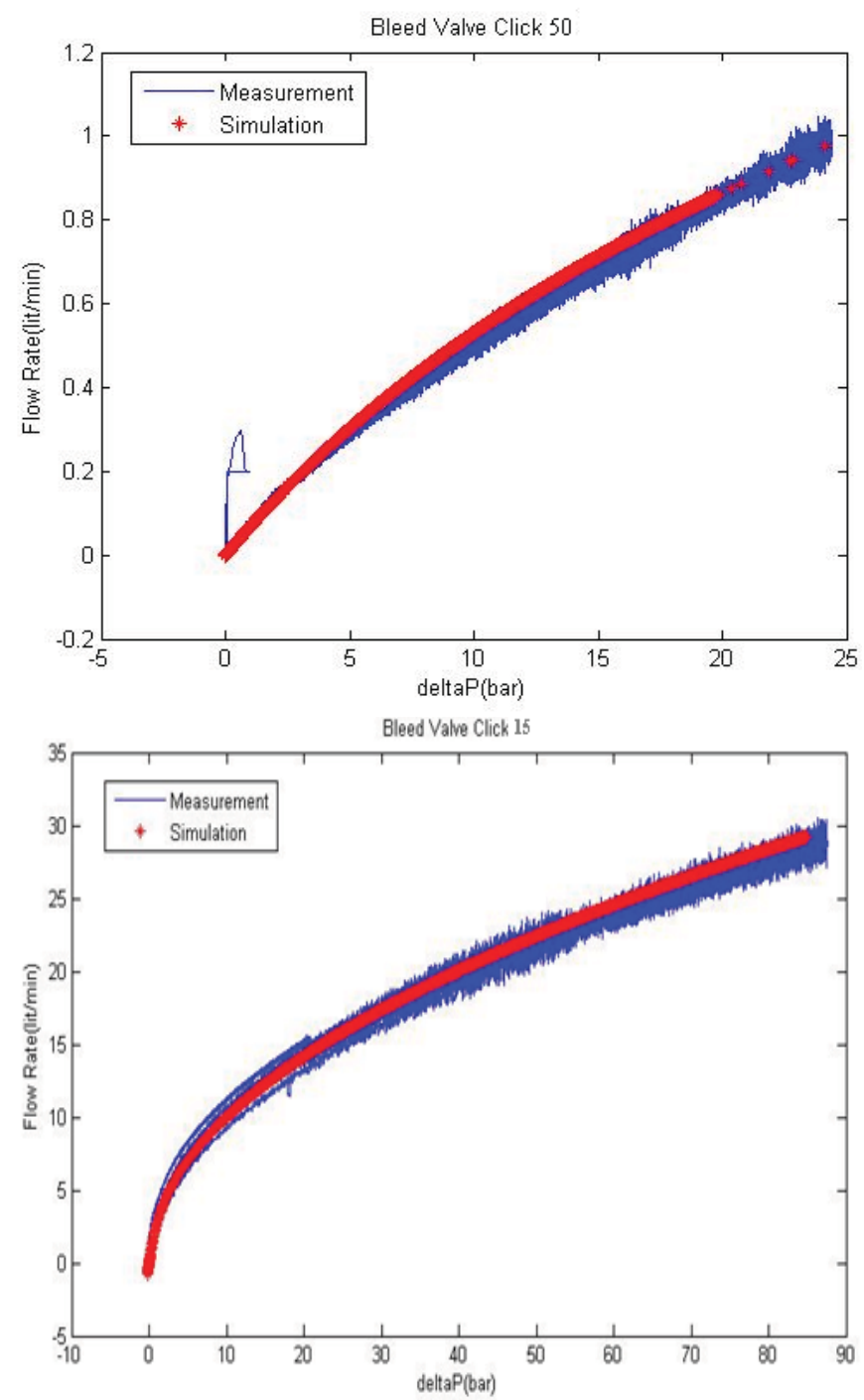

Figure 7-2. Flow bench validation of the bleed valve for clicks 50 and 15

As shown in Figure7-2, the curves follow the general orifice flow rate equation. In addition, at lower clicks the orifice opening is larger; therefore the flow rate is higher at a certain pressure drop. Figure7-2 illustrates the high accuracy of the LS valve model in simulating the real behavior. The agreement is perfect in a large range of flow rates.

\subsection{High Speed Adjusters}

Similar spectrum setup is used for the poppet valve, as shown if Figure7-3. Numerical results are compared to measurements for the highest and lowest clicks, as presented in Figure7-4. Flow bench curves for other clicks settings are presented in Appendix A. 


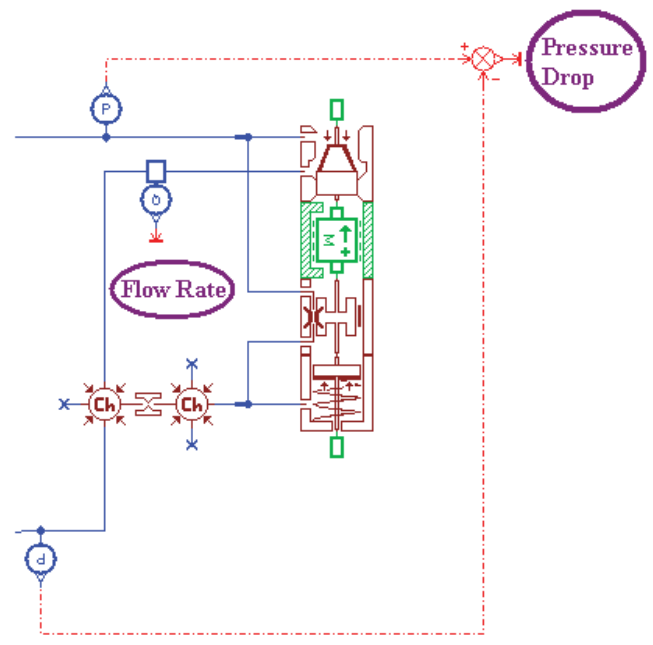

Figure 7-3. Measuring flow rate and pressure drop over the poppet valve
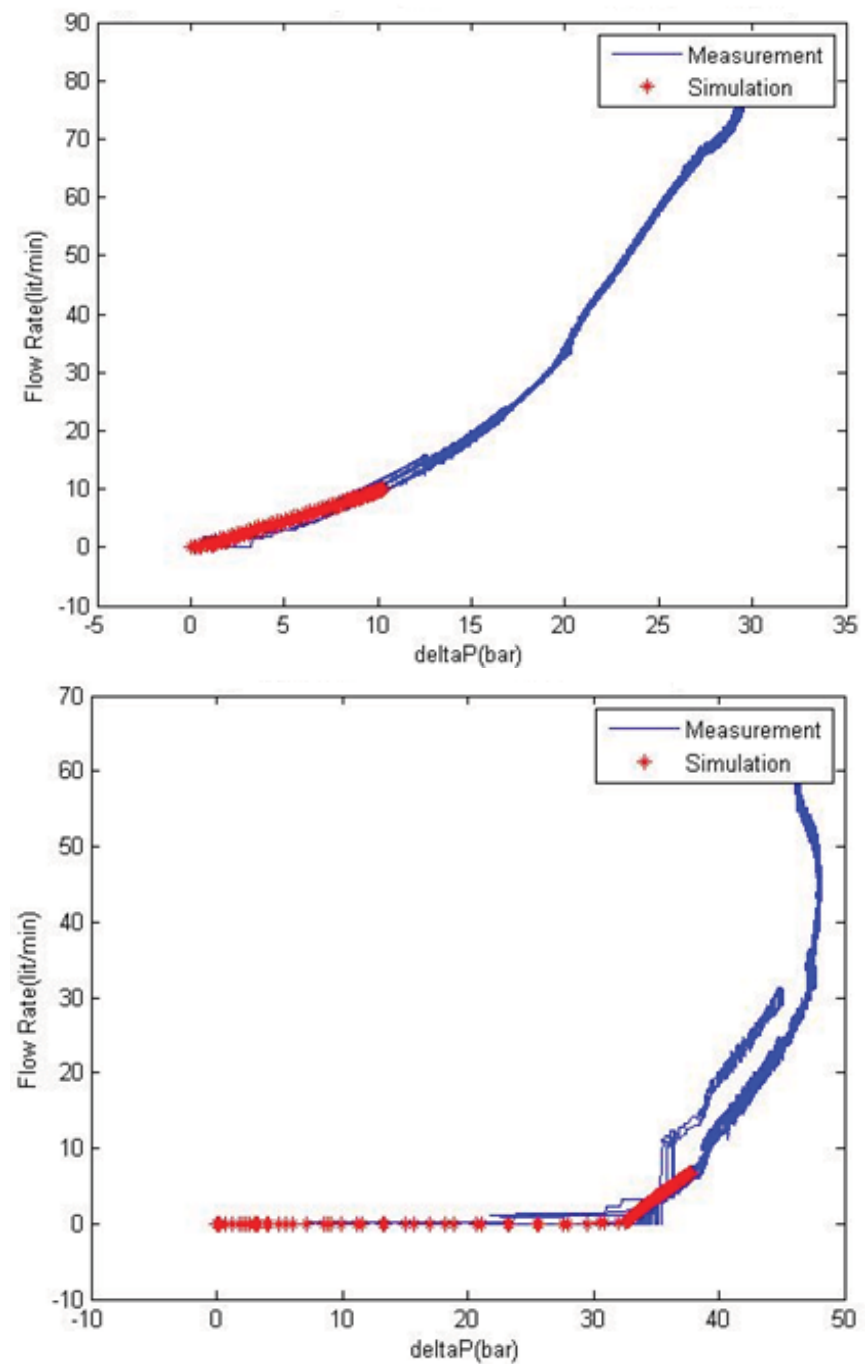

Figure 7-4. Flow bench validation of the poppet valve for clicks 0 and 40 
The agreement is quite good at low velocity inputs and consequently low flow rates. In all of the clicks, the crack pressure of the valve as well as its behavior, are estimated well by the simulation model for flow rates below $10 \mathrm{lit} / \mathrm{min}$. While, the accuracy decreases for higher range of flow rates. In order to improve the model accuracy at higher flow rates, a more advanced model of the poppet valve is required. One example can be the influence of flow forces in valve dynamics. The effect of jet forces is investigated for the default jet angle, i.e. the conical poppet half angle $(\sim 10 \mathrm{deg})$, and no significant change in flow behavior is observed. Using the AMESim optimization tool together with the measurements, can help in finding the best jet angle which improves the flow bench characteristics.

\subsection{Check Valves}

As mentioned in 6.3, in order to set the unknown parameters of the check valve advanced model, the AMESim optimization tool is used. Figure7-5 shows the measured behavior of flow versus pressure drop over the check valve used in TTR damper.

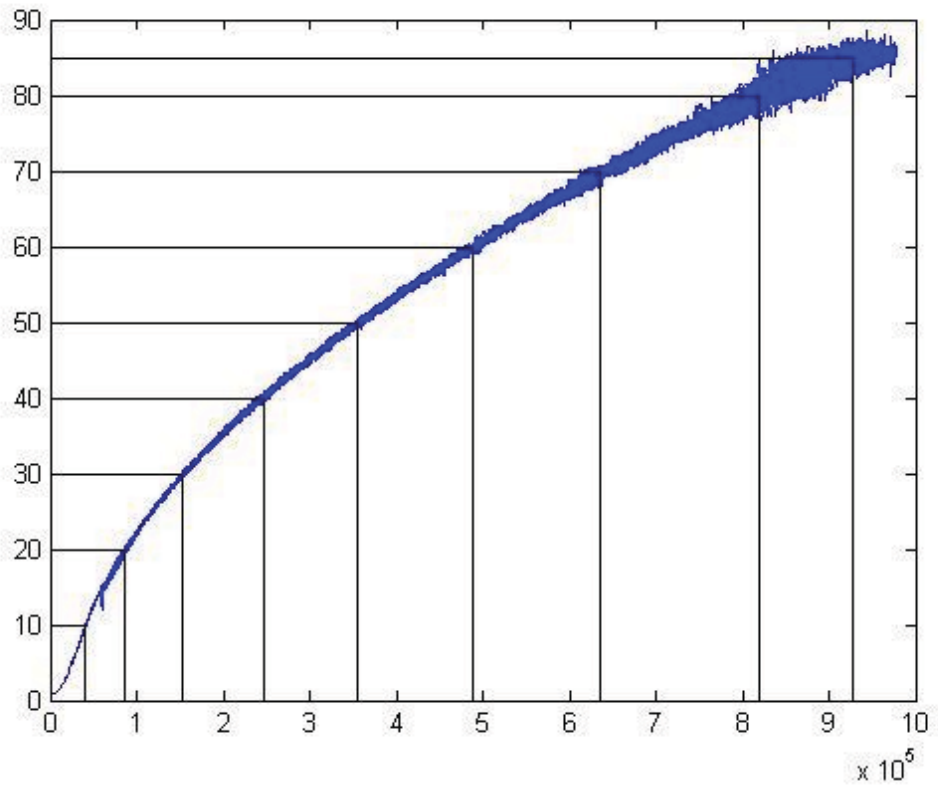

Figure 7-5. Flow bench measured data over the check valve

According to the measurement figure valve has a very low crack pressure. In order to catch the valve behavior in simulation model, the Optimization (Design Exploration) tool of AMESim is used. The procedure is to give the required behavior (flow-pressure drop) of the valve as input and ask the software to tune different parameters in a way to catch the required behavior.

A simple control algorithm is needed to be defined which calculates the difference between the required and real values as error, and asks the optimization tool to minimize the second ordered integrated error. Consequently, the following geometrical dimensions are optimized in order to obtain the required characteristics. 
- Poppet diameter

- Cone length

- Poppet half angle

- $\quad$ Spring stiffness

- Spring pre-load

- Cylinder diameter

The optimization model setup is shown in Figure 7-6.

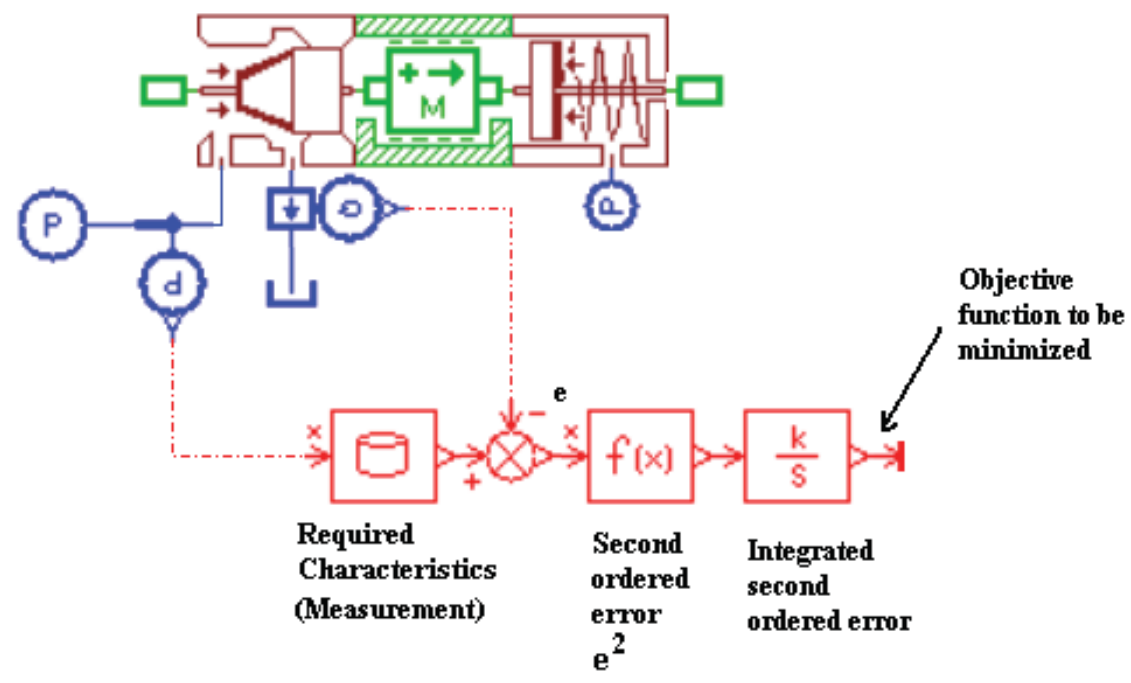

Figure 7-6. Design optimization for the check valve model

The mentioned properties are the design variables, and the second ordered integrated error is the objective function to be minimized. Some restrictions on the variables can also be imposed as constraints of the optimization problem. Measurements are done on the check valve alone; therefore the optimization is applied to the check valve HCD model isolated from the complete damper model (similar to the LS and HS adjusters). Table7-1, shows the iteration number and design variables of the iterative optimization (NLPQL).

Table 7-1. Check valve HCD model, optimization results (confidential)

\begin{tabular}{|l|}
\hline Total number of iterations : 9 \\
\hline Algorithm completed successfully \\
\hline The best solution found is: \\
\hline K \\
\hline F0 \\
\hline Hdisp \\
\hline Dp \\
\hline Lcone \\
\hline D \\
\hline Pang \\
\hline error $=7.15481507770680 \mathrm{e}+001$ \\
\hline
\end{tabular}


Figure 7-7 illustrates the check valve characteristic curve compared to the measurements, after implementing the optimized parameters in the model components.

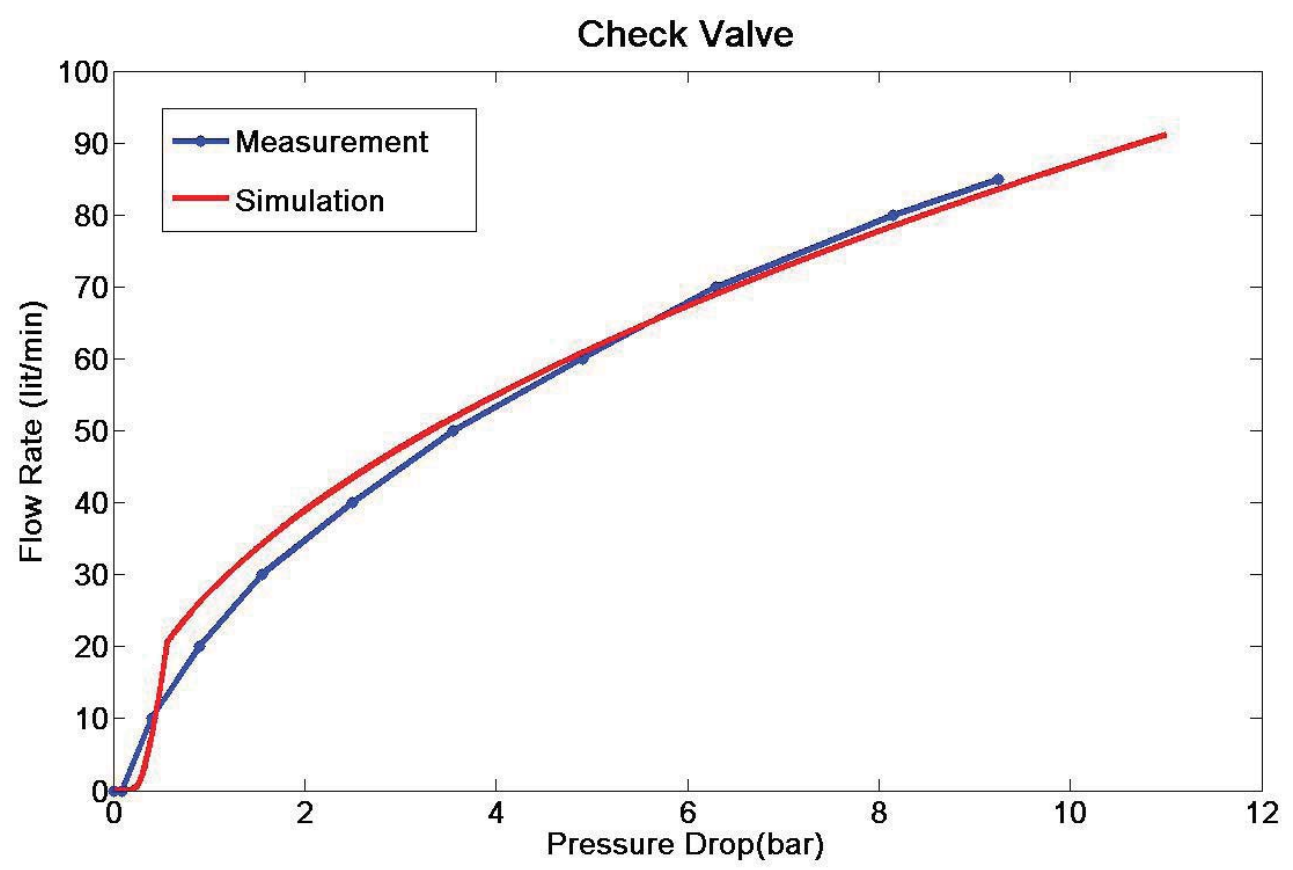

Figure 7-7. Flow bench validation of the check valve

According to Figure7-7, the agreement at low flow rates which is of more interest is not much better than the simple HYD check valve. Therefore, in order to decrease the computational time, the simple model is still used. 


\section{Advanced Model Validation with Dynamic Measurements}

The damping characteristic of the advanced model is investigated based on the available measurements. The measurements follow a logic strategy which makes it possible to gather data from all of the damper critical working points, in the shortest time. Regarding the sine wave input velocity, measurements are done at four different frequencies of $4,8,16,24 \mathrm{~Hz}$ for each of the click settings.

Regarding the click setting, some terms must be introduced first. LS valves or the bleeders generate high force at higher clicks (smaller orifice opening), and low force at lower clicks (larger orifice opening). Clicks with normalized values of $0.75,0.5$, and 0.25 are chosen as suitable clicks to perform the high, medium, and low force behavior respectively. Similarly, the HS or poppet valves produce high damping force at higher clicks (larger spring pre-load), and low force at lower clicks (smaller spring pre-load). Clicks 30, 10, and 2 are chosen as suitable clicks to perform the high, medium, and low force behavior respectively. The main case study is the regular setting of the damper in which all of the LS and HS valves generate medium force. It is then followed by more critical settings. Different combinations of the four valves, with high and low force click settings, produce 10 damper settings chosen for the measurement runs, which some of them are investigated in 8.3.

In order to avoid confusion with the number of clicks in different combination, capitals $\mathrm{M}, \mathrm{H}$, and $\mathrm{L}$ are used for medium, high, and low force clicks respectively.

Data measured by the dynamometer is filtered with a $400 \mathrm{~Hz}$ filtering frequency to extract a smooth and sufficiently accurate curve from the measurements.

\subsection{Similar Click Setting on Compression and Rebound Sides}

To start with the dynamic validation, among a large number of possible click settings and types of the input velocity, a regular setting is chosen as the main case study. It is of great importance for the simulation model to be able to mimic the damping behavior of the most common operational point. The input velocity has nominal frequency of $4 \mathrm{~Hz}$ and the setting presents the normal operational condition for the shock absorber, for which both of the LS and HS valves produce medium force. Due to the highest application, it is the most critical setting for the model validation. Bleeders are at click 30 and poppet valves at click 10 on both compression and rebound sides.

The poppet valve hole generates an overshoot in the damping curve and its diameter is inversely proportional to the overshoot amplitude. As mentioned in 6.2.2, the hole diameter can vary in a specific range. Figure 8-1 demonstrates the damping behavior of TTR with the normal click setting and different poppet valve hole diameters. 

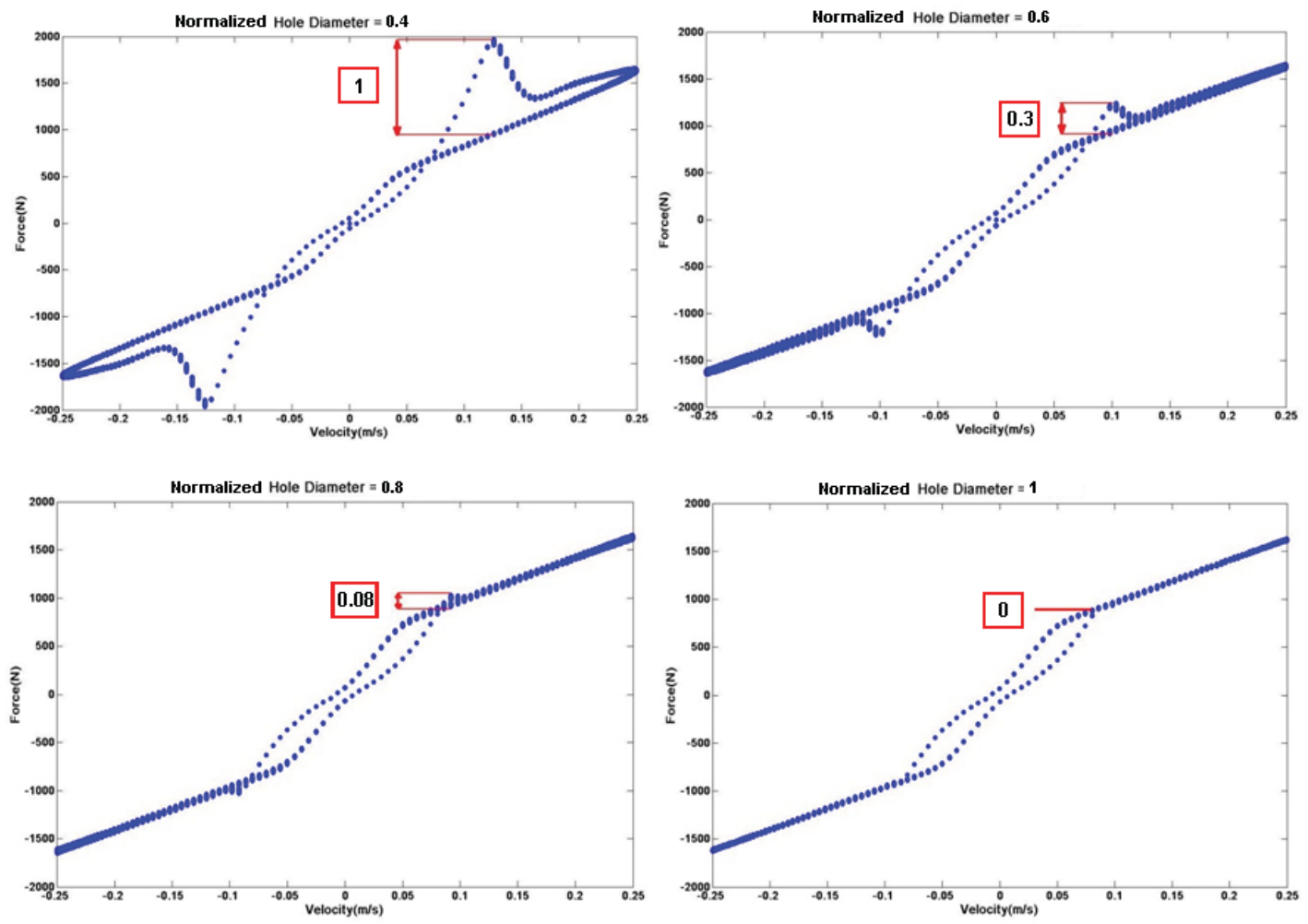

Figure 8-1. Influence of the poppet valve hole diameter on the damping curve

Therefore, the value of the diameter must be tuned considering the measured data. Furthermore, it is observed that influence of the hole enhances by increasing the input frequency, i.e. the same hole produces larger overshoot at higher frequencies.

Results for a number of selected click settings for two frequencies of 4 and $16 \mathrm{~Hz}$, are presented below. The rest of the click combinations and frequencies are added to Appendix A. 


\begin{tabular}{|l|l|l|}
\hline Run1 & LS & HS \\
\hline Comp. & $\mathrm{M}$ & $\mathrm{M}$ \\
\hline Reb. & $\mathrm{M}$ & $\mathrm{M}$ \\
\hline
\end{tabular}
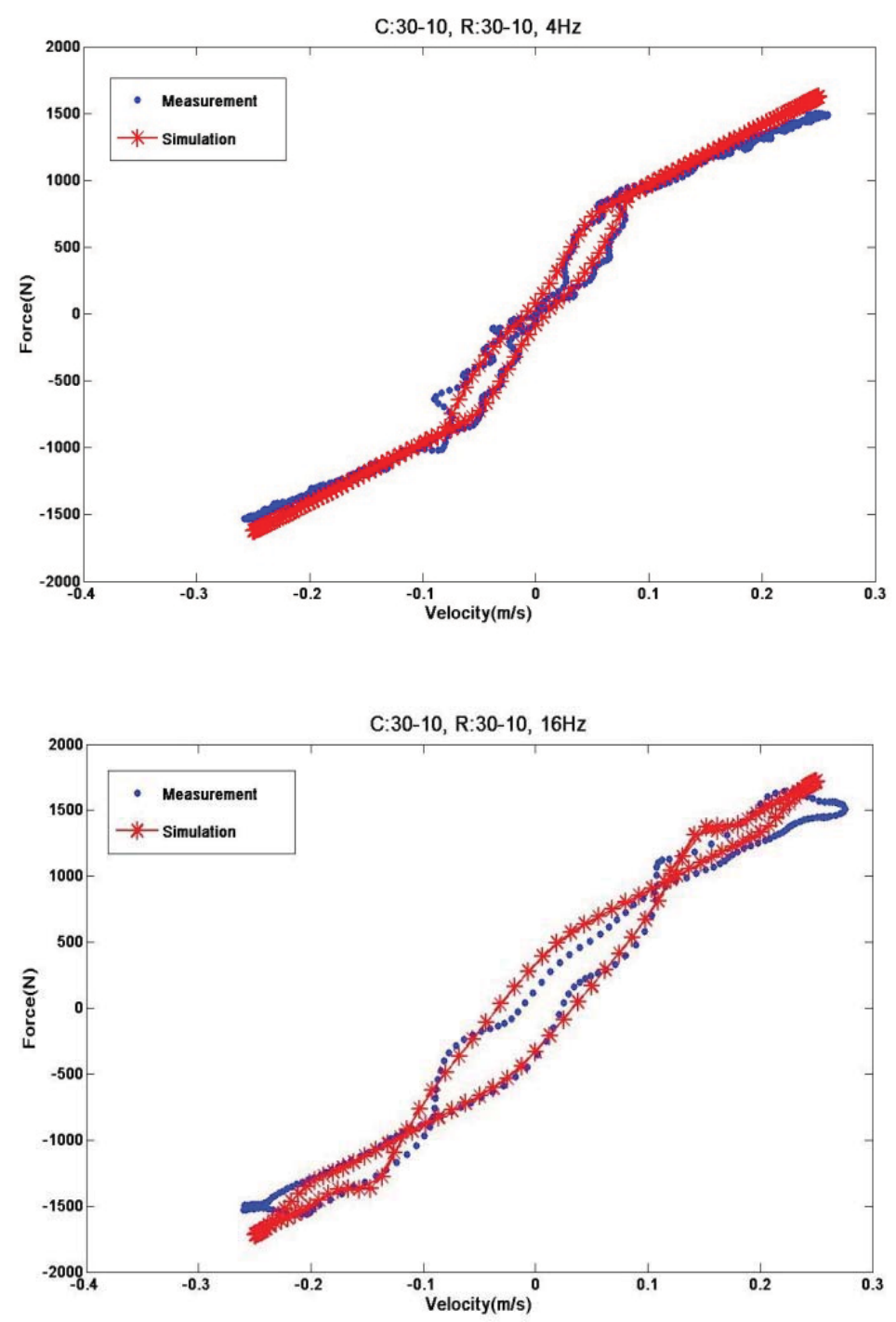

Figure 8-2. Dynamic validation for the nominal click setting at different frequencies

According to Figure8-2, the agreement of measurement and simulation at the nominal frequency of $4 \mathrm{~Hz}$, is great. As the input velocity frequency increases more, difference between the real and simulated behaviors becomes more and more visible. In order to find the reason of these differences and the responsible sub-model, more number of click combinations is required to be investigated.

In the following test, still the LS and HS valves have similar settings on compression and rebound sides. The LS valves are mainly open while the HS valves are highly forced. Flow which is the reason of damping force generation mainly passes the bleeders. Therefore, the damping behavior is more dependent on the LS valves characteristics. 


\begin{tabular}{|l|l|l|}
\hline Run2 & LS & HS \\
\hline Comp. & L & H \\
\hline Reb. & L & H \\
\hline
\end{tabular}
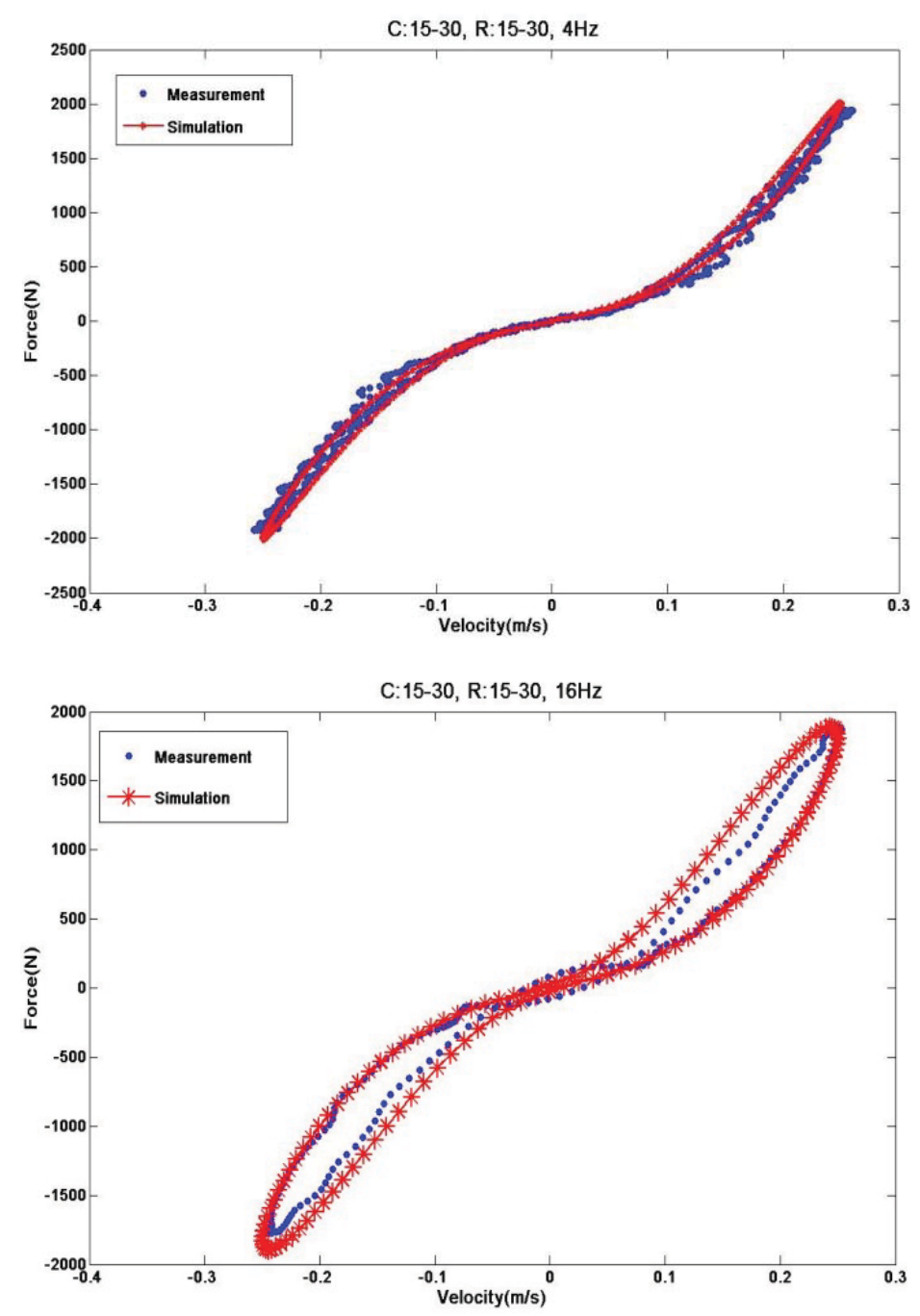

Figure 8-3. Dynamic validation for the low LSA and high HSA click settings at different frequencies

As it is clear from Figure 8-3, there exists a great agreement between the measurements and simulation results, even at quite high frequencies compared to Figure 8-2. In Run2 the low speed adjusters are at low clicks which correspond to large orifice opening. Therefore, the flow mainly goes through the bleed valves and poppet valves are less active compared to Run1. The better agreement in Figure 8-3 compared to Figure 8-2 shows that the low speed adjusters models are more accurate than the high speed ones. Thus, a more advanced model of the poppet valve can improve the model dynamic behavior. 


\subsection{Different Click Setting on Compression and Rebound Sides}

It is now time to judge the simulation model under a more specific condition for which the LS and HS valves do not have the same clicks on compression and rebound sides. In these cases the generated damping curve is not anymore symmetric, and the shock absorber shows different behaviors in different sides of a damping cycle.
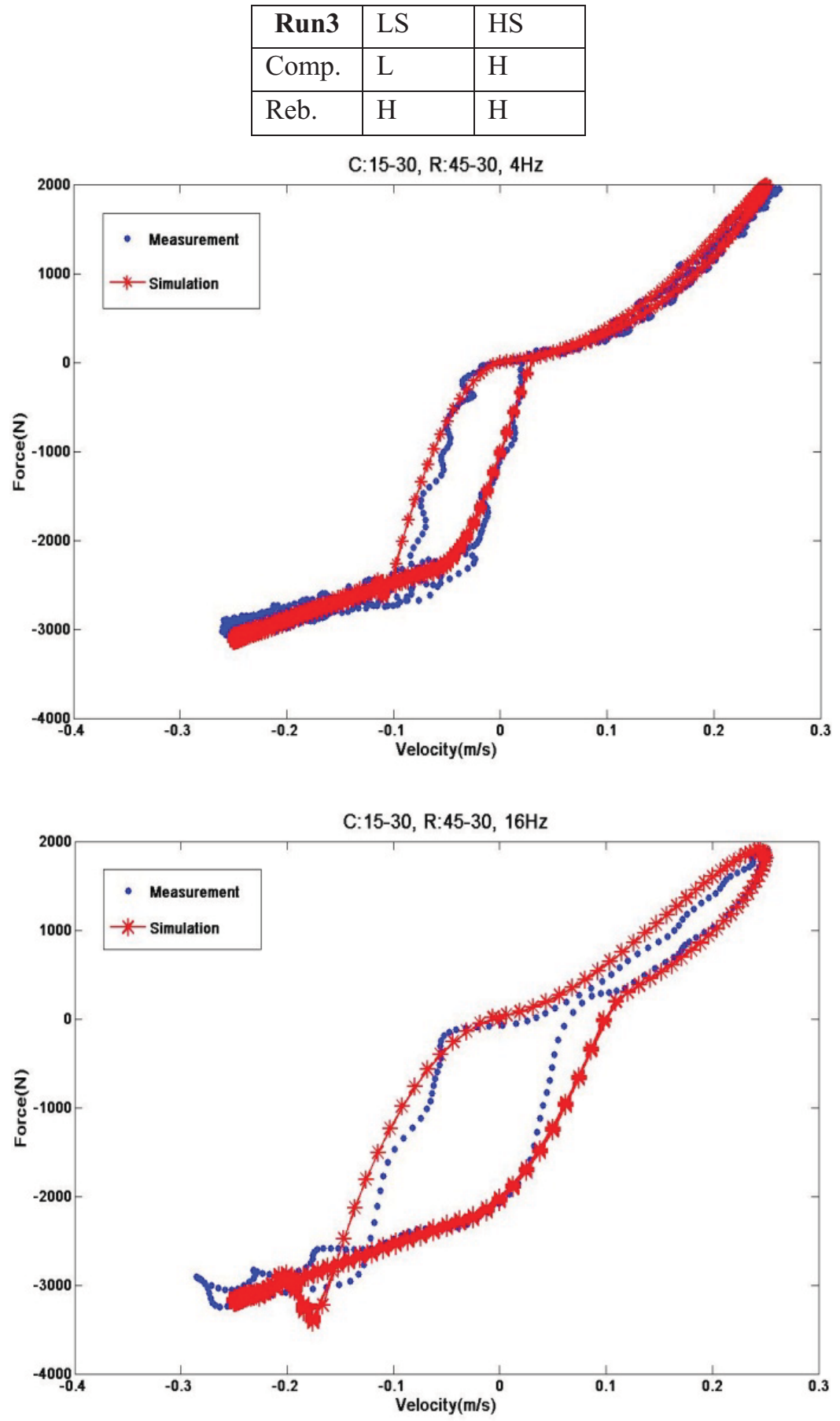

Figure 8-4. Dynamic validation for different LS click settings on compression and rebound sides, at different frequencies 
Figure8-4 shows the less agreement when the bleed valves have different click settings on compression and rebound sides compared to the symmetric setting. The difference is mainly in the rebound high speed zone. Therefore, a more advanced model of the poppet valve is required to improve the dynamics.

\begin{tabular}{|l|l|l|}
\hline Run4 & LS & HS \\
\hline Comp. & L & H \\
\hline Reb. & L & L \\
\hline
\end{tabular}
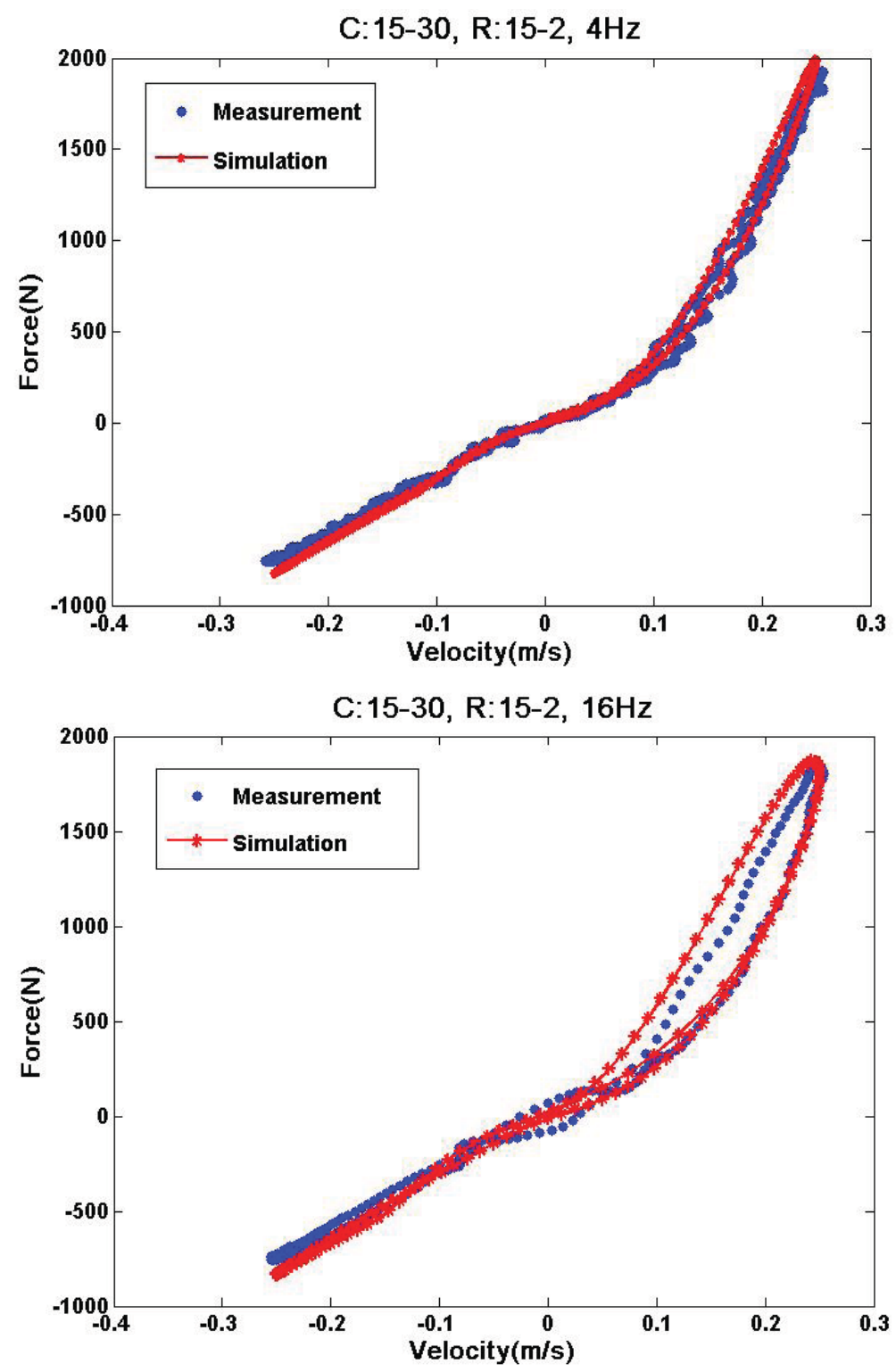

Figure 8-5. Dynamic validation for different HS click settings on compression and rebound sides, at different frequencies 
It is clear that the agreement at Run5, for which poppet valves imposed different forces on compression and rebound sides, is better compared to Run4. It has the same reason mentioned in 8.1. Similar to Run2, here the bleed valves are fairly open. This decreases the functionality of poppet valves and results in good agreement even without a perfectly accurate valve model. 


\section{Conclusion}

In this study the physical behavior of an advanced automotive racing shock absorber is investigated. The product known as TTR is developed by Öhlins Racing AB which is one of the world leaders in the suspension industry. The design of this hydro-mechanical system is replicated in detail in the 1D simulation environment, AMESim. The numerical model is composed of five sub-models: the main cylinder with through rod piston design, the high speed adjuster or the poppet valve, the low speed adjuster or the bleed valve, the check valve, and the accumulator. Furthermore, the AMESim numerical model presents three separate inputs. The main input is represented by the piston velocity; while the low and high speed valves external adjustment in terms of 'clicks', represent the other inputs. The output of the simulation model is the damping force generated by the piston rod when subjected to either a static or a dynamic cycle. Modeling is performed in two level of complexity in order to improve the dynamic behavior, adding the physical phenomena such as leakage flow rate, static and viscous friction, and elastic deformation of solid bodies.

The simulation results are validated under both static and dynamic conditions. Validation is done based on the measurements conducted on the flow benches and dynamometers available at the Öhlins measurement laboratory. Flow bench measurements allow obtaining the characteristic of the TTR check valves, low speed fixed orifice valves and high speed poppet valves individually. In addition, the entire suspension system is measured in the dynamometer, depending on the velocity input, statically and dynamically. Therefore, the physics behind different damping behaviors together with its responsible component is captured.

A thorough dynamic validation work is presented for the TTR shock absorber model under different 'click' settings and input frequencies. Simulation results present good agreement to the measurements especially at low and medium frequencies. Moreover, the symmetric clicks setting on compression and rebound sides, as well as the low click setting of the bleed valves enhance the model accuracy even more.

The numerical model, generated in AMESim, also allows assessing the potential of such a software package to accurately model this type of automotive hydro-mechanical systems. AMESim offers a high level of flexibility in design which permits user to choose the level of model complexity based on the required accuracy level. Furthermore, the well-developed libraries containing large variety of components, each illustrated by a common symbol, makes it easy to choose the suitable sub-model for the desired behavior.

\section{Future Work}

A more advanced model of the high speed adjusters is needed to be developed in order to improve the flow bench characteristics especially at high flow rates. The improvement can be done in calculating the flow forces using an optimal jet angle. Furthermore, an advanced modeling of the sealing elements can enhance the model ability in estimating the correct hysteresis level. 


\section{References}

[1] Inside TTX, The Öhlins TTX40 manual

[2] LMS Imagine.Lab AMESim - online help

[3] Diskussion kring modellering av TTR stötdämpare

[4] Öhlins materials

[5] LMS Imagine.Lab AMESim training - HYD2 COPM, Design of Hydraulic Components

[6] X. Lin, Y. Bo, G. Xuexun, Y. Jun, 'Simulation and Performance Evaluation of Hydraulic Transmission Electromagnetic Energy-regenerative Active Suspension'

[7] Y. Shiao, C. C. Lai and Q. A. Nguyen, 'The Analysis of a Semi-Active Suspension System'

[8] N. Al-Holou, A. Bajwa and D. S. Joo, 'Computer Controlled Individual Semi-Active Suspension System'

[9] 'http://en.wikipedia.org/'

[10] Sensors and Signal Conditioning, TMMS04 Mechatronics course material

[11] LMS Imagine.Lab AMESim training - AME 1, Getting started with AMESim 


\section{Appendix A - Complementary Figures}

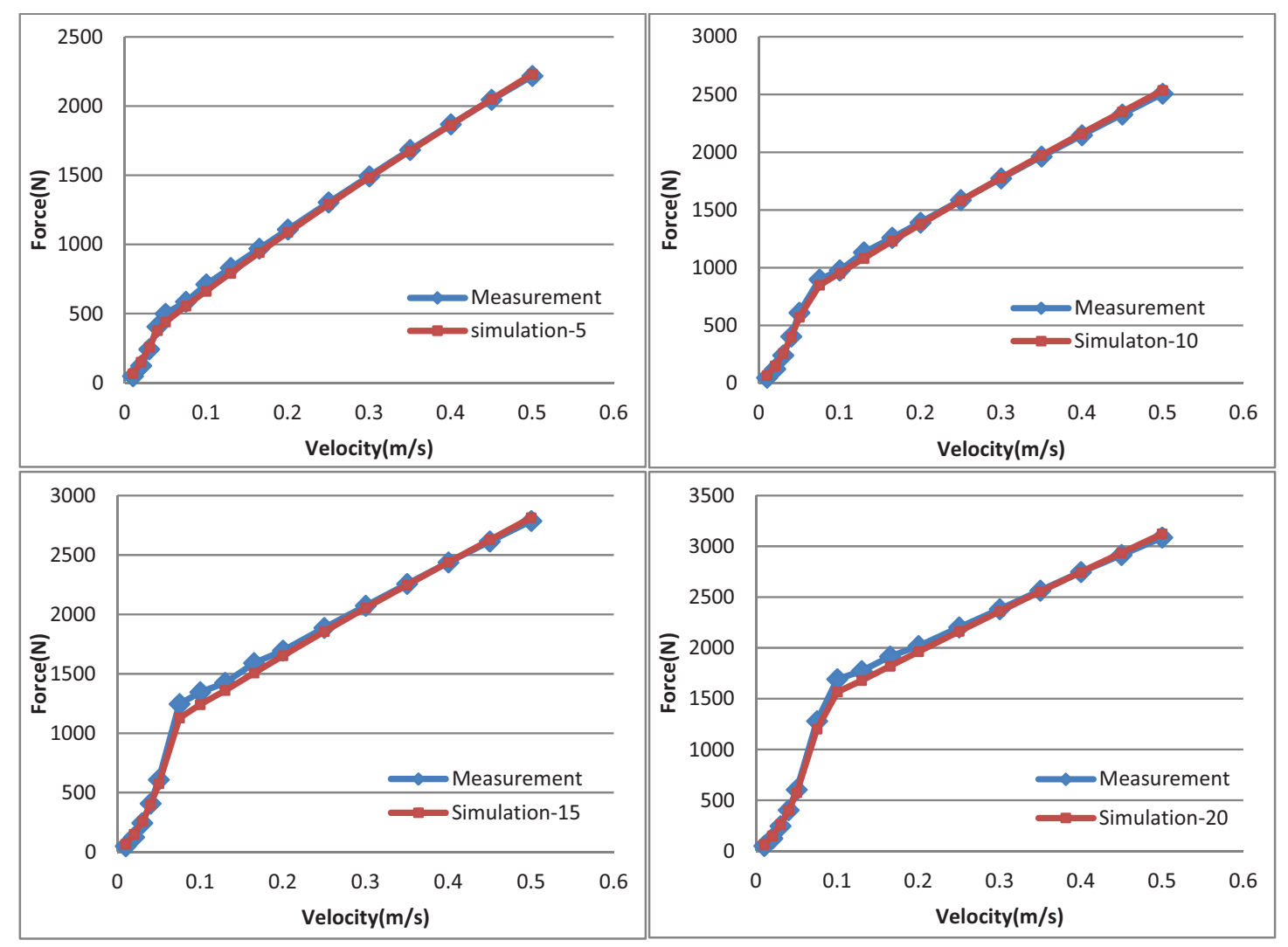




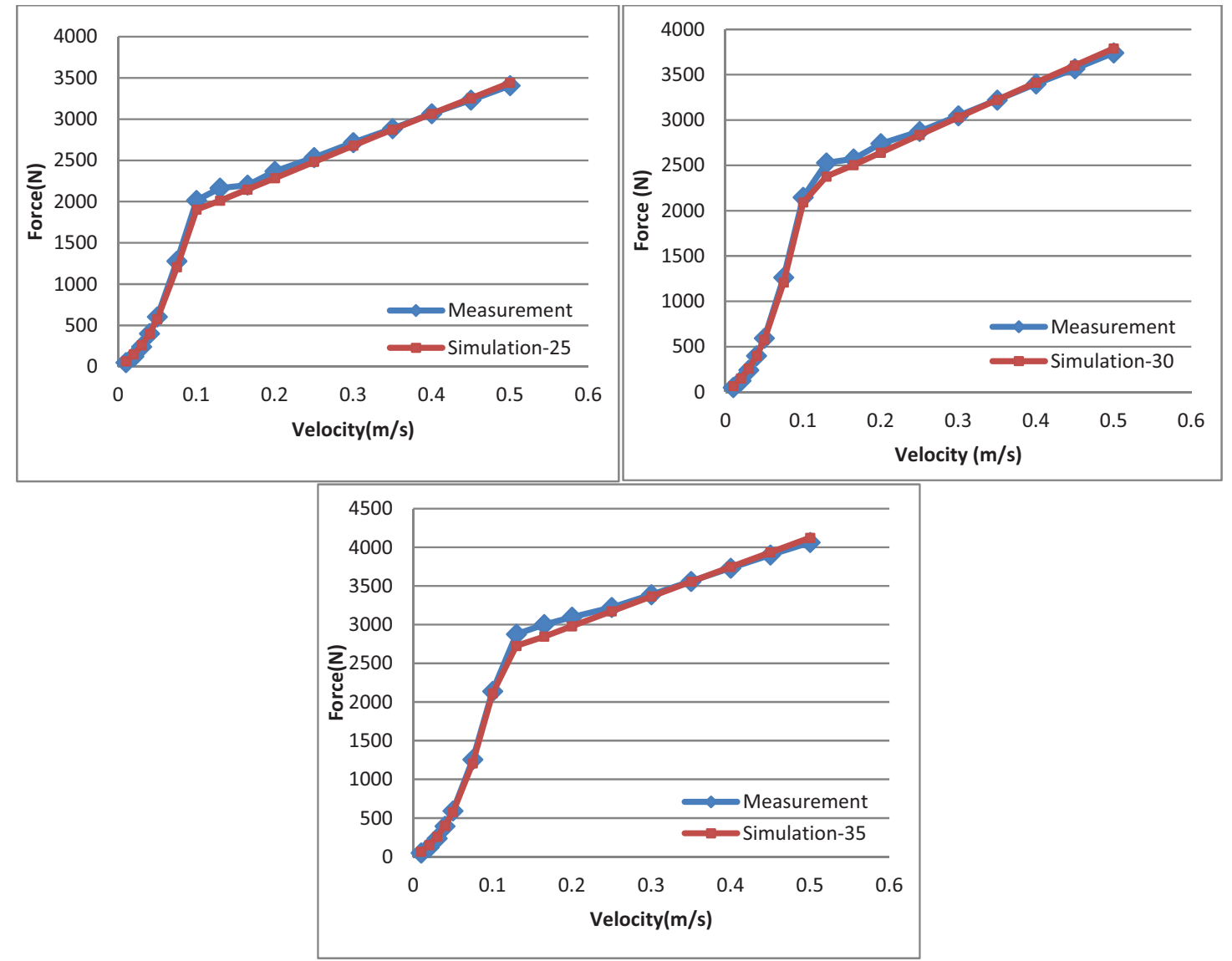

Figure A- 1. Static Validation in different HS click 0-40 

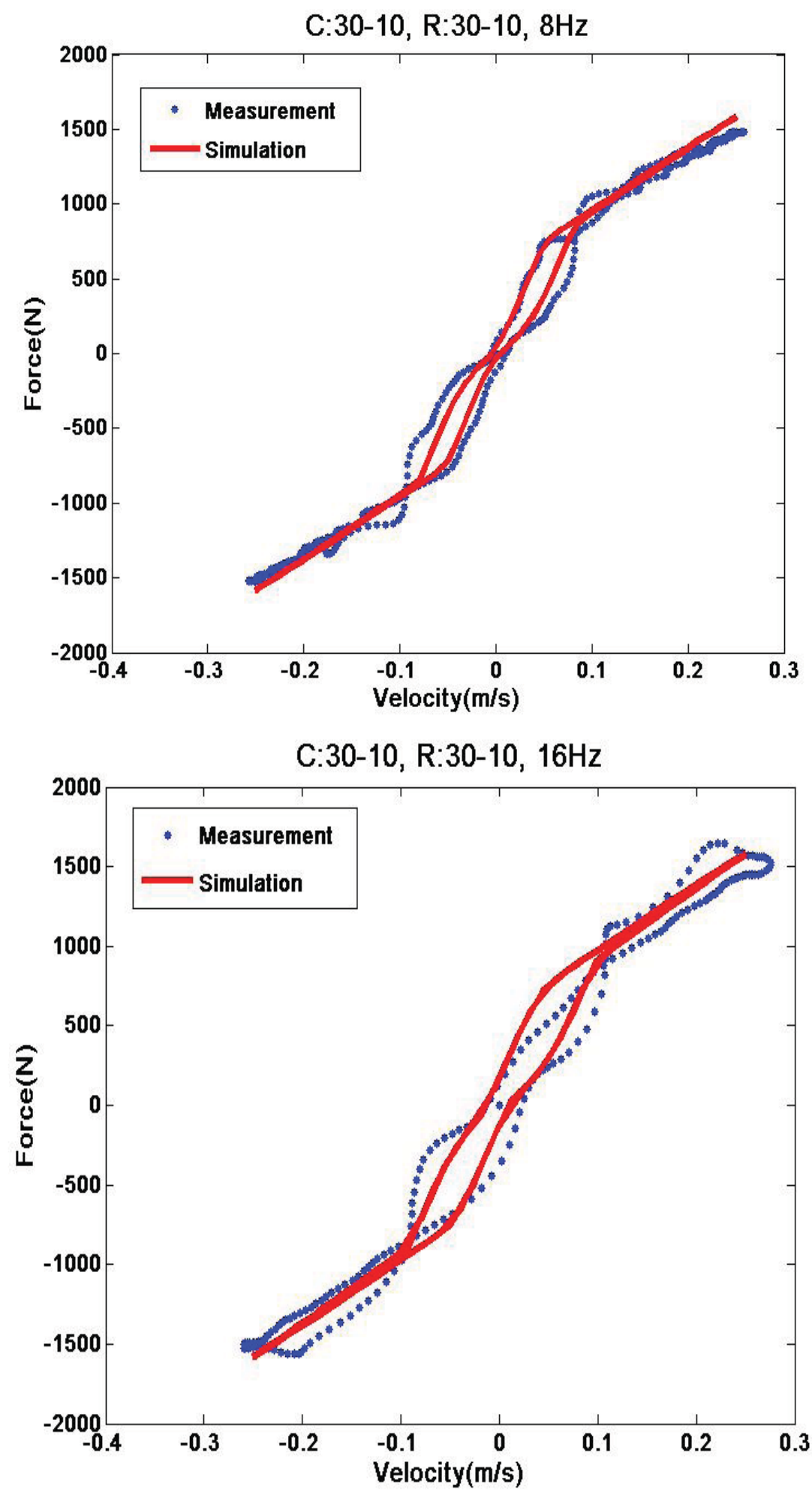

Figure A- 2. Dynamic response of the simple model at medium click setting 

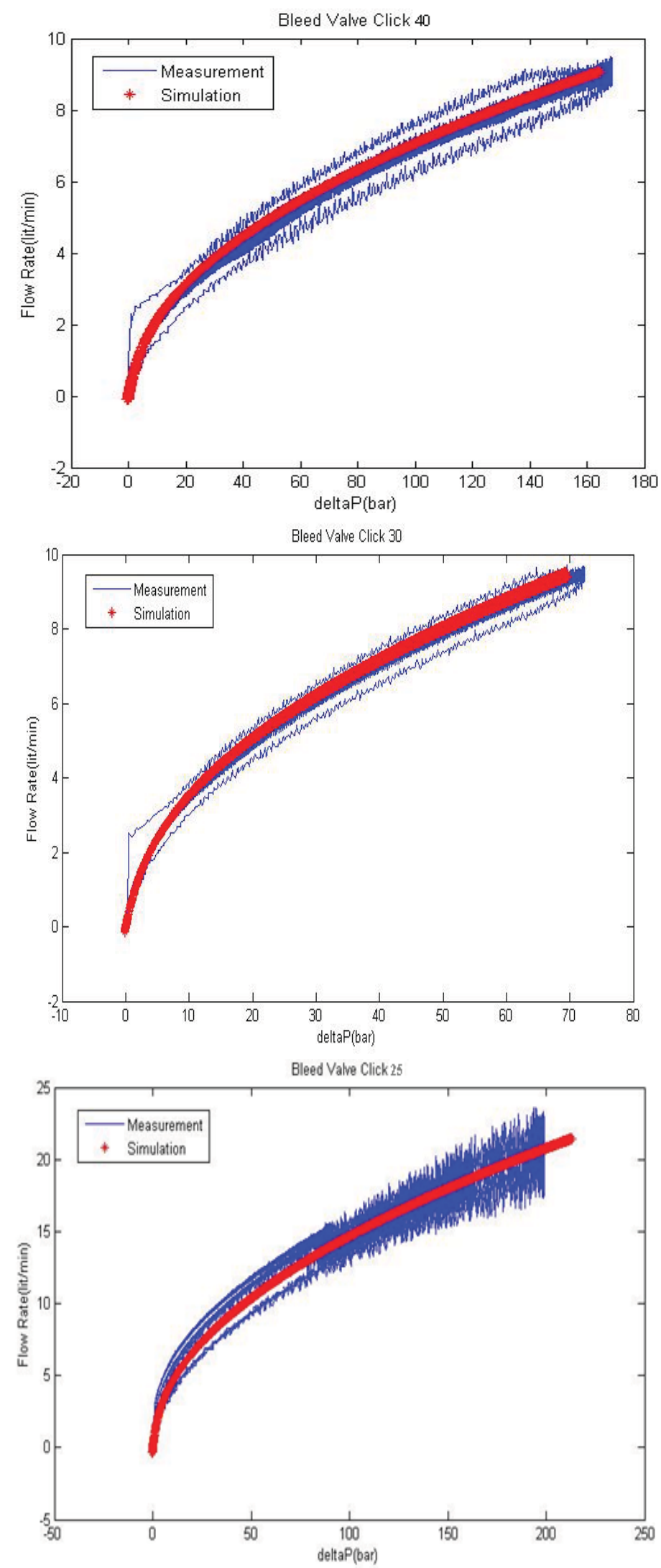

Figure A- 3. Flow bench validation of the bleed valve for different clicks 

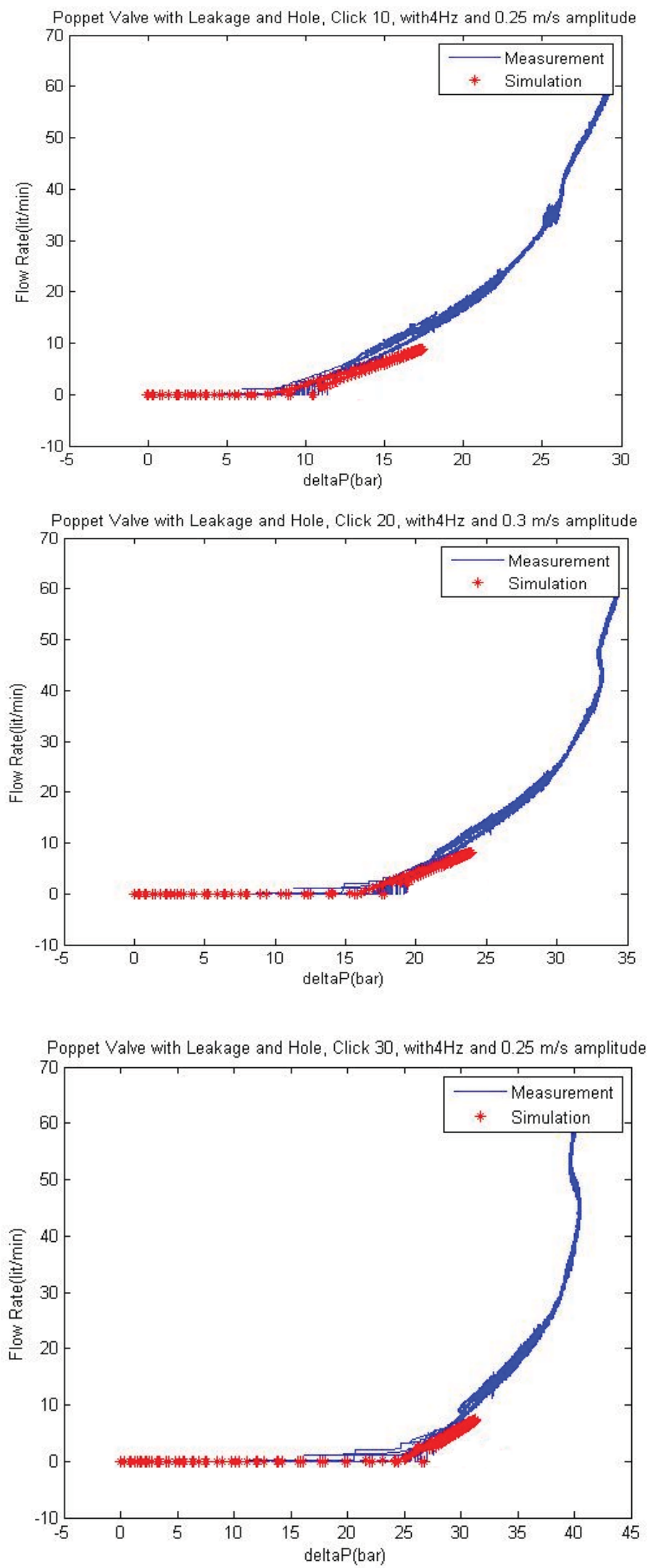

Figure A- 4. Flow bench validation of the poppet valve for different clicks 


\begin{tabular}{|l|l|l|}
\hline Run1 & LS & HS \\
\hline Comp. & $\mathrm{M}$ & $\mathrm{M}$ \\
\hline Reb. & $\mathrm{M}$ & $\mathrm{M}$ \\
\hline
\end{tabular}
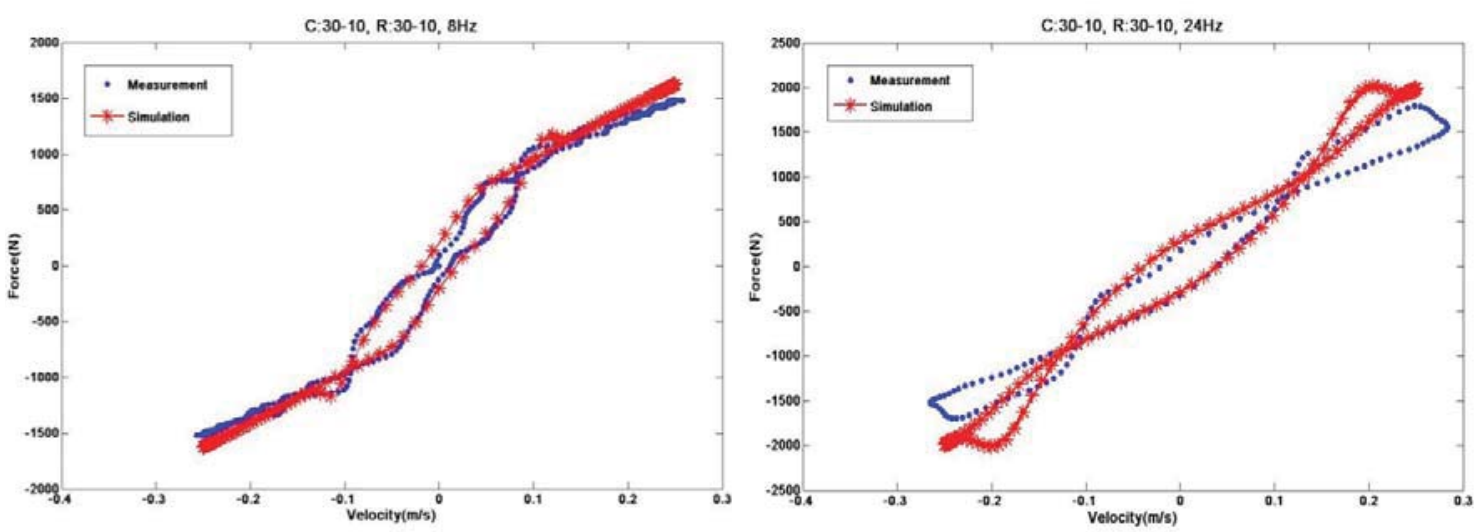

Figure A- 5. Dynamic validation for the nominal click setting at different frequencies

\begin{tabular}{|l|l|l|}
\hline Run2 & LS & HS \\
\hline Comp. & L & H \\
\hline Reb. & L & H \\
\hline
\end{tabular}
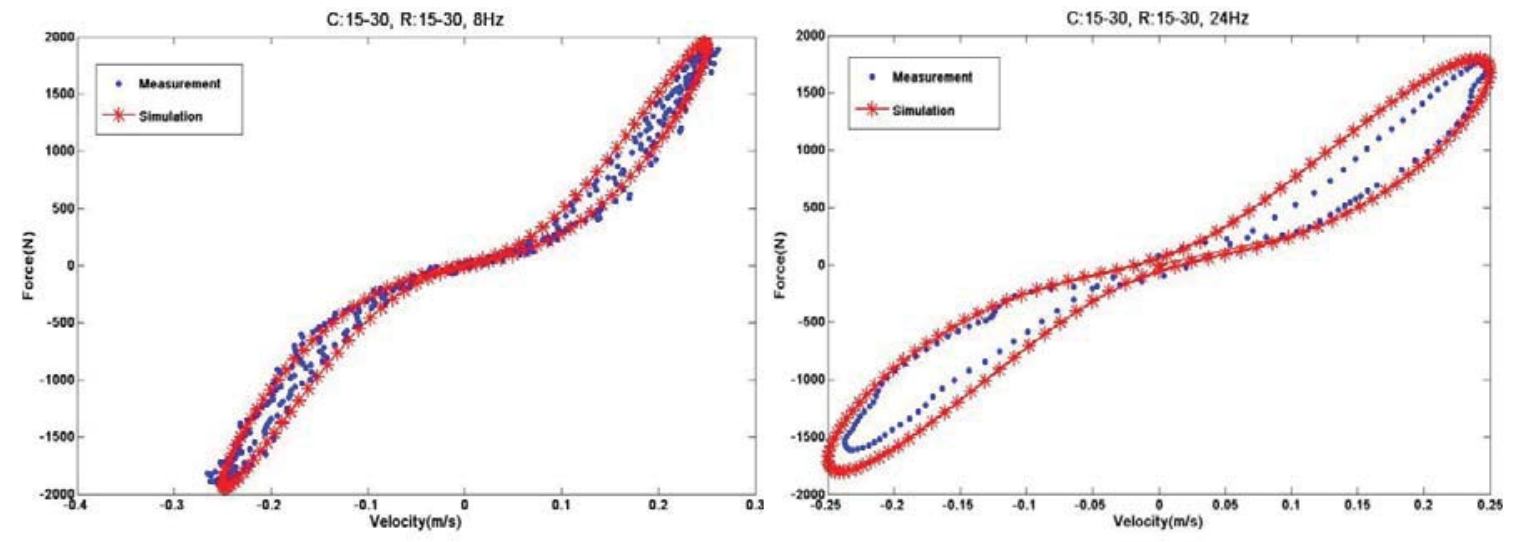

Figure A- 6. Dynamic validation for the low LSA and high HSA click settings at different frequencies 


\begin{tabular}{|l|l|l|}
\hline Run3 & LS & HS \\
\hline Comp. & L & H \\
\hline Reb. & H & H \\
\hline
\end{tabular}
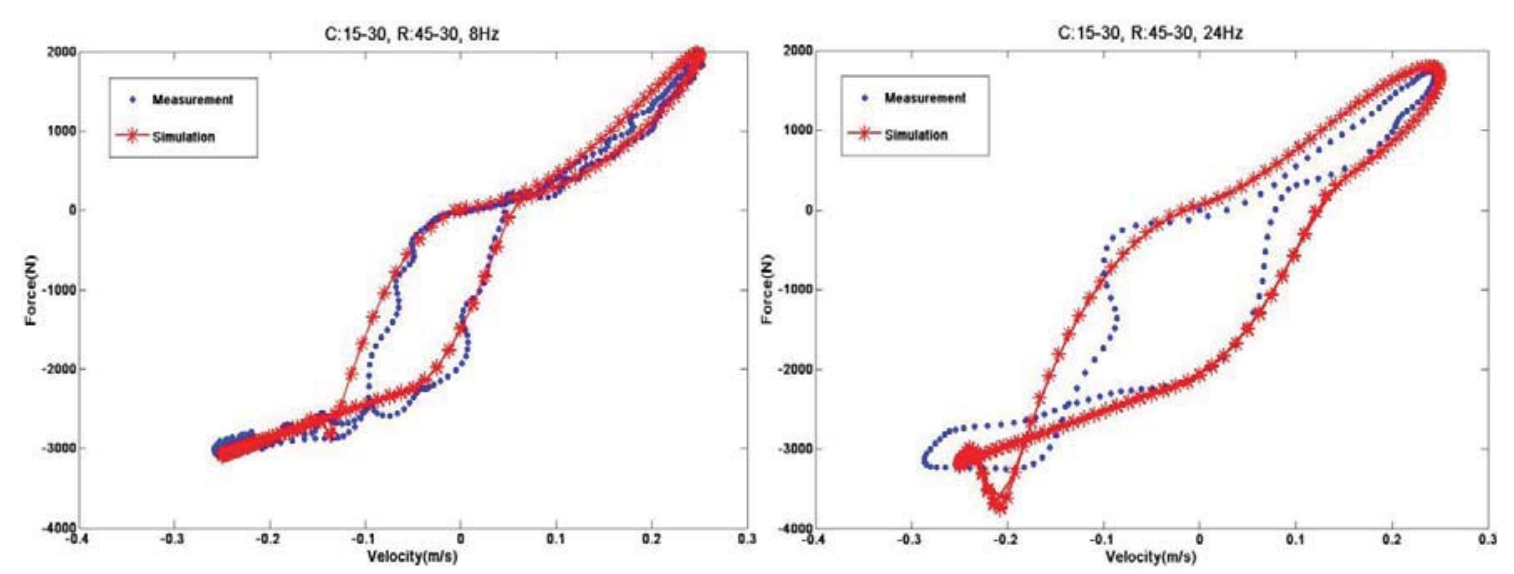

Figure A- 7. Dynamic validation for different LS click settings on compression and rebound sides, at different frequencies

\begin{tabular}{|l|l|l|}
\hline Run4 & LS & HS \\
\hline Comp. & L & H \\
\hline Reb. & L & L \\
\hline
\end{tabular}
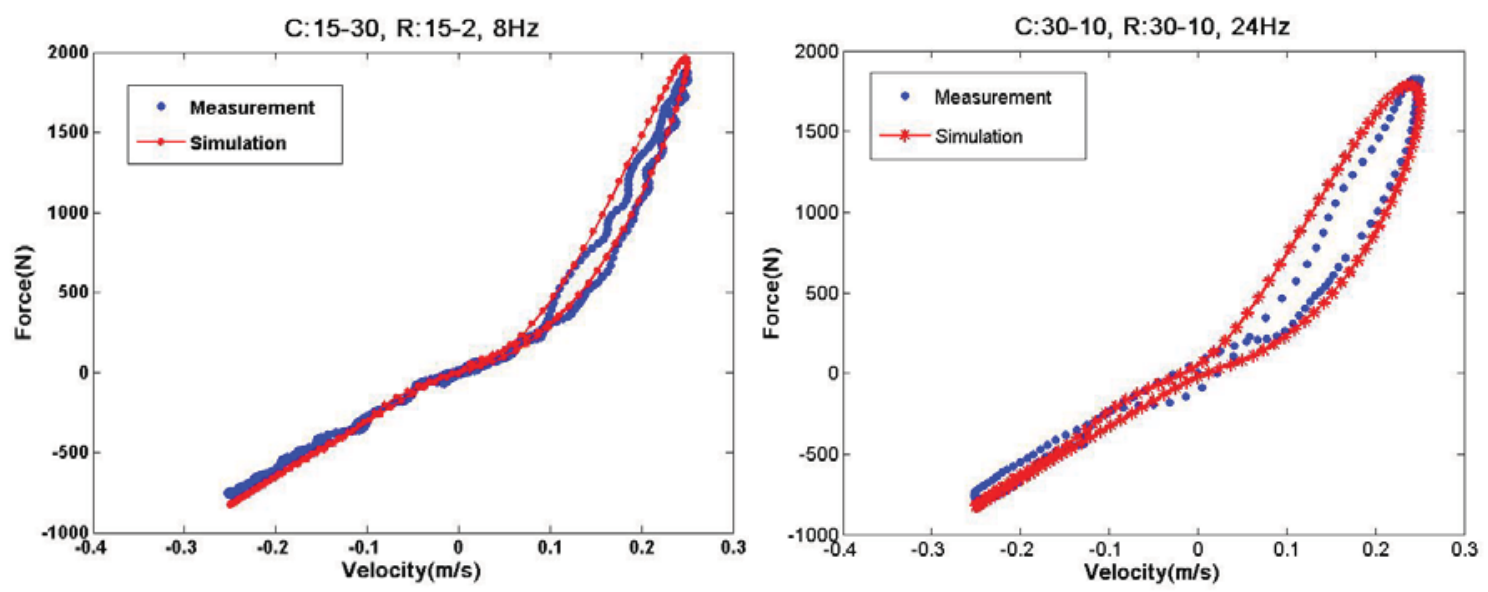

Figure A- 8. Dynamic validation for different HS click settings on compression and rebound sides, at different frequencies 
In Run4 all of the valves are at low clicks. There is a quite low restriction in the way of the flow. Therefore, it is expected to have low level of damping force even at high velocities.

\begin{tabular}{|l|l|l|}
\hline Run5 & LS & HS \\
\hline Comp. & L & L \\
\hline Reb. & L & L \\
\hline
\end{tabular}
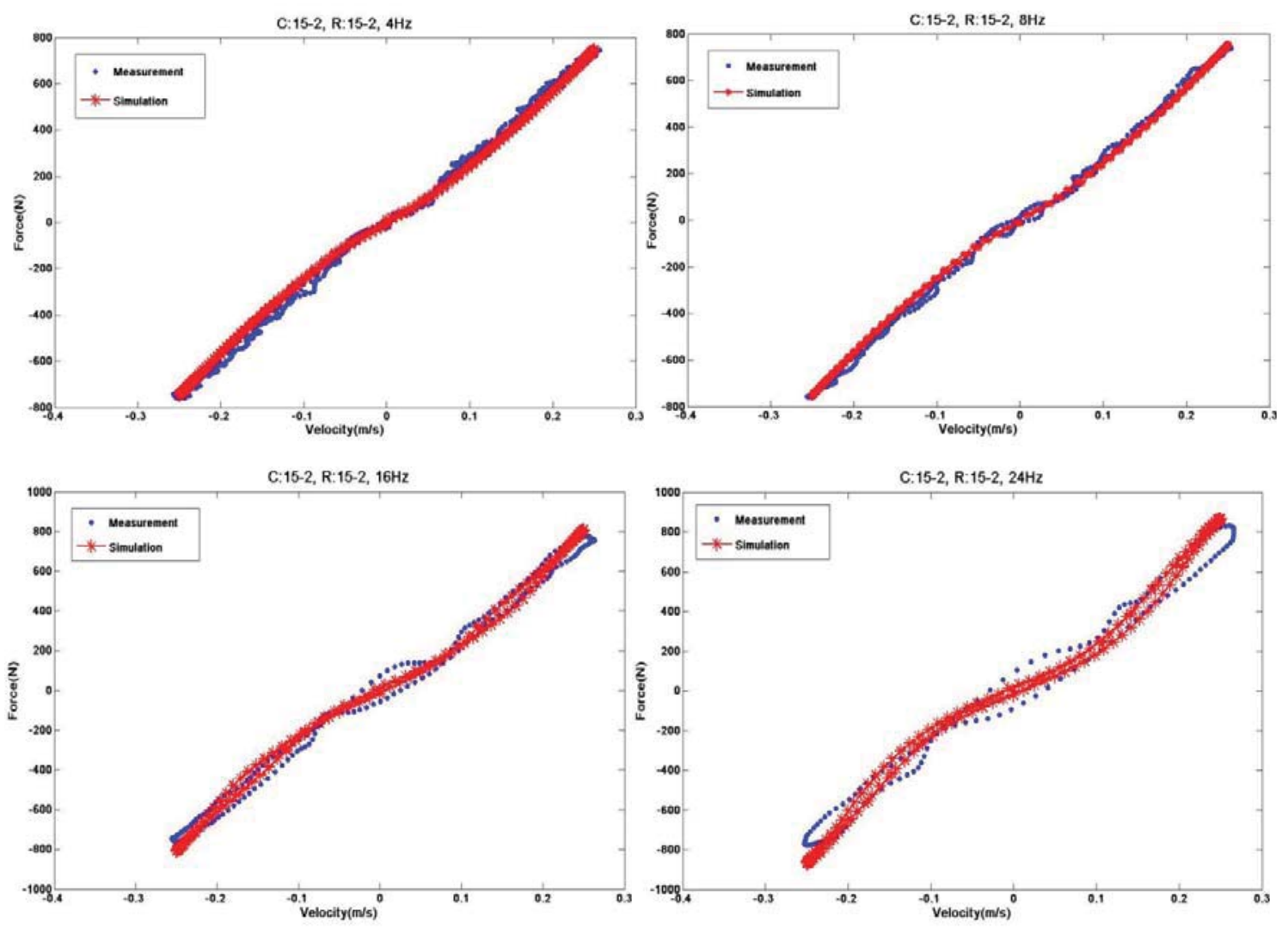

Figure A- 9. Dynamic validation for the low LSA and low HSA click settings at different frequencies

Results are in an acceptable level of agreement. As expected, the damper cannot produce high forces with valves at low click settings. 


\section{Appendix B - Derivation of Equations}

\section{System Dynamics}

The first step in investigating the dynamics of a system is to detect the inputs and outputs of it. As mentioned before, TTR has three main inputs which are externally introduced to the model,

$>$ Main piston velocity : $V_{\text {piston }}$

$>$ Low Speed Adjuster click, i.e. the opening diameter of the fixed orifice $: d_{\text {orifice }}$

$>$ High Speed Adjuster click, i.e. the pre-load of the poppet valve spring : $F_{\text {pre-load }}$

The output of the system is the damping force generated in the rod of the main cylinder.

\section{Governing Equations}

1) Orifice equation, Bernoulli eq.: $\quad q=C_{q} A_{\text {orifice }} \sqrt{\frac{2|\Delta P|}{\rho}} \operatorname{sign}(\Delta P)$

Where, $\Delta P$, is the pressure difference over the valve.

2) Continuity equation, pressure built up eq.: $\quad \Sigma q=\frac{d V}{d t}+\frac{V}{\beta_{e}} \frac{d P}{d t}$

Where, $\beta_{e}$, is the bulk modulus

3) Force equilibrium: $\quad P_{1} A_{1}-P_{2} A_{2}=F_{\text {piston }}+F_{f}+M \ddot{x}$

For a symmetric cylinder, $A_{1}=A_{2}=A_{\text {piston }}$, that yields to

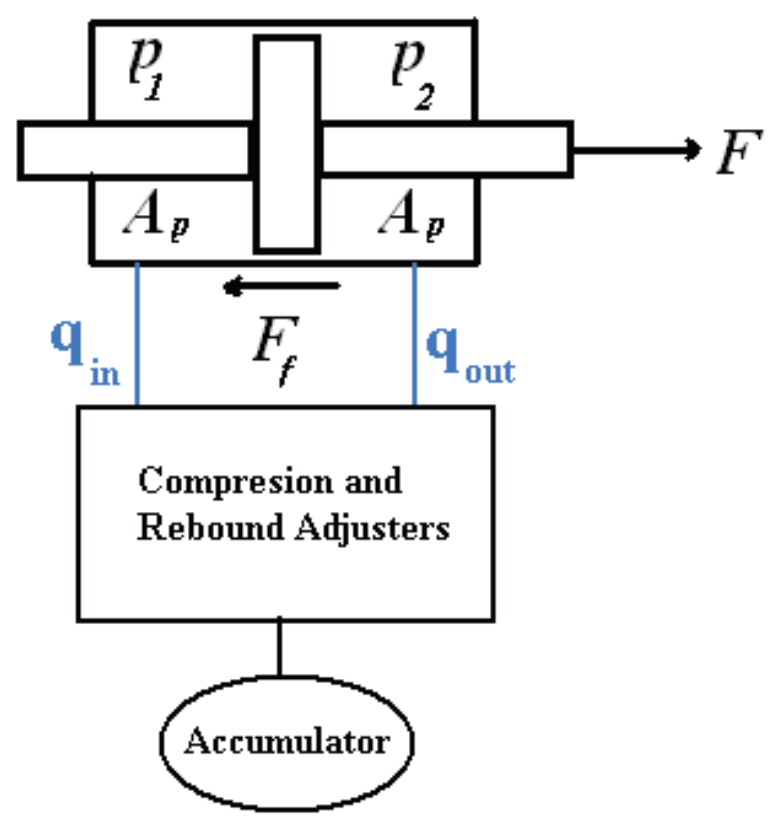

Figure B- 1. Simple schematic of the damper 
$q_{\text {in }}=q_{\text {out }}=q$. Let $F_{f}=0$ (since there is no friction term involved in the model yet). Applying the orifice equation to $q_{i n}$ and $q_{o u t}$, and putting them equal, considering the fact that the compression and rebound sides are identical, yields to,

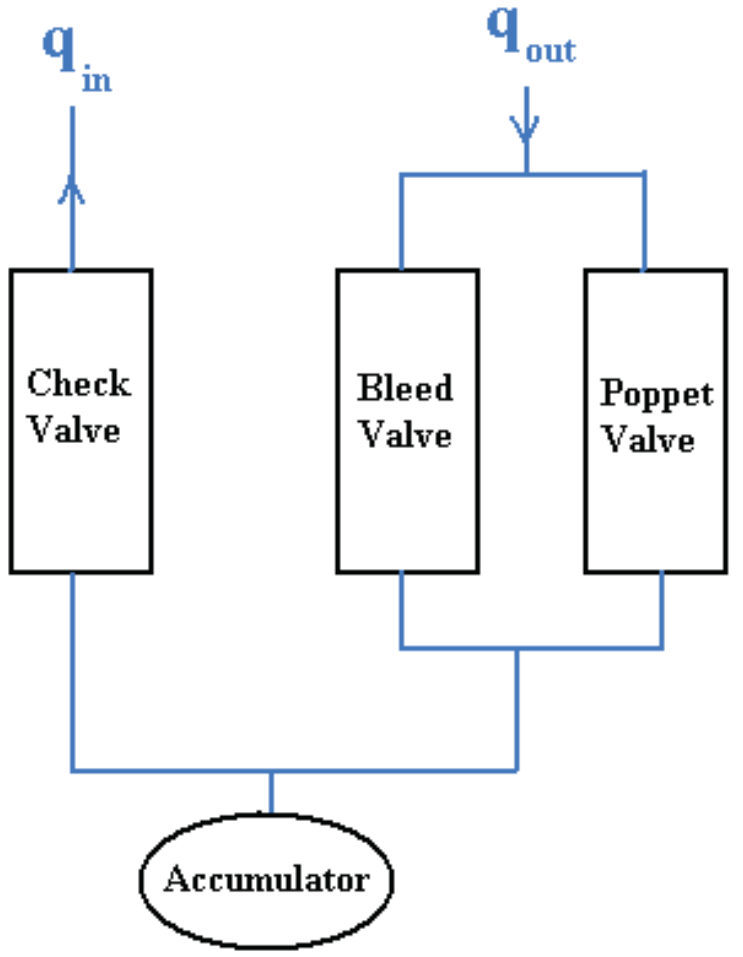

Figure B- 2. Flow distribution during the compression cycle

$$
\begin{gathered}
q_{\text {out }}=c_{q}\left(A_{\text {poppet }}+A_{\text {bleed }}\right) \sqrt{\frac{2}{\rho}\left(P_{2}-P_{\text {acc }}\right)} \\
q_{\text {in }}=c_{q} A_{\text {checkvalve }} \sqrt{\frac{2}{\rho}\left(P_{\text {acc }}-P_{1}\right)} \\
q_{\text {in }}=q_{\text {out }} \Rightarrow \quad P_{2}=(1+C) P_{\text {acc }}-C P_{1} \quad, C=\left(\frac{A_{\text {checkvalve }}}{A_{\text {poppet }}+A_{\text {bleed }}}\right)^{2}
\end{gathered}
$$

Defining the load pressure as $P_{L}=P_{1}-P_{2}$ makes it possible to have both $P_{1}$ and $P_{2}$ as a function of $P_{a c c}$ and $P_{L}$.

$$
P_{1}=\frac{P_{L}}{1+C}+P_{a c c} \quad, \quad P_{2}=P_{a c c}-\frac{C}{1+C} P_{L}
$$

Inserting $P_{1}$ and $P_{2}$ into the flow equations results in one single equation instead of two.

$$
q=c_{q} A_{\text {checkvalve }} \sqrt{\frac{-2 P_{L}}{\rho(1+C)}} \quad \text { eq. } 1-1
$$

Next is to apply the continuity equation to each of the cylinder chambers.

$$
q_{\text {in }}-0=\frac{d V_{1}}{d t}+\frac{V_{1}}{\beta_{e}} \frac{d P_{1}}{d t} \quad, \quad 0-q_{\text {out }}=\frac{d V_{2}}{d t}+\frac{V_{2}}{\beta_{e}} \frac{d P_{2}}{d t}
$$

As the piston moves to the right, $V_{1}$ increases and $V_{2}$ decreases. Therefore, 
Moreover,

$$
\frac{d V_{1}}{d t}=A_{\text {piston }} \dot{x_{p}} \quad, \quad \frac{d V_{2}}{d t}=-A_{\text {piston }} \dot{x_{p}}
$$

$$
\frac{d P_{1}}{d t}=\frac{1}{1+C} \frac{d P_{L}}{d t} \quad, \quad \frac{d P_{2}}{d t}=\frac{-C}{1+C} \frac{d P_{L}}{d t}
$$

Inserting them to the continuity equations gives,

$$
V_{1}=C V_{2}
$$

Since $V_{1}+V_{2}=V_{t}$

$$
V_{1}=\frac{C V_{t}}{1+C} \quad, \quad V_{2}=\frac{V_{t}}{1+C}
$$

Similar to the previous stage, substituting the values in continuity equations reduces them to one single equation,

$$
q=A_{\text {piston }} \dot{x_{p}}+\frac{C V_{t}}{\beta_{e}(1+C)^{2}} \dot{P_{L}} \quad \text { eq. } 2-1
$$

The last is the force equilibrium which can be simplified to,

$$
P_{L} A_{\text {piston }}=F_{L}+F_{f}+M \ddot{x_{p}} \quad \text { eq. } 3-1
$$

In the next step the three coupled differential equations should be linearized to be ready for the Laplace transformation. Considering constant area for the bleed, poppet and check valves,

$$
\Delta Q=\frac{\partial q}{\partial P_{L}} \Delta P_{L}=k_{c} \Delta P_{L} \quad \text { eq. } 1-2
$$

Where $k_{c}=c_{q} A_{\text {checkvalve }} \sqrt{\frac{-1}{2 \rho P_{L 0}(1+C)}}$, is the flow pressure coefficient defines at a stationary point (0).

$$
\begin{aligned}
\Delta Q & =A_{\text {piston }} \Delta \dot{x_{p}}+\frac{C V_{t}}{\beta_{e}(1+C)^{2}} \Delta \dot{P}_{L} & \text { eq. } 2-2 \\
\Delta P_{L} A_{\text {piston }} & =\Delta F_{L}+\Delta F_{f}+M \Delta \ddot{x}_{p} & \text { eq. } 3-2
\end{aligned}
$$

Laplace transformation gives,

$$
\begin{array}{cc}
\Delta Q=k_{c} \Delta P_{L} & e q .1-3 \\
\Delta Q=A_{\text {piston }} S \Delta X_{p}+\frac{C V_{t}}{\beta_{e}(1+C)^{2}} S \Delta P_{L} & \text { eq. } 2-3 \\
\Delta P_{L} A_{\text {piston }}=\Delta F_{L}+\Delta F_{f}+M S^{2} \Delta X_{p} & \text { eq. } 3-3
\end{array}
$$




\section{Appendix C - MATLAB Codes}

\section{Flow Bench Plot Codes}

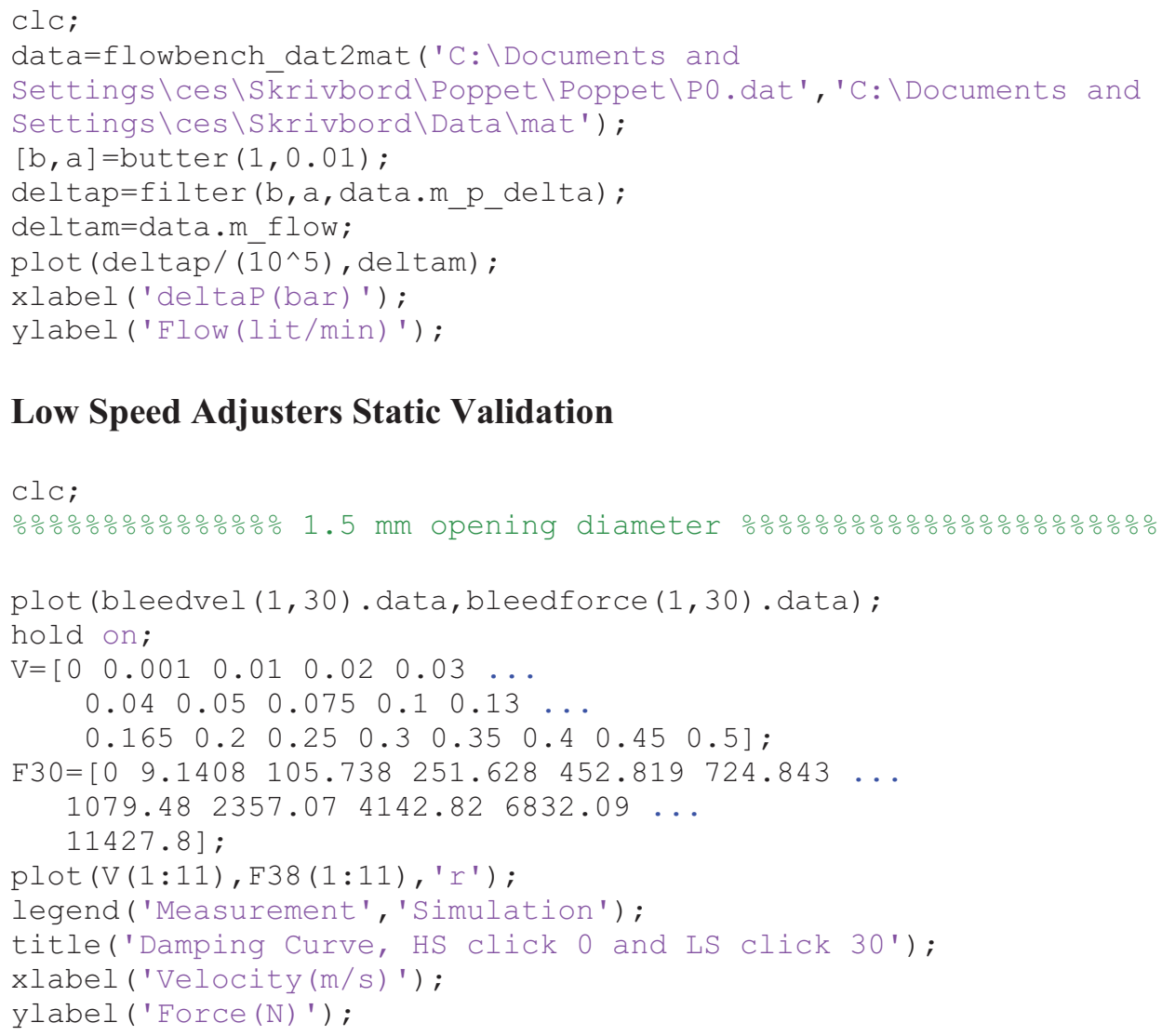

\section{Low Speed Adjusters Static Validation}

